Cite this paper as: F. Cheng, J. Zhu, Th. Pauporté, Chlorides, other Halides and Pseudohalides as Additives for the Fabrication of Efficient and Stable Perovskite Solar Cells.

ChemSusChem 14 (2021) 3665-3692. DOI: 10.1002/cssc.202101089

\title{
Chlorides, other Halides and Pseudo-halides as Additives for the Fabrication of Efficient and Stable Perovskite Solar Cells
}

Fei Cheng, ${ }^{[a]}$ Jie Zhang ${ }^{*[b]}$ and Thierry Pauporté*[a]

[b] Dr J. Zhang

The Key Lab of Fuel Cell Technology of Guangdong Province, Guangdong, School of Chemistry and Chemical Engineering, South China University of Technology, Guangzhou, 510640, China.

E-mail : cejzhang@scut.edu.cn;

[a] F. Cheng and Prof. T. Pauporté

Chimie ParisTech, PSL Research University, CNRS, Institut de Recherche de Chimie Paris (IRCP), UMR8247, 11 rue P. et M. Curie, F-75005 Paris, France.

E-mail : thierry.pauporte@chimieparistech.psl.eu;

www.pauportegroup.com

*Authors for the correspondence 
Cite this paper as: F. Cheng, J. Zhu, Th. Pauporté, Chlorides, other Halides and Pseudohalides as Additives for the Fabrication of Efficient and Stable Perovskite Solar Cells.

ChemSusChem 14 (2021) 3665-3692. DOI: 10.1002/cssc.202101089

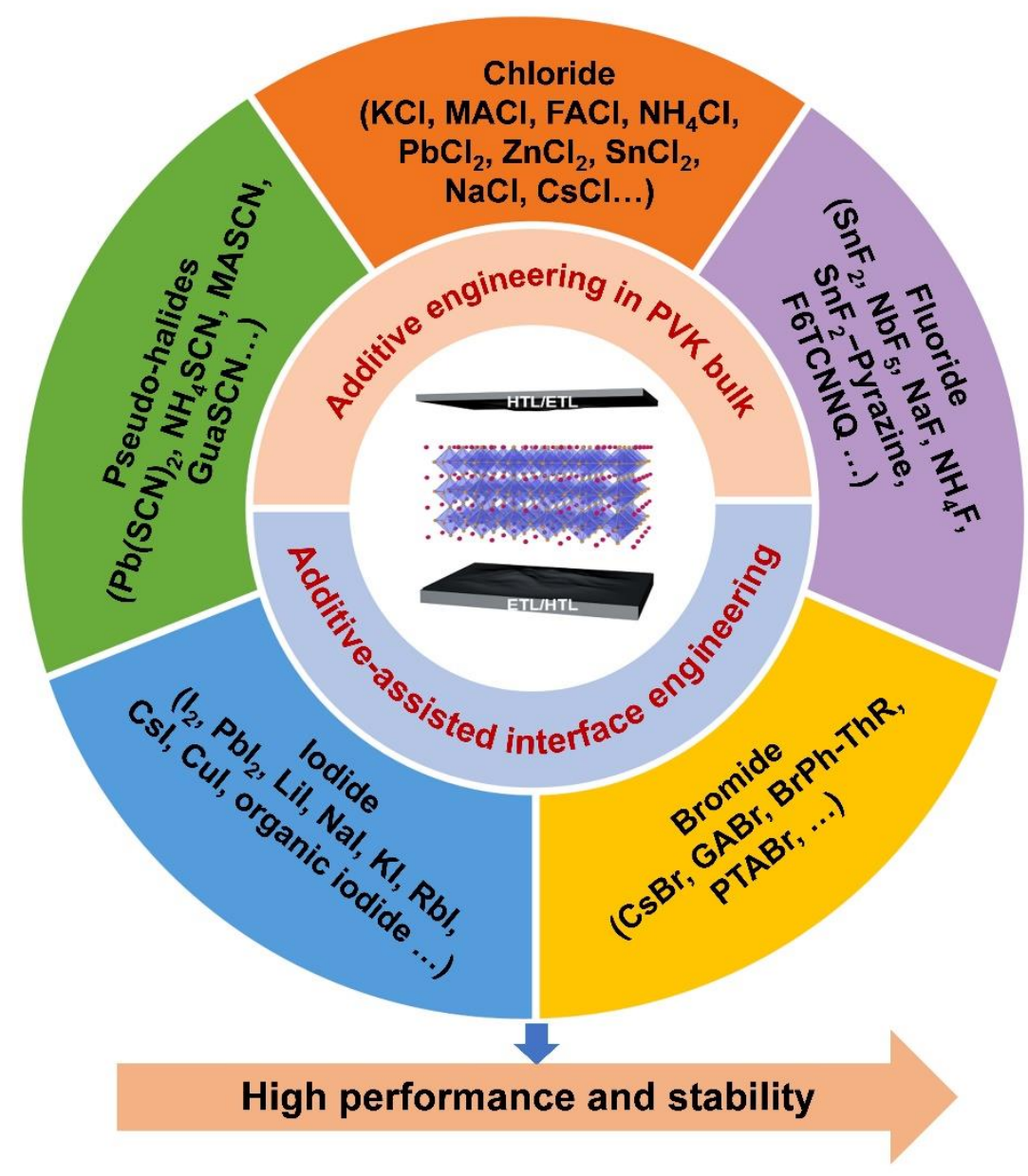

\section{Abstract}

Perovskite solar cells (PSCs) are attracting a tremendous attention from the scientific community due to their excellent power conversion efficiency, low cost and great promise for the future of solar energy. The best PSCs have already achieved a certified power conversion efficiency (PCE) of $25.5 \%$ after an unprecedented rapid performance rise. However, high requirement with respect to large area, high efficiency devices and stability are still the challenges. Major efforts, especially for achieving a high degree of chemical control, have been made to reach these targets. The use of halide additive has been playing a critical role in improving the efficiency and stability. The present paper reviews the important breakthroughs in PSC technologies made by using halide additives, especially chloride, and pseudo-halide additives for the preparation of the perovskite layers, other layers and interfaces of the devices. These additives help perovskite (PVK) crystallization and layer morphology control, grain boundary reduction, bulk and interface defects passivation and so on. Normally, these halide 
Cite this paper as: F. Cheng, J. Zhu, Th. Pauporté, Chlorides, other Halides and Pseudohalides as Additives for the Fabrication of Efficient and Stable Perovskite Solar Cells.

ChemSusChem 14 (2021) 3665-3692. DOI: 10.1002/cssc.202101089

additives play different roles depending on their categories and their location. Herein, we review recent progresses made due to additives employment in every possible layer of PSCs. We develop chloride, other halides and pseudohalides as additives in PVK films, halide additives in carrier transport layers and at PVKcontact interfaces. Finally, an outlook of halide additive engineering in PSC progress is given.

Keywords: Perovskite solar cell; Halide additives; Chloride additives; Pseudo-Halide additives; High efficiency; High stability. 
Cite this paper as: F. Cheng, J. Zhu, Th. Pauporté, Chlorides, other Halides and Pseudohalides as Additives for the Fabrication of Efficient and Stable Perovskite Solar Cells.

ChemSusChem 14 (2021) 3665-3692. DOI: 10.1002/cssc.202101089

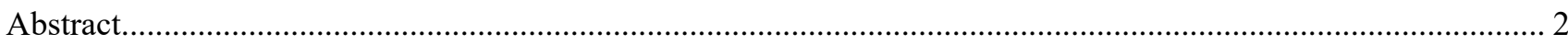

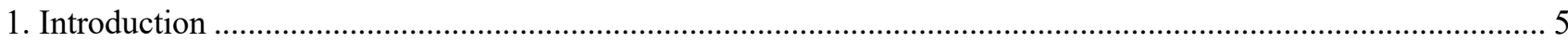

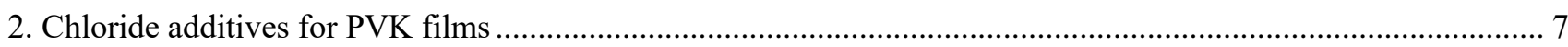

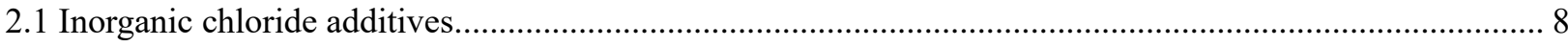

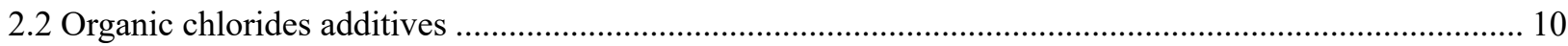

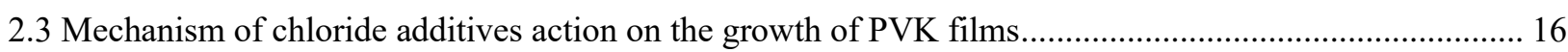

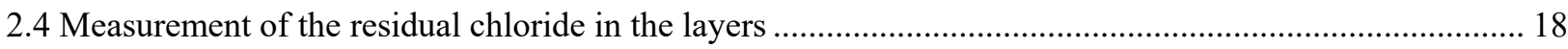

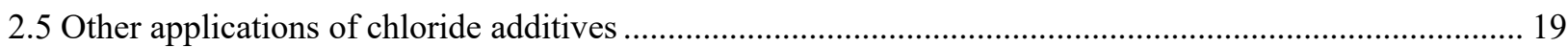

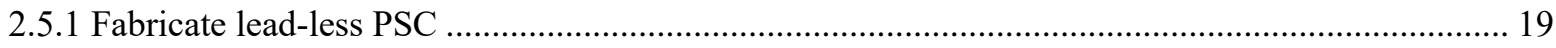

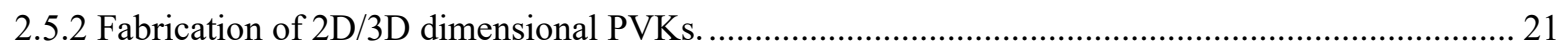

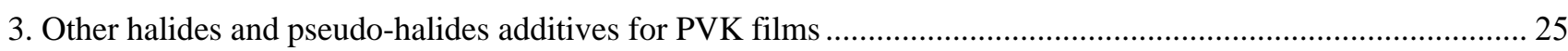

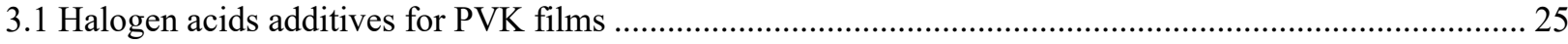

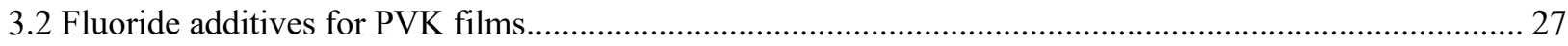

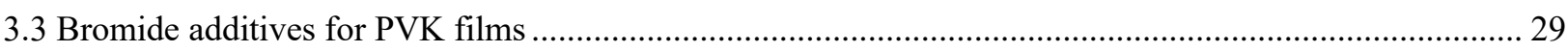

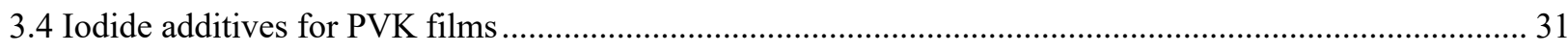

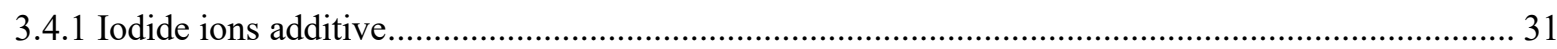

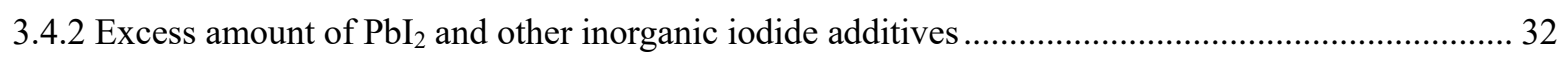

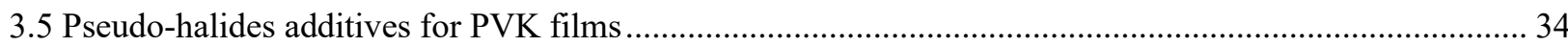

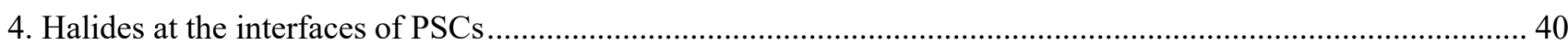

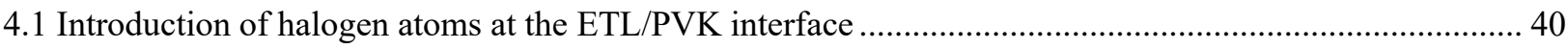

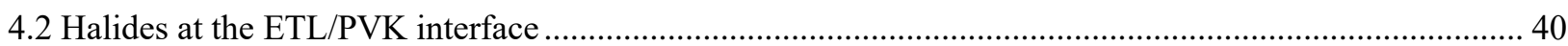

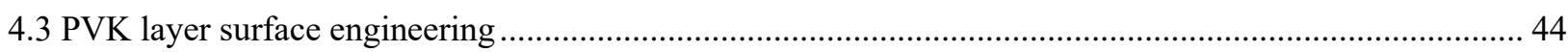

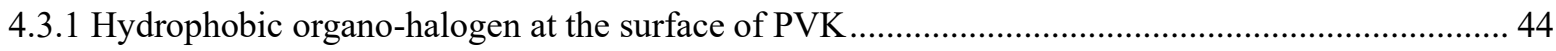

4.3.2 Passivation of PVK defects and near surface film modification............................................... 46

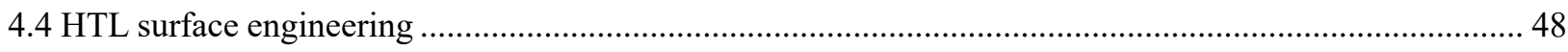

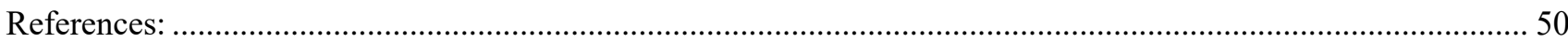


Cite this paper as: F. Cheng, J. Zhu, Th. Pauporté, Chlorides, other Halides and Pseudohalides as Additives for the Fabrication of Efficient and Stable Perovskite Solar Cells. ChemSusChem 14 (2021) 3665-3692. DOI: 10.1002/cssc.202101089

\section{Introduction}

The use of halide perovskites (PVKs) in all solid-state solar cells appeared less than a decade ago and has revolutionized the field of photovoltaics $(\mathrm{PV}) .^{[1-6]} \mathrm{PVKs}$ are highly flexible semiconductors with many advantages for this application such as high light absorption coefficient, ${ }^{[7]}$ high charge carrier mobility, ${ }^{[8]}$ long charge carrier diffusion length ${ }^{[9]}$ and a bandgap tunable over a large energy range. ${ }^{[10]}$ PVK thin films can be prepared from precursor solutions at mild temperature $\left(\leq 160^{\circ} \mathrm{C}\right)$ on either insulating or conducting substrates. ${ }^{[11-}$ 14]

Perovskite solar cells (PSCs) can be considered as a competitor of silicon solar cells as well as a complementary technology in the case of multijunction solar cells. ${ }^{[15,16]}$ A typical hybrid metal halide PVK has a three-dimensional structure (3D) with a chemical formula of $\mathrm{ABX}_{3}$, where $\mathrm{A}$ is an organic or inorganic cation, such as $\mathrm{FA}^{+}$(formamidinium), $\mathrm{MA}^{+}$(methylammonium) or $\mathrm{Cs}^{+}$(cesium), $\mathrm{B}$ is a metal cation, such as $\mathrm{Pb}^{2+}$ or $\mathrm{Sn}^{2+}$, and $\mathrm{X}$ is an halogen anion, such as $\mathrm{I}^{-}$or $\mathrm{Br}^{-} \cdot{ }^{[17,18]}$ In PSCs, the PVK thin film is only several hundred nanometers thick and is contacted on both sides by semiconductor selective contact layers. An electron transporting layer (ETL) ensures the photogenerated electron collection and transport. ${ }^{[19,20]}$ While, on the other side, holes are collected and transported by a hole transporting layer (HTL). ${ }^{[21,22]}$ Depending on the position and structure of these layers, three different typical PSC architectures are distinguished : direct mesoporous, direct planar and inverted planar as schematically presented in Fig. 1A. ${ }^{[23]}$ According to NREL, the certified power conversion efficiency (PCE) for a PVK cell achieves a present $25.5 \%$ value, ${ }^{[24]}$ which is superior to any other thin film technology and approaches the record for Si single crystal technologies. However, according to the recalculated Shockley-Queisser limit, ${ }^{[25,26]}$ for AM 1.5G $\left(1000.4 \mathrm{~W} \mathrm{~m}^{-2}\right)$ and a temperature of $298.15 \mathrm{~K}$, a highest theoretical PCE of $32.91 \%$ (short-circuit photocurrent density $\left(J_{s c}\right)=32.88 \mathrm{~mA} \mathrm{~cm}^{-2}$, open circuit voltage $V_{o c}=1.122 \mathrm{~V}$, and fill factor $\left.(F F)=89.3 \%\right)$ can be expected for a single junction PSC with a bandgap $\left(E_{g}\right)$ of $1.4 \mathrm{eV}$. It indicates that PSC technology still presents space for performance improvement. Finding a light absorbing PVK material with the optimal $E_{g}$, improving the lifetime and diffusion length of carriers, as well as reducing the recombination due to traps states at the interfaces, grain boundaries and in the bulk are of utmost importance to maximize the performance of PSCs. Comparing the parameter of certified efficiency in 2019 by KRICT/MIT and in 2018 by ISCAS, the improvement of PCE from $23.3 \%$ to $25.2 \%$ is owed to the improvement of the fill factor, ${ }^{[27]}$ which is mainly limited by the carriers transport times. ${ }^{[28]}$ Huang et al. ${ }^{[29]}$ reported that 
Cite this paper as: F. Cheng, J. Zhu, Th. Pauporté, Chlorides, other Halides and Pseudohalides as Additives for the Fabrication of Efficient and Stable Perovskite Solar Cells. ChemSusChem 14 (2021) 3665-3692. DOI: 10.1002/cssc.202101089

$\mathrm{FAPbI}_{3}$-based PSCs could achieve an efficiency of $28.4 \%$ with the trap density of thin film being reduced to its single crystal value. Besides, long-term stability is also a challenge for the commercialization and broad diffusion of PSCs. ${ }^{[30,31]}$ Thus, much efforts have focused on fabricating highly oriented crystal films, increasing grain size, reducing traps, increasing heat, humidity, illumination stability and so on. ${ }^{[32-36]}$ Among all the improvement methods, the employment of halide and pseudohalide additives for the preparation of various layers and treatments of interfaces is of major interest. The analysis of the web of science database reveals that the percentage of papers in which halide and pseudohalide additives are used in PSC is increasing (Fig. 1B). We can cite as recent examples You and co-workers ${ }^{[37]}$ who got a certified PCE of $23.32 \%$ via a post-treatment by phenylethylammonium iodide (PEAI) and Kim and co-workers ${ }^{[38]}$ who achieved a certified PCE of $23.48 \%$ using $\mathrm{MACl}$ as an additive and treating the PVK layer surface by PEAI. More impressively, Seok et al. ${ }^{[39]}$ got a PCE of $25.17 \%$ and improved the device heat stability by relaxing the lattice strain of $\mathrm{FAPbI}_{3}$ via cooperating methylenediamine dihydrochloride $\left(\mathrm{MDACl}_{2}\right)$ and cesium iodide (CsI) into the PVK precursor.

These additives consist in salts composed of a large organic or inorganic cation combined to a halide anion: $\mathrm{F}^{-}, \mathrm{Cl}^{-}, \mathrm{Br}^{-}, \mathrm{I}^{-}$or a pseudo halide such as $\mathrm{SCN}^{-}$(Fig. 1C). These additives can be added into the PVK precursor solution, in the carrier transport material precursor solution or employed at the PVK-selective contact (ETL or HTL) interface. Finally, it is important to note that most of these additives will be fully or partly removed upon the post-annealing treatment of the layers. They will help the crystal to grow, the defect passivation, the stabilization of the structure, the improvement of interfaces and so on. Park et al. ${ }^{[0]}$ comprehensively worked on the effect of different halide additives on $\mathrm{FAPbI}_{3}$ films growth by introducing $\mathrm{AX}\left(\mathrm{A}=\mathrm{FA}, \mathrm{MA}, \mathrm{Cs}, \mathrm{Rb}, \mathrm{NH}_{4}\right.$, $\mathrm{X}=\mathrm{Cl}, \mathrm{Br}, \mathrm{I}$ ) into $\mathrm{PVK}$ precursor, giving a sight of synergy effect of different halide species with $\mathrm{FAPbI}_{3}$. Liu et al. ${ }^{[41]}$ compared the additives of $\mathrm{PbCl}_{2}, \mathrm{PbBr}_{2}$ and $\mathrm{MAI}$ in $\mathrm{MAPbI}_{3}$. Researchers commonly focus on one or two kinds of halide additive in the specific PVK without a large view on the topic. ${ }^{[42-45]}$ It thus appears important to review on how these varied halide additives cooperate with different PVK materials and different PVK solar cell layers in various PSC structures. In this perspective, we summarize the recent progresses on species of halide additives in halide PVK solar cells and their function such as the morphology adjusting, phase stabilizing, energy-level adjusting, trap state passivation and hysteresis elimination. A deep understanding of the relationship between halide/pseudohalide additive and the improved properties of PVK solar cell is presented. We have attached a special attention to the chloride and pseudohalide ones. First, in Section 2, we develop the employment of chloride additives for the preparation of PVK layers. Section 3 is dedicated to other halide and 
Cite this paper as: F. Cheng, J. Zhu, Th. Pauporté, Chlorides, other Halides and Pseudohalides as Additives for the Fabrication of Efficient and Stable Perovskite Solar Cells.

ChemSusChem 14 (2021) 3665-3692. DOI: 10.1002/cssc.202101089

pseudohalide additives employed for PVK films synthesis. Section 4 reports on the use of halide additives in the carrier transport layers and interfaces of PSC. Finally, we provide a conclusion and an outlook of halide additive engineering in PSC progress.

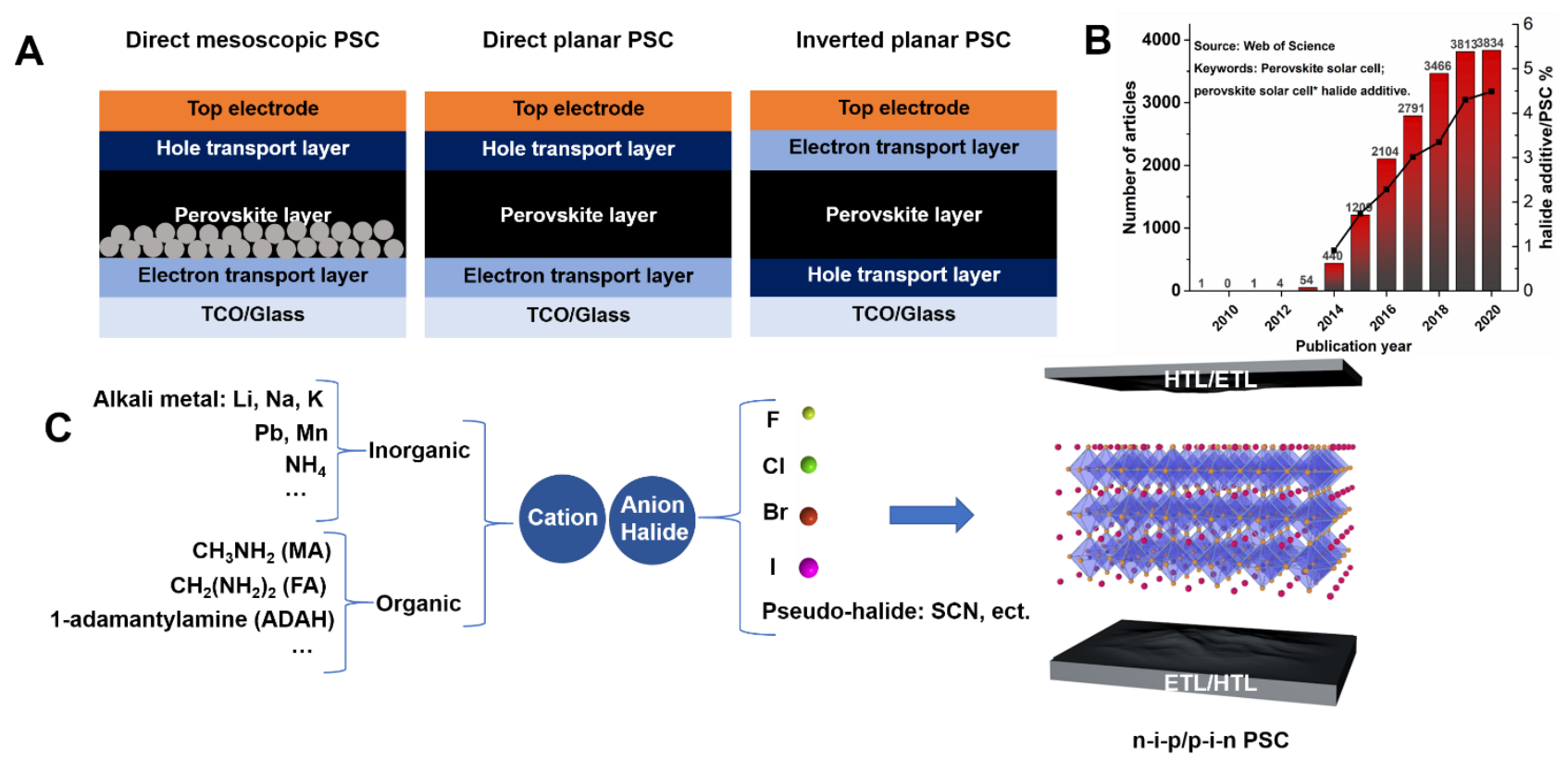

Fig. 1 (A) Schematic of the different PSC structures: direct mesoscopic, direct planar and inverted planar. (B) Halide additive research activities seen from the number of papers on PVK solar cell published each year. (C) Structure of this review, the additive species introduced into PSC.

\section{Chloride additives for PVK films}

A first breakthrough in PVK solar cell research field was achieved in 2012 with the first fabrication of allsolid-state devices. ${ }^{[46]}$ At the early age of PSC science, the possibility of playing on non-stoichiometry and of using added halide compound in the precursor solution attracted the curiosity of scientists. Snaith et al. ${ }^{[47]}$ combined an excess of methylammonium iodide (MAI) with a non-iodide lead source $\mathrm{PbCl}_{2}$ in a 3:1 $\mathrm{MAI}: \mathrm{PbCl}_{2}$ molar ratio, to deposit high-quality films into mesoporous alumina. The PCE of $12.3 \%$ was attributed to the efficient transport of carriers with minimal recombination losses in $\mathrm{MAPbI}_{3}(\mathrm{Cl})$. Zhang et al. ${ }^{[48]}$ latterly verified whether $\mathrm{Cl}$ or excess $\mathrm{MA}^{+}$was responsible for the enhanced diffusion length by fabricating a typical 1:1 $\mathrm{PbI}_{2}$ :MAI and comparing it with the non-stoichiometric $\mathrm{PbCl}_{2}: 3 \mathrm{MAI}$ system. The higher optoelectronic property in the presence of $\mathrm{PbCl}_{2}$ was explained by the easy removal of the $\mathrm{MACl}$ by-product upon the final annealing step at $100^{\circ} \mathrm{C}$. They concluded that $\mathrm{Cl}$ is the key for high performance. Then after, a lot of research efforts 
Cite this paper as: F. Cheng, J. Zhu, Th. Pauporté, Chlorides, other Halides and Pseudohalides as Additives for the Fabrication of Efficient and Stable Perovskite Solar Cells.

ChemSusChem 14 (2021) 3665-3692. DOI: 10.1002/cssc.202101089

focused on the employment of a large variety of either organic or inorganic chloride salts as additives to fabricate better performance PSCs. Most recently, Xu et al. ${ }^{[49]}$ fabricated a two-terminal monolithic tandem cell with a triple-halide alloys PVK as top cell and achieved a PCE of 27\% with an area of 1 square centimeter. $\mathrm{Cl}$ from $\mathrm{MAPbCl}_{3}$ additive was detected throughout the film and was incorporated into the PVK lattice. Chloride, among all the halogens, is the most promising element for PSC performance improvement.

\subsection{Inorganic chloride additives}

In inorganic chloride additives, the cation includes alkali metal $\left(\mathrm{K}^{+}, \mathrm{Na}^{+}, \mathrm{Li}^{+}\right),{ }^{[50]} \mathrm{Pb}^{2+}, \mathrm{Mn}^{2+[44]}$ and ammonia species $\mathrm{NH}_{4}{ }^{+} \cdot{ }^{[50]}$ Normally, inorganic chloride additives present in the PVK precursor solution increase the grain size as well as enhance the grain orientation and finally often increase the PCE of the device.

Following the pioneering research by Snaith et al. in $2012^{[51]}$ and $2013^{[47]}$, the effects of metal chloride additives, especially $\mathrm{PbCl}_{2}$, were investigated in many further studies. Wang et al. ${ }^{[52]}$ reported an improved PSC performance by incorporating $\mathrm{PbCl}_{2}$ into the $\mathrm{PVK}$ precursor, forming a Lewis acid-base adduct. They showed that $2.5 \mathrm{~mol} \%$ of $\mathrm{PbCl}_{2}$ increases the grain size, charge carrier lifetime and electron-hole collection efficiency in $\mathrm{MAPbI}_{3}$ PSCs. As a result, they achieved an average efficiency of $18.1 \%$. Cao et al. ${ }^{[53]}$ studied the effect of $\mathrm{PbCl}_{2}$ in a two-step method formation of $\mathrm{MAPbI}_{3}(\mathrm{Cl})$, different concentrations of $\mathrm{PbCl}_{2}(0 \%, 5 \mathrm{~mol} \%, 10 \mathrm{~mol} \%)$ were introduced into $\mathrm{PbI}_{2} / \mathrm{DMF}$ solution. The mean grain size of $\mathrm{MAPbI}_{3}$ increased from $223 \mathrm{~nm}$ to $353 \mathrm{~nm}$ when $5 \mathrm{~mol} \% \mathrm{PbCl}_{2}$ was introduced. The diffraction peak intensity ratios of $I_{(110)} / I_{(310)}$ and $I_{(220) /} I_{(310)}$ were introduced to quantify the effects of chloride incorporation on grain orientation. The values of $I_{(110)} / I_{(310)}$ and $\mathrm{I}_{(220) / \mathrm{I}_{(310)}}$ increased to 15.13 and 6.49 , respectively, when $5 \mathrm{~mol} \% \mathrm{PbCl}_{2}$ was introduced, compared to 3.15 and 1.70 for the pristine film. It indicated a better preferred (110) grain orientation. The fast photoluminescence (PL) decay time and slow PL decay time of the $5 \mathrm{~mol} \% \mathrm{PbCl}_{2}$ modified device were $0.43 \mathrm{~ns}$ and $40.81 \mathrm{~ns}$, respectively (compared to the $3.47 \mathrm{~ns}$ and $39.08 \mathrm{~ns}$ without $\mathrm{PbCl}_{2}$ ). Finally, the device reached a maximum PCE of 17.05\%.

The influence of alkali metal halides $(\mathrm{KCl}, \mathrm{NaCl}, \mathrm{LiCl})$ as additives on the performance of PVK solar cells has been studied in a large extent. 0.75 wt. $\% \mathrm{KCl}, 1$ wt.\% $\mathrm{NaCl}$ and $0.25 \mathrm{wt} \% \mathrm{LiCl}$ were introduced into $\mathrm{PbI}_{2} /$ salt mixture. ${ }^{[54]}$ The detailed parameters of the measured photovoltaic performances are gathered in Table 1. The best dosage for each alkali metal halide was given, among them, $\mathrm{KCl}$ at $0.75 \mathrm{wt} . \%$ got the best PCE. By $\mathrm{x}$-ray diffraction (XRD) measurement, the average crystallite size was estimated using the Scherrer relationship:

$$
\mathrm{D}=0.89 \lambda / \beta \cos \theta
$$


Cite this paper as: F. Cheng, J. Zhu, Th. Pauporté, Chlorides, other Halides and Pseudohalides as Additives for the Fabrication of Efficient and Stable Perovskite Solar Cells.

ChemSusChem 14 (2021) 3665-3692. DOI: 10.1002/cssc.202101089

$\mathrm{D}$ is the crystallite size, $\lambda$ is the wavelength of the X-rays, $\beta$ is the full width at half maximum (FWHM) of the diffraction peak, and $\theta$ is the diffraction angle. The crystallite sizes of the PVKs prepared with $0.75 \mathrm{wt} \% \mathrm{KCl}$, 1 wt. $\% \mathrm{NaCl}$, and $0.25 \mathrm{wt} . \% \mathrm{LiCl}$ were $468 \pm 50 \mathrm{~nm}, 384 \pm 40 \mathrm{~nm}$, and $422 \pm 40 \mathrm{~nm}$, respectively. The intensity of crystallinity and crystallite size (Fig. 2A, 2B) of the PVK film gave a glimpse of the reason why 0.75 wt.\% of $\mathrm{KCl}$ got the best efficiency. Zheng et al. have clearly shown that $\mathrm{K}^{+}$from $\mathrm{KCl}$ suppresses iodide mobility in PVK and linked it to $J$ - $V$ curve hysteresis cancellation. ${ }^{[50]}$

Table 1. Photovoltaic performance parameters of devices prepared with various salt additives. (from Ref ${ }^{[54]}$ with permission from The Royal Society of Chemistry, copyright 2013.)

\begin{tabular}{ccccc}
\hline Salt & $\begin{array}{c}V_{o c} \\
(\mathrm{~V})\end{array}$ & $\begin{array}{c}J_{s c} \\
\left(\mathrm{~mA} \mathrm{~cm}^{-2}\right)\end{array}$ & $\begin{array}{c}\text { FF } \\
(\%)\end{array}$ & $\begin{array}{c}\text { PCE } \\
(\%)\end{array}$ \\
\hline $0.75 \% \mathrm{KC}$ & 1.04 & 19.42 & 74.67 & $15.08^{\mathrm{a}}(14.12)^{\mathrm{b}}$ \\
$1 \% \mathrm{NaCl}$ & 0.96 & 17.59 & 75.62 & $12.77^{\mathrm{a}}(12.14)^{\mathrm{b}}$ \\
$0.25 \% \mathrm{LiCl}$ & 0.91 & 15.97 & 68.67 & $9.98^{\mathrm{a}}(9.35)^{\mathrm{b}}$ \\
Without salt & 0.9 & 15.88 & 76.31 & $11.4^{\mathrm{a}}(10.86)^{\mathrm{b}}$
\end{tabular}

${ }^{a}$ Best device performance. ${ }^{b}$ Average performance from 10 devices.
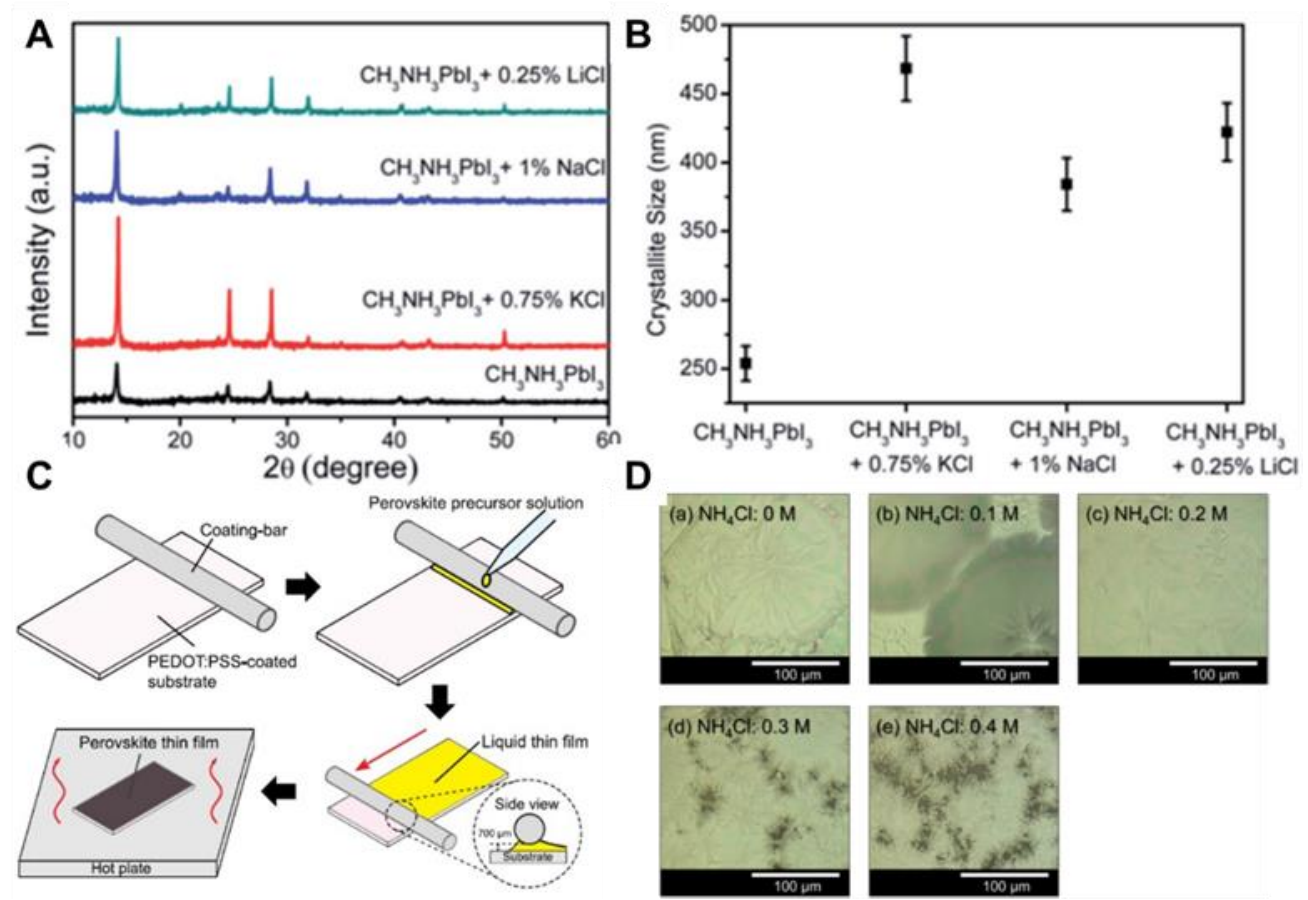

Fig. 2 (A) XRD patterns and (B) crystallite sizes in PVK thin films prepared without and with $\mathrm{KCl}, \mathrm{NaCl}$, and LiCl salt additives. ${ }^{[54]}$ with permission from The Royal Society of Chemistry, copyright 2013; (C) Schematic 
Cite this paper as: F. Cheng, J. Zhu, Th. Pauporté, Chlorides, other Halides and Pseudohalides as Additives for the Fabrication of Efficient and Stable Perovskite Solar Cells.

ChemSusChem 14 (2021) 3665-3692. DOI: 10.1002/cssc.202101089

diagram of the fabrication process of PVK thin film by bar-coating; (D) Microscope images of MAPbI $I_{3}$ thin films fabricated by bar-coating with various concentrations of $\mathrm{NH}_{4} \mathrm{Cl}^{\left[{ }^{[5]}\right]}$ with permission from Elsevier, copyright 2013.

Fujii et al. ${ }^{[55]}$ introduced $\mathrm{NH}_{4} \mathrm{Cl}$ additive into the $\mathrm{MAPbI}_{3}$ precursor solution. By a bar-coating process (Fig. 2C) they obtained a highly (100)-oriented and uniform thin film of $\mathrm{MAPbI}_{3}$ with large grains, giving a reference for industrial mass-production. As shown in Fig. 2D the homogeneous and large grains were obtained for 0.2 $\mathrm{M} \mathrm{NH}_{4} \mathrm{Cl}$ additive. The solar cell utilizing the $\mathrm{MAPbI}_{3}$ thin film prepared with $0.2 \mathrm{M} \mathrm{NH}_{4} \mathrm{Cl}$ demonstrated a hysteresis-free behavior and achieved a PCE of $12.5 \%$ with $J_{s c}$ of $20.6 \mathrm{~mA} \mathrm{~cm}{ }^{-2}, V_{o c}$ of $0.83 \mathrm{~V}$, and $F F$ of 0.73 in the forward scan. Zong et al. ${ }^{[56]}$ added $\mathrm{NH}_{4} \mathrm{Cl}$ with a molar ratio value of 0.8 to $\mathrm{PbI}_{2}$ into the $\mathrm{PVK}$ precursor solution to adjust the kinetics of crystallization and growth of the active layer and it resulted in high-quality $\mathrm{MAPbI}_{3}$ film formation. The diffraction peak intensity of the (110) face was enhanced and the FWHM reached a minimum value with an additive ratio of 0.8 . It proved an increase of the crystallinity by $\mathrm{NH}_{4} \mathrm{Cl}$. Combined with a hydrophobic carbon electrode, the final device got a PCE of $9.89 \%$ with a $\mathrm{V}_{\text {oc }}$ of $878.9 \mathrm{mV}$, $\mathrm{J}_{\mathrm{sc}}$ of 22.38 $\mathrm{mA} \mathrm{cm}{ }^{-2}$, FF of 0.503 . Under the condition of ambient air, the PSCs maintained $96 \%$ of the initial efficiency after $576 \mathrm{~h}$ due to the triple mesoporous scaffold ${ }^{[36]}$ and PVK material quality. Pauporté et al. ${ }^{[50]}$ demonstrated the benefit of employing $\mathrm{NH}_{4} \mathrm{Cl}$ additive combined with $\mathrm{KCl}$ for the preparation of methylammoniumfree bromide-free $\mathrm{Cs}_{0.1} \mathrm{FA}_{0.9} \mathrm{PbI}_{3}$ perovskite layers. They showed that $\mathrm{KCl}$ favors the $\mathrm{PbI}_{2}$ precursor solubilization and it resulted in pure perovskite phase. The crystal growth speed and direction were controlled by $\mathrm{NH}_{4} \mathrm{Cl}$ which led to the formation of large crystal grains and well-crystallized layers. These authors used the glow-discharge optical emission spectroscopy (GD-OES) technique to directly visualize that potassium incorporated in the whole film blocks the iodide mobility by defect passivation. They clearly correlated the reduction (or suppression) of iodide mobility and the reduction (or suppression) of the $J-V$ curve hysteresis. Combined with the PVK surface treatment with n-propylammonium iodide (PAI), the cells reached at stabilized PCE of $21.1 \%$.

\subsection{Organic chlorides additives}

Organic chloride additives include a bigger-size cation, such as $\mathrm{MA}^{+}, \mathrm{FA}^{+}$or 1-adamantylamine (ADAH), compared to inorganic ones. Due to the bulky size of the organic cation, the interionic space is large, thus, the 
Cite this paper as: F. Cheng, J. Zhu, Th. Pauporté, Chlorides, other Halides and Pseudohalides as Additives for the Fabrication of Efficient and Stable Perovskite Solar Cells.

ChemSusChem 14 (2021) 3665-3692. DOI: 10.1002/cssc.202101089

attractive electrostatic force is weaker. Because chloride ion is volatile, it results in an easy removal of the organic chloride additive during the PVK annealing post-treatment.

Choy et al. ${ }^{[58]}$ proposed that $\mathrm{Cl}^{-}$additive can significantly increase the hole and electron diffusion lengths, in agreement with the previously mentioned research by Snaith ${ }^{[47]}$ in 2013 . It also reduces the bulk trap-state density in PVK thin film. To investigate the role of chloride in different PSC devices architectures and thus provide a deeper understanding of its action mechanism, Burda et al. ${ }^{[59]}$ prepared varied ratios of MACl : MAI $\left(0: 1,0.5: 1,1: 1\right.$, and 2:1) PVK film on planar and mesoporous $\mathrm{TiO}_{2} / \mathrm{FTO}$ substrates. They found by time-resolved photoluminescence (TRPL) spectroscopy (Table 2) that the interfacial electron injection rate from PVK to planar $\mathrm{TiO}_{2}$ is accelerated with increasing $\mathrm{Cl}^{-}$content. It explained the increased PCE in direct planar device using $\mathrm{Cl}^{-}$ as modifier. In contrast, $\mathrm{Cl}^{-}$demonstrated no influence on electron injection into mesoporous $\mathrm{TiO}_{2}$, suggesting that a reduction of interfacial charge recombination gives rise to the improved performance.

Table 2. Grain size, PL wavelength $\left(\lambda_{P L}\right), P L F W H M$, PL decay lifetimes $\left(\tau_{P L}\right)$, PL rate constants $\left(k_{P L}\right)$, injection rate constants $\left(k_{i n j}\right)$, injection efficiencies $\left(\Phi_{n j}\right)$, and PCEs $\left(\eta_{f}\right)$ of PVK films on planar or mesoporous $\mathrm{TiO}_{2}$ coated FTO substrates. ${ }^{[59]}$ With permission from The Royal Society of Chemistry, copyright 2018.

\begin{tabular}{|c|c|c|c|c|c|c|c|c|c|}
\hline Architecture & $\begin{array}{c}\text { Sample } \\
\mathrm{x} \mathrm{MACl} \text { for } 1 \mathrm{MAI}\end{array}$ & $\begin{array}{c}\text { Grain size } \\
(\mathrm{nm})\end{array}$ & $\begin{array}{c}\lambda_{P L} \\
(\mathrm{~nm})\end{array}$ & $\begin{array}{l}\text { FWHM } \\
(\mathrm{nm})\end{array}$ & $\begin{array}{c}\tau_{\mathrm{PL}} \\
( \pm 0.19 \mathrm{~ns})\end{array}$ & $\mathrm{k}_{\mathrm{PL}}\left(\mathrm{s}^{-1}\right)$ & $\mathrm{k}_{\mathrm{inj}}\left(\mathrm{s}^{-1}\right)$ & $\phi_{\text {inj }}(\%)$ & $\eta_{f}^{a}(\%)$ \\
\hline \multirow[t]{4}{*}{ Planar } & $0 \mathrm{MACl}$ & 28 & 775 & 52 & 2.68 & $3.7 \times 10^{8}$ & $2.1 \times 10^{8}$ & 52 & 1.34 \\
\hline & $0.5 \mathrm{MACl}$ & 39 & 778 & 49 & 2.27 & $4.4 \times 10^{8}$ & $2.7 \times 10^{8}$ & 59 & 9.5 \\
\hline & $1 \mathrm{MACl}$ & 42 & 786 & 41 & 1.77 & $5.6 \times 10^{8}$ & $4.0 \times 10^{8}$ & 68 & 10.51 \\
\hline & $2 \mathrm{MACl}$ & 46 & 784 & 47 & 0.98 & $1.0 \times 10^{9}$ & $8.5 \times 10^{8}$ & 83 & 10.85 \\
\hline \multirow[t]{5}{*}{ Mesoporous } & $0 \mathrm{MACl}$ & 36 & 765 & 41 & 1.4 & $7.1 \times 10^{8}$ & $5.5 \times 10^{8}$ & 75 & 7.64 \\
\hline & $0.5 \mathrm{MACl}$ & 22 & 754 & 54 & 1.05 & $9.5 \times 10^{8}$ & $7.9 \times 10^{8}$ & 81 & 9.12 \\
\hline & $1 \mathrm{MACl}$ & 27 & 757 & 54 & 1.07 & $9.3 \times 10^{8}$ & $7.7 \times 10^{8}$ & 81 & 9.57 \\
\hline & $2 \mathrm{MACl}$ & 36 & 766 & 57 & 1.18 & $8.5 \times 10^{8}$ & $6.8 \times 10^{8}$ & 79 & 10.09 \\
\hline & rom ref. ${ }^{[60-63]}$ & & & & & & & & \\
\hline
\end{tabular}

2D PVKs are a class of two-dimensional quantum wells (QWs) compounds which include Dion-Jacobson (DJ) and Russlesden-Popper (RP) phases. ${ }^{[60-63]}$ By incorporating $10 \mathrm{mg} \mathrm{mL}^{-1} \mathrm{MACl}$ into (GA)(MA) ${ }_{n} \mathrm{~Pb}{ }_{n} \mathrm{I}_{3 \mathrm{n}+1}$ (GA=guanidinium; n=3) DJ film precursor solution, Luo et al. ${ }^{[40]}$ got a champion stabilized PCE of $18.36 \%$ (with a stable $J_{s c}$ of $20.86 \mathrm{~mA} . \mathrm{cm}^{-2}$ ). In Luo's work, the grain size increased from $\approx 0.3-1.0 \mu \mathrm{m}$ up to $>3 \mu \mathrm{m}$ as shown in Fig. 3A, and then grain boundaries were reduced. FWHM decreased from $0.165^{\circ}$ to $0.143^{\circ}$, indicating an increased crystallite size. The emission peak position of the bulk phase varied from 760 to $754 \mathrm{~nm}$ in the PL measurement, the blueshift was attributed to a trap density reduction, yielding lower nonradiative recombination 
Cite this paper as: F. Cheng, J. Zhu, Th. Pauporté, Chlorides, other Halides and Pseudohalides as Additives for the Fabrication of Efficient and Stable Perovskite Solar Cells.

ChemSusChem 14 (2021) 3665-3692. DOI: 10.1002/cssc.202101089

losses. The average lifetimes increased to $94.0 \mathrm{~ns}$ in TRPL measurements. The influence of additive concentration on the thickness distribution of QWs was also evaluated by femtosecond transient absorption (TA) spectroscopy. The additive enabled the formation of low-n QWs and a narrower thickness distribution of highn QWs, leading to a gradient distribution of QW thickness. The carrier-populating time significantly decreased to $0.6 \sim 0.8 \mathrm{ps}$ from $30 \mathrm{ps}$ with the addition of $10 \mathrm{mg} \mathrm{mL}^{-1} \mathrm{MACl}$, indicating that the additive enabled highly efficient electron transfer from low-n QWs to the bulk phase due to an optimized thickness distribution of the QWs (Fig. 3B), which is beneficial for charge transport/extraction in solar cells. Finally, the optimized solar cells without encapsulation had much better environmental stability, thermal stability, and illumination stability.

A

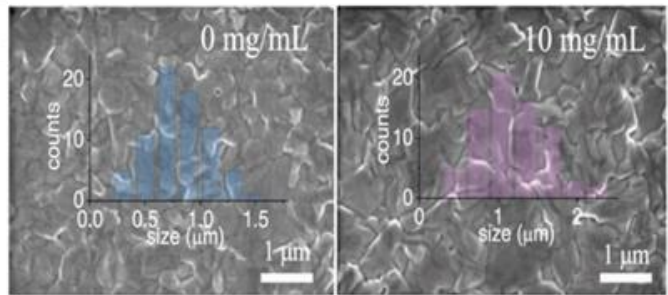

C

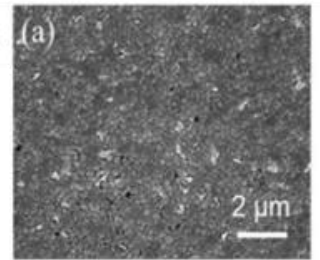

D

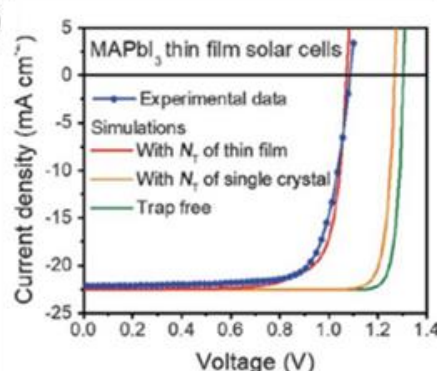

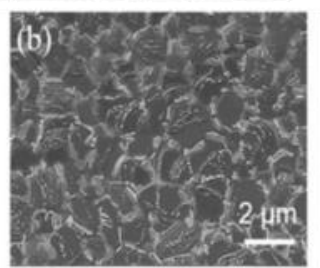
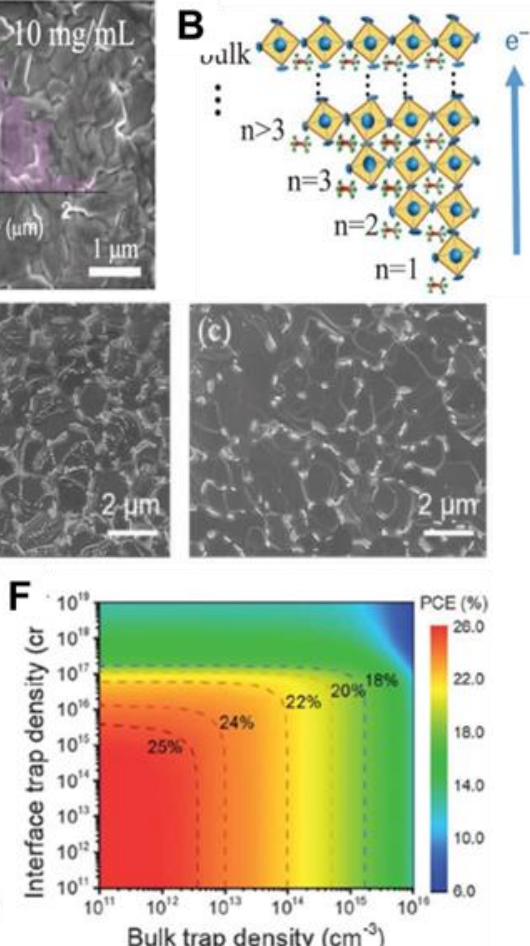

Fig. 3 (A) Top-view scanning electron microscopy (SEM) images and statistical chart of grain size of the 2D (GA)(MA) ${ }_{3} \mathrm{~Pb}_{3} \mathrm{I}_{10}$ films without and with $10 \mathrm{mg} \mathrm{mL}^{-1} \mathrm{MACl}$ additive. (B) Schematical thickness distribution of QWs and electron transfer from low- $n$ to high- $n$ QWs. ${ }^{[64]}$ with permission from Wiley-VCH, copyright 2019.

(C) Effect of $\mathrm{MACl}$ and CNT-NH $\mathrm{H}_{2}$ additives on the morphologies of $\mathrm{MA}_{0.85} \mathrm{FA}_{0.15} \mathrm{PbI}_{3}$ thin films. SEM images of a) $\mathrm{MA}_{0.85} \mathrm{FA}_{0.15} \mathrm{PbI}_{3}$, b) $\mathrm{MA}_{0.85} \mathrm{FA}_{0.15} \mathrm{PbI}_{3}(\mathrm{MACl})$, and c) $\mathrm{MA}_{0.85} \mathrm{FA}_{0.15} \mathrm{PbI}_{3}(\mathrm{MACl}) / \mathrm{CNT}-\mathrm{NH}_{2}$ thin films. ${ }^{[65]}$ with permission from Wiley-VCH, copyright 2019. (D) Measured and simulated J-V curves of planar-structured solar cells based on $\mathrm{MAPbI}_{3}$ polycrystalline thin films. The thin-film (single crystal) bulk and interface trap densities were adopted for the simulations. (E) Dependence of the PCE on $\mathrm{MAPbI}_{3}$ thin-film bulk and interface trap densities. The dashed lines denote the contour lines of iso-PCE values. ${ }^{[29]}$ With permission from the American Association for the Advancement of Science, copyright 2020 
Cite this paper as: F. Cheng, J. Zhu, Th. Pauporté, Chlorides, other Halides and Pseudohalides as Additives for the Fabrication of Efficient and Stable Perovskite Solar Cells.

ChemSusChem 14 (2021) 3665-3692. DOI: 10.1002/cssc.202101089

In the work by Zhao et al., ${ }^{[65]} 0.05 \mathrm{mg} \mathrm{mL}^{-1}$ of amino-functionalized carbon nanotube $\left(\mathrm{CNT}-\mathrm{NH}_{2}\right)$ and 0.21 $\mathrm{M}$ of MACl were employed to fabricate highly crystalline uniaxial-orientated PVK thin films with enhanced charge carrier transport. The $\mathrm{MA}_{0.85} \mathrm{FA}_{0.15} \mathrm{PbI}_{3}(\mathrm{MACl})$ film showed enhanced crystallinity by $\mathrm{XRD}$, and the peak intensity ratios of (110)/(310) and (220)/(310) became larger. It proved a preferred growth along the (110) and (220) crystallographic planes. The morphologies of modified film are shown in Fig. 3C. The average grain size reached $>1.5 \mu \mathrm{m}$ by addition of $\mathrm{MACl}$ which was further enlarged to $2 \mu \mathrm{m}$ with $\mathrm{CNT}-\mathrm{NH}_{2}$. The champion PSC device $\left(\mathrm{FTO} / \mathrm{c}-\mathrm{TiO}_{2} / \mathrm{SnO}_{2} / \mathrm{PVK} / \mathrm{Spiro}-\mathrm{OMeTAD} / \mathrm{Ag}\right)$ achieved a PCE of $21.05 \%$ with a $J_{s c}$ of $23.52 \mathrm{~mA}$ $\mathrm{cm}^{-2}, V_{o c}$ of $1.091 \mathrm{~V}$, and $F F$ of 0.82 . The long-lasting charge carriers' lifetime in $\mathrm{MA}_{0.85} \mathrm{FA}_{0.15} \mathrm{PbI}_{3}(\mathrm{MACl})$ films improved from $6.28 \mathrm{~ns}$ to $18.85 \mathrm{~ns}$, compared with $\mathrm{MA}_{0.85} \mathrm{FA}_{0.15} \mathrm{PbI}_{3}$, but decreased to $4.78 \mathrm{~ns}$ with $\mathrm{CNT}-\mathrm{NH}_{2}$. Such a decrease of PL lifetime is similar to the case of PVK films covered with charge transport (carrierquencher) layers and indicated a promotion of charge-carrier transport by CNT- $\mathrm{NH}_{2}$.

Normally, the defects at the film surface and grain boundaries of PVK cause deep traps. These traps act as recombination centers for charge carriers. Ni et al. ${ }^{[29]}$ studied the spatial and energetic distributions of trap states in halide PSC by Drive-level capacitance profiling (DLCP) method. They calculated that the trap density of the interfaces of polycrystalline PVK ranges between $9.0 \times 10^{15} \mathrm{~cm}^{-3}$ and $2.0 \times 10^{17} \mathrm{~cm}^{-3}$, which is $1 \sim 2$ orders of magnitude the bulk value. For the polycrystalline $\mathrm{MAPbI}_{3}$ fabricated solar cell discussed in their work, the authors calculated that decreasing the interface trap density from $1.0 \times 10^{17} \mathrm{~cm}^{-3}$ to $2.0 \times 10^{15} \mathrm{~cm}^{-3}$, would enhance the PCE to $25.4 \%$, which is comparable to the PCE of $26.6 \%$ for trap-free $\mathrm{MAPbI}_{3}$ thin film PVK solar cell (Fig. 3D and 3E).

Grätzel et al. ${ }^{[66]}$ fabricated planar PSCs with $\mathrm{SnO}_{2} / \mathrm{TiO}_{2}$ double layer oxide for an efficient electron extraction. They used MACl additive to aid the crystallization of the PVK film and get high quality large grains of PVK. The grain size enlarged to over $1 \mu \mathrm{m}$. Additionally, they treated the PVK film surface by iodine dissolved in isopropanol to passivate trap states. With Spiro-OMeTAD as HTL, the best PCE achieved $21.65 \%\left(J_{s c}\right.$ of 23.2 $\mathrm{mA} \mathrm{cm}^{-2}$, a $V_{o c}$ of $1193 \mathrm{mV}$, and $F F$ of 78.2\%). By using PTAA as hole transporting material (HTM), the device maintained $96 \%, 90 \%$, and $85 \%$ of their initial PCE values after $500 \mathrm{~h}$ continuous light soaking at 20, 50, and $65^{\circ} \mathrm{C}$, respectively.

In a typical unstable $\mathrm{PVK} \mathrm{FAPbI}_{3}$, the main function of $\mathrm{MACl}$ additive is to stabilize the black $\alpha$-phase since it is easily transformed into yellow non-PVK $\delta$-phase at ambient environment. Kim et al. ${ }^{[38]}$ fabricated a high quality pure $\alpha$-phase $\mathrm{FAPbI}_{3}$ by employing $40 \mathrm{~mol} \%$ of $\mathrm{MACl}$ as additive in the $\mathrm{PVK}$ precursor solution. The 
Cite this paper as: F. Cheng, J. Zhu, Th. Pauporté, Chlorides, other Halides and Pseudohalides as Additives for the Fabrication of Efficient and Stable Perovskite Solar Cells.

ChemSusChem 14 (2021) 3665-3692. DOI: 10.1002/cssc.202101089

mechanism of MACl effect on the formation of $\alpha$-phase PVK was elucidated using DFT calculation. The formation energies revealed that $\mathrm{Cl}$ stabilizes the PVK structure thermodynamically. The projected density of states (PDOS) results revealed that $\mathrm{Cl}$ enhances the intensity of the $\mathrm{p}$ orbital of $\mathrm{I}$ at the HOMO state, then, the interactions of FA and I could be enhanced, thus improving the stability of $\mathrm{FAPbI}_{3}$. Attractively, the device got a PCE of $24.02 \%$ (23.48\% for the certified one) with improved surface morphology, crystallographic properties, optical absorption, and PL properties.

One of us and co-workers employed methylammonium chloride (MACl) as additive at 20 to $55 \mathrm{~mol} \%$ of $\mathrm{PbI}_{2}$ precursor for the growth of $\mathrm{FA}_{1-\mathrm{x}} \mathrm{MA}_{x} \mathrm{PbI}_{3} \mathrm{PVK}_{\text {layers. }}{ }^{[36,67]}$ The average grain size increased continuously with $\mathrm{MACl}$ with average values at $604 \mathrm{~nm}, 775 \mathrm{~nm}$ and $982 \mathrm{~nm}$ for $40 \mathrm{~mol} \%, 48 \mathrm{~mol} \%$ and $55 \mathrm{~mol} \%$, respectively. Monolithic PVK large grains were formed. Liquid-NMR was developed to analyze the photovoltaic layers. NMR peaks of MA, FA and of condensation products were identified and were reliably used to measure MA and FA content in films actually used in PSCs (Fig. 4A). $x$ was quantified at $0.06 \pm 0.01$ for the pure $\alpha$-phase films and was shown to correspond to the best entropic compound stabilization. The MACl excess was eliminated upon the annealing step. The best performance was achieved for $48 \mathrm{~mol} \% \mathrm{MACl}$. It resulted in a stabilized PCE as high as $22.1 \%$. These devices were also highly stable under solar irradiation and high moisture.

Kim et al. ${ }^{[68]}$ found that the addition of $\mathrm{MACl}$ into PVK precursor solution not only improves the crystallinity, but also increases the solubility of $\mathrm{GeI}_{2}$ (Fig. 4B). The 3\% MACl-assisted Ge doped Pb-hybrid PVK film show superior PL lifetime of $18846 \mathrm{~ns}$, a PCE of $22.7 \%$, and a great stability toward illumination and humidity. $80 \%$ of the initial device performance was maintained after 1 month in $30 \sim 40 \%$ of relative humidity (RH). 
Cite this paper as: F. Cheng, J. Zhu, Th. Pauporté, Chlorides, other Halides and Pseudohalides as Additives for the Fabrication of Efficient and Stable Perovskite Solar Cells. ChemSusChem 14 (2021) 3665-3692. DOI: 10.1002/cssc.202101089

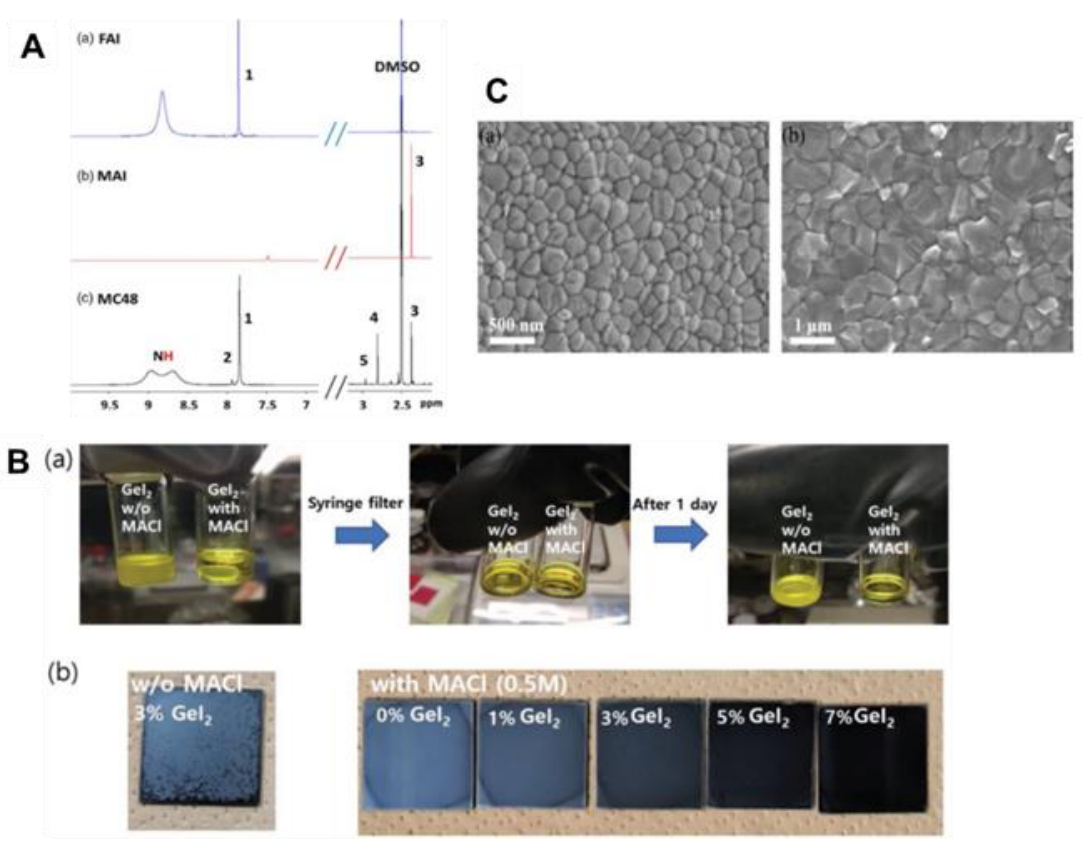

Fig. 4 (A) ${ }^{1} H$-NMR spectra of a) $M A I$, b) FAI, and c) $F A_{0.94 M A} A_{0.06} \mathrm{PbI}_{3}$ layer with indexation. 1. $\mathrm{NH}=\mathrm{CHNH}_{3}$; 2. $\mathrm{CH}_{3} \mathrm{NH}_{2} \mathrm{CH}=\mathrm{NHI}$; 3. $\mathrm{CH}_{3} \mathrm{NH}_{3} I$; 4. $\mathrm{CH}_{3} \mathrm{NH}_{2} \mathrm{CH}=\mathrm{NHI} p \mathrm{CH}_{3} \mathrm{~N}=\mathrm{CHNH}_{2} \mathrm{CH}_{3} \mathrm{I}$; 5. $\mathrm{CH}_{3} \mathrm{~N}=\mathrm{CHNH}_{2} \mathrm{CH}_{3} \mathrm{I}\left(\mathrm{N}, \mathrm{N}^{\prime}-\right.$ dimethyl FAI). ${ }^{[36]}$ with permission from Wiley-VCH, copyright 2020. (B) a) GeI ${ }_{2}$-containing DMF/DMSO organic-inorganic PVK (3\% GeI, $\left.\mathrm{FA}_{0.83} \mathrm{MA}_{0.17} \mathrm{~Pb}_{0.97} \mathrm{Ge}_{0.03}\left(\mathrm{I}_{0.9} \mathrm{Br}_{0.1}\right)_{3}\right)$ inks with and without $\left.\mathrm{MACl}(0.5 \mathrm{M}) . \mathrm{b}\right)$ Pictures of $\mathrm{PVK}$ films of $\mathrm{FA}_{0.83} \mathrm{MA}_{0.17} \mathrm{Ge}_{x} \mathrm{~Pb}_{1-x}\left(\mathrm{I}_{0.9} \mathrm{Br}_{0.1}\right)_{3}$ prepared without and with $\mathrm{MACl}$ additive and with various concentration of $\mathrm{GeI}_{2}(x=0-0.07) .{ }^{[68]}$ with permission from Wiley-VCH, copyright 2020. (C) Top-view SEM images of PVK films a) reference and b) with the FACl additive. ${ }^{[69]}$ with permission from Wiley-VCH, copyright 2021.

Formamidinium chloride (FACl) is another alternative for chloride source, with better solubility than $\mathrm{MACl}$ helping to get higher crystallinity. Suzuki et al. ${ }^{[70]}$ mixed various mol\% of $\mathrm{FACl}$ into the MAI and $\mathrm{PbCl}_{2}$ precursor solution. Using $10 \mathrm{~mol} \%$ of $\mathrm{FACl}$ additive, energy dispersive X-ray spectroscopy (EDX) mapping gave the molar ratio of $\mathrm{Cl}$ in the halogen component with the sum of $\mathrm{I}$ and $\mathrm{Cl}$ which was slightly increased to be about $7.5 \%$. The performance with the photovoltaic PCE was improved from $9.59 \%$ to $13.75 \%$ with $J_{s c}$ of $22.5 \mathrm{~mA} \mathrm{~cm}^{-2}, V_{o c}$ of $0.888 \mathrm{~V}, F F$ of 0.690 . XRD patterns showed an increase of the (100) diffraction peak, a decrease of the FWHM and a peak shift due to a texturation of the layer, an increase of the crystal domain size and an enlargement of the d-spacing with addition of $\mathrm{FACl}$ at $10 \mathrm{~mol} \%$. Kong ${ }^{[69]}$ modified PVK bulk with FACl while another $\mathrm{Cl}$ additive, 1-adamantylamine hydrochloride (ADAHCl, $3 \mathrm{mg} \cdot \mathrm{mL}^{-1}$ in chlorobenzene, $\mathrm{CB}$ ) was employed for the surface treatment. It formed a high-density SAM and passivated the surface (Fig. 4C). A longer carrier lifetime at $22.3 \mathrm{~ns}$ and reduced carrier recombination were found. Based on the double $\mathrm{Cl}$ modification, a $\mathrm{SnO}_{2}$-based planar PSC was achieved with a PCE of 21.2\%, low hysteresis, and high open circuit voltage of 
Cite this paper as: F. Cheng, J. Zhu, Th. Pauporté, Chlorides, other Halides and Pseudohalides as Additives for the Fabrication of Efficient and Stable Perovskite Solar Cells. ChemSusChem 14 (2021) 3665-3692. DOI: 10.1002/cssc.202101089

1.152 V. $88 \%$ of initial PCE was retained after $700 \mathrm{~h}$ of aging under continuous illumination. $\mathrm{Cl}$ doping of $\mathrm{MAPbI}_{3}$ is difficult to obtain due to the low formation energy and low boiling point of $\mathrm{MAPbCl}_{3}$ at the origin of layer defects. A novel $\mathrm{Cl}$ containing additive, chloroformamidinium chloride $(\mathrm{Cl}-\mathrm{FACl})^{[71]}$, was presented as a "stabilizer" to restrain the removal of $\mathrm{Cl}$ avoiding the formation of defects in the layer. Gradually positive shift in XRD measurement indicated the shrinking of crystal lattice with the increase of smaller ions content doping, that is $\mathrm{Cl}$ and not $\mathrm{Cl}-\mathrm{FA}$. SEM showed that the grain size became larger with the concentration of $\mathrm{Cl}-$ FACl. The defects density based on the space charge limited current (SCLC) measurements and lifetime of TRPL decay measurements were calculated at $4.75 \times 10^{15} \mathrm{~cm}^{-3}$ and $110.1 \mathrm{~ns}$, respectively, for the Cl-FACl doped PVK films. It was much lower and longer than that of without Cl-FACl $\left(5.70 \times 10^{15} \mathrm{~cm}^{-3}\right.$ and $\left.90.3 \mathrm{~ns}\right)$. For devices with 5 mol\% Cl-FACl, a maximum PCE of $20.36 \%$ was achieved with lower hysteresis, $94 \%$ of their initial performance was retained after 600 minutes. Seok et al. ${ }^{[72]}$ stabilized the $\alpha-\mathrm{FAPbI}_{3}$ phase by doping with $3.8 \mathrm{~mol} \%$ of methylenediammonium dichloride in replacement of $\mathrm{MAPbBr}_{3}$ to get a methylammoniumfree PSC. They achieved a certified PCEs of $23.7 \%$. For the modified device, more than $90 \%$ of the initial efficiency was retained after 600 hours of operation at the maximum power point. Unencapsulated devices retained more than $90 \%$ of their initial PCE after annealing at $150^{\circ} \mathrm{C}$ in air for 20 hours.

\subsection{Mechanism of chloride additives action on the growth of PVK films}

$\mathrm{Cl}$ additives are mixed to the PVK precursor solution employed to prepare the films. Based on a coupled scanning transmission electron microscopy and energy-dispersive spectroscopy (STEM-EDS) measurements done by Dar et al. ${ }^{[73]}$ in 2014, and a combined in-situ X-ray diffraction and ex-situ TOF-SIMS chemical analysis study done by Yang et al. ${ }^{[74]}$ in $2016, \mathrm{Cl}$ ions were proved to control the nucleation as well as the growth of $\mathrm{MAPbI}_{3}$ without entering into the lattice. It rather resides at the grain boundaries after post-annealing because of its volatile property. Precisely, $\mathrm{MACl}$ controls the homogeneity of $\mathrm{MAPbI}_{3}$ thin films by formation of intermediates with $\mathrm{PbI}_{2}$ and reduction of the reaction rate between $\mathrm{PbI}_{2}$ and MAI. The crystal growth rate is slowed-down and the crystals are more uniform. Consequently, the grains are larger, the film morphology is improved with less pinholes. It finally enhances the photovoltage property of the cell. To verify the function of $\mathrm{MACl}$ in the intermediate state, Dai et al. ${ }^{[75]}$ demonstrated a novel facile intermediate engineering. They dripped $20 \mathrm{mg} \cdot \mathrm{mL}^{-1} \mathrm{MACl}$ onto the deposited FAI-MAI-PbI $2-\mathrm{DMSO}$ intermediate film before the end of the second stage of spinning. They showed that this MACl treatment induces an ion exchange process in the FAI-MAI- 
Cite this paper as: F. Cheng, J. Zhu, Th. Pauporté, Chlorides, other Halides and Pseudohalides as Additives for the Fabrication of Efficient and Stable Perovskite Solar Cells.

ChemSusChem 14 (2021) 3665-3692. DOI: 10.1002/cssc.202101089

$\mathrm{PbI}_{2}-\mathrm{DMSO}$ intermediate phase and transforms it into FAI-MAI-MACl-PbI $2-\mathrm{DMSO}$ intermediate phase, further suppressing the crystal evolution rate and letting grains more time to evolve and self-embedding into the lattice network. As illustrated in Fig. 5A, $20 \mathrm{mg} \mathrm{mL}^{-1} \mathrm{MACl}$ modified film got a maximum grain size of $770 \mathrm{~nm}$, and the lowest root-mean-square roughness of 11.6. Finally, the fabricated $\mathrm{FTO} / \mathrm{SnO}_{2} / \mathrm{PVK} /$ spiro-OMeTAD/Au achieved a PCE of $20.4 \%$.
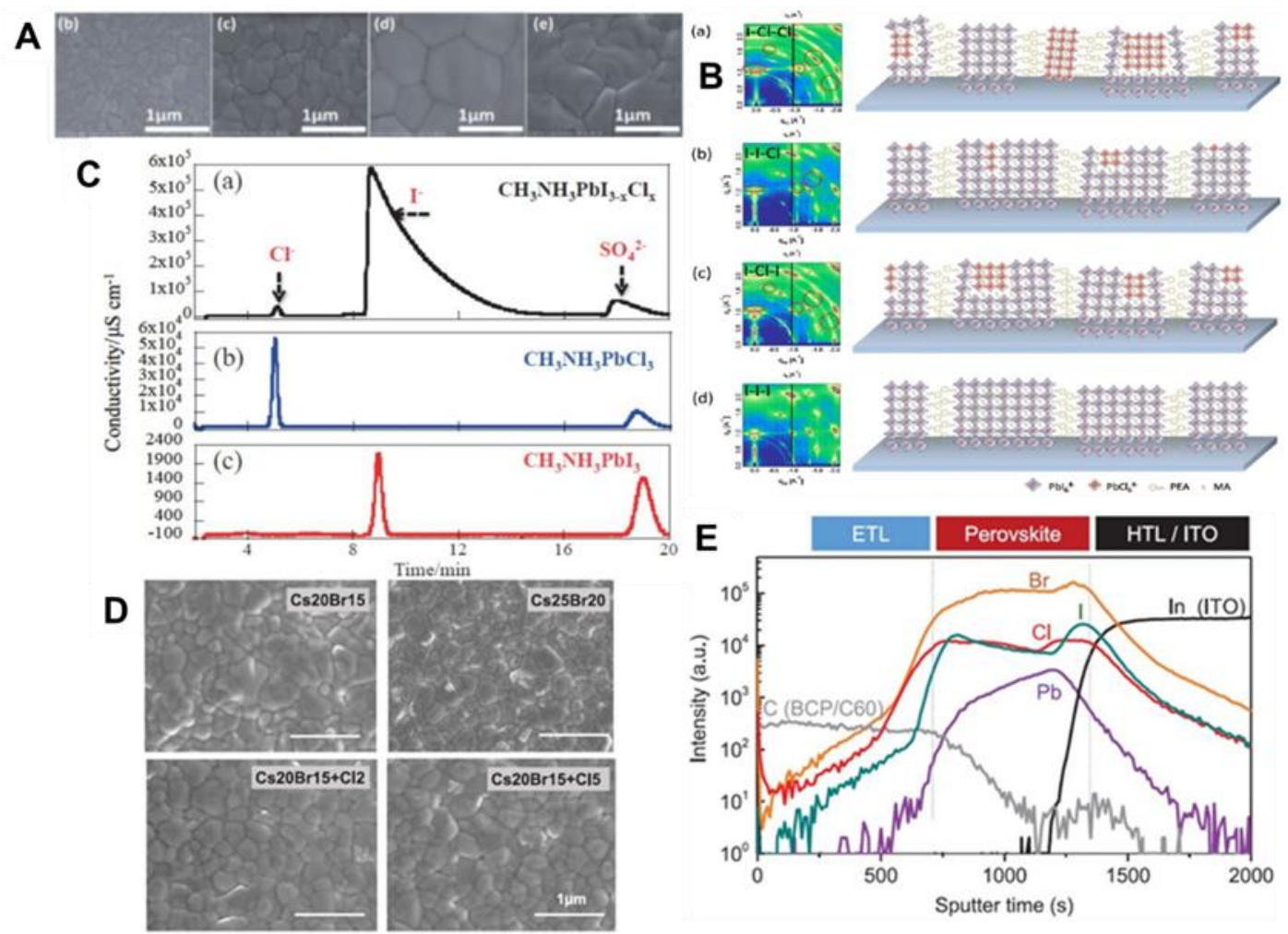

Fig. 5 (A) Surface SEM images of the films prepared with varied concentrations of $M A C l$, (b) control film without-treatment, and films treated with c) MACl-10, d) MACl-20, e) MACl-30. ${ }^{[75]}$ with permission from the American Chemical Society, copyright 2020. (B) GIWAXS images and proposed crystal orientation for a) I-ClCl, b) I-I-Cl, c) I-Cl-I and d) I-I-I LDRP PVK films. The characteristic peaks in chloride-containing systems are shown in red rings. ${ }^{[76]}$ with permission from Elsevier, copyright 2019 (C) Ion chromatography analysis of three different PVK solutions a) $\mathrm{CH}_{3} \mathrm{NH}_{3} \mathrm{PbI}_{3-x} \mathrm{Cl}$, b) $\mathrm{CH}_{3} \mathrm{NH}_{3} \mathrm{PbCl}_{3}$, and c) $\mathrm{CH}_{3} \mathrm{NH}_{3} \mathrm{PbI}_{3 .}{ }^{\left[{ }^{[7]} \text { With permission from }\right.}$ the The Chemical Society of Japan, copyright 2015 (D) Top-view SEM images showing no evident difference in apparent grain size between triple-halide PVKs and double-halide control films; (E) TOF-SIMS depth profiles show the uniform distribution of halides throughout the entire film thickness of the triple-halide PVK $\left(\mathrm{Cs}_{20} \mathrm{Br}_{15}+\mathrm{Cl}_{5}\right) .{ }^{[49]}$ With permission from the American Association for the Advancement of Science, copyright 2020

The mechanism of optical and electronic properties improvement by $\mathrm{Cl}$ for low dimensional RuddlesdenPopper (LD-RP) PVKs solar cell was also investigated. Devices with $\mathrm{PbI}_{2}+\mathrm{PEACl}+\mathrm{MAI}$ (I-Cl-I), $\mathrm{PbI}_{2}+\mathrm{PEAI}+\mathrm{MACl}(\mathrm{I}-\mathrm{I}-\mathrm{Cl}), \mathrm{PbI}_{2}+\mathrm{PEAI}+\mathrm{MAI}(\mathrm{I}-\mathrm{I}-\mathrm{I}), \mathrm{PbI}_{2}+\mathrm{PEACl}+\mathrm{MACl}(\mathrm{I}-\mathrm{Cl}-\mathrm{Cl})$ were fabricated. ${ }^{[76]} \mathrm{It}$ was 
Cite this paper as: F. Cheng, J. Zhu, Th. Pauporté, Chlorides, other Halides and Pseudohalides as Additives for the Fabrication of Efficient and Stable Perovskite Solar Cells.

ChemSusChem 14 (2021) 3665-3692. DOI: 10.1002/cssc.202101089

confirmed by XRD that a part component of chloride generated the (PEA) $)_{2} \mathrm{MA}_{n-1} \mathrm{~Pb}_{n} \mathrm{Cl}_{3 n+1}\left(\mathrm{PbCl}_{6}{ }^{4-}\right)$ phase. Grazing-incidence wide-angle X-ray scattering (GIWAXS Fig. 5B) technique was used to understand the effect of $\mathrm{Cl}$ position on crystallinity of the film. Results proved that $\mathrm{Cl}$ on $\mathrm{PEA}$ prefers to form $\mathrm{PbCl}_{6}{ }^{4-}$ compared to that on $\mathrm{MACl}$. PVK prepared from mixed $\mathrm{Cl}$ and I precursor demonstrated a longer charge carrier lifetime (668.15 ns) and diffusion length. SEM results showed that the incorporation of chloride significantly improved the PVK morphology with increased grain size, enhanced crystallinity, and uniform and smooth surface. Finally, a best PCE of $12.78 \%$ was achieved for the I-I-Cl system in a ITO/PEDOT:PSS/PVK/PCBM/LiF/Al solar cell structure.

The role of $\mathrm{Cl}$ on the PVK synthesis mechanism can be explained by the formation of intermediate species that favor the growth and crystallization of the final compound. It results in improved carrier lifetime and diffusion length, defect passivation and a phase stabilization which are of great profit for the final performance.

\subsection{Measurement of the residual chloride in the layers}

We have seen that many studies have reported the application of chloride additives in PVK precursor solution to optimize the morphology and surface passivation but with little or no chloride incorporation into the bulk material. It is commonly known that $\mathrm{Cl}^{-}$volatilizes (evaporates) during annealing of the PVK film but could also reside at the grain boundaries or on PVK film surface. Chloride compounds mainly act as film crystallization controllers or play a role in the passivation of the PVK-contact interface. The content of probably residual $\mathrm{Cl}$ in the bulk were investigated by EDS, XPS, XRD and so on. $\mathrm{Cl}^{-}$content is always below the detection limit of these techniques. For instance, Pauporté et al. ${ }^{[36,67]}$ could not detect a quantifiable amount of Cl by EDX in $\mathrm{FA}_{1-\mathrm{x}} \mathrm{MA}_{\mathrm{x}} \mathrm{PbI}_{3}$ layers prepared with precursor solutions containing $48 \mathrm{~mol} \%$ of $\mathrm{MACl}$ with respect to $\mathrm{PbI}_{2}$.

Moreover, the lattice parameters determined by XRD are easily influenced by other factors such as mechanical stress. Therefore, some researchers claimed that $\mathrm{Cl}^{-}$is removed without incorporation into the crystal lattice. However, the content of $\mathrm{Cl}$ residual could be measured in some cases, depending on the doping level, source of $\mathrm{Cl}$, halogen balance in the perovskite precursor solution/initial stoichiometry, and measurement technique.

Mosca et al. ${ }^{[78]}$ found in 2013 that low concentration of $\mathrm{Cl}$ incorporated in a iodide-based structure did not change the $E_{g}$, but improved the charge transport in the PVK layer. Devices with methyl ammonium lead iodide PVK (PS1) layer, methyl ammonium lead iodide chloride (PS2) layer (3:1 MAI: $\mathrm{PbCl}_{2}$ ) and lead halide mixture 
Cite this paper as: F. Cheng, J. Zhu, Th. Pauporté, Chlorides, other Halides and Pseudohalides as Additives for the Fabrication of Efficient and Stable Perovskite Solar Cells.

ChemSusChem 14 (2021) 3665-3692. DOI: 10.1002/cssc.202101089

(PS3) layer (1:1MACl:PbI 2 ) were fabricated. Their bandgap was $1.60 \pm 0.01 \mathrm{eV}$. PS1 was poorly crystal oriented, while PS2 had a high orientation. A $0.7 \%$ reduction of the unit cell volume with respect to PS1 proved Cldoping in PS2. For PS3, a high orientation pointed out a further phase, cubic $\mathrm{MAPbCl}_{3}(\mathrm{a}=5.683(2) \AA)$. The segregation of the cubic $\mathrm{MAPbCl}_{3}$, besides the $\mathrm{Cl}$-doped $\mathrm{MAPbI}_{3}$ phase proved the low incorporation of $\mathrm{Cl}$ into I based PVK films. In 2015, Cojocaru et al. ${ }^{[77]}$ were the first to calculate the exact content of $\mathrm{Cl}^{-}$in the final film by ion chromatography. $\mathrm{CH}_{3} \mathrm{NH}_{3} \mathrm{PbI}_{3}, \mathrm{CH}_{3} \mathrm{NH}_{3} \mathrm{PbCl}_{3}$, and $\mathrm{CH}_{3} \mathrm{NH}_{3} \mathrm{PbI}_{3-\mathrm{x}} \mathrm{Cl}_{\mathrm{x}}$ layers were dissolved in $0.15 \mathrm{M}$ sulfuric acid and injected into an ion analyzer equipped with an anion-exchange column and a conductivity detector. Standard solutions of known concentration were used for $\mathrm{I}^{-}$and $\mathrm{Cl}^{-}$calibration. As shown in Fig. 5C, for the film prepared with $\mathrm{PbCl}_{2}$ and $\mathrm{CH}_{3} \mathrm{NH}_{3} \mathrm{I}$ in a 1:3 molar ratio, they found a 0.06:2.94 molar ratio of $\mathrm{Cl}$ to I which is equivalent to $2 \%$.

In the work by $\mathrm{Xu}$ et al. ${ }^{[49]}, \mathrm{MAPbCl}_{3}$ was employed into $\mathrm{FA}_{0.75} \mathrm{Cs}_{0.25} \mathrm{~Pb}\left(\mathrm{I}_{0.8} \mathrm{Br}_{0.2}\right)_{3} \mathrm{PVK}$. In contrast to prior reports that $\mathrm{Cl}$ additive increases the grain size by modifying the nucleation and crystal growth, enlargement of grain domains was not observed in this research (Fig. 5D). As shown by time-of-flight secondary ion mass spectrometry (TOF-SIMS) depth profiling (Fig. 5E), Cl was uniformly distributed throughout the film. Taken the EQE, XRD, SEM, XPS, and SIMS results together, it was concluded that $\mathrm{Cl}$ was incorporated into the PVK lattice and increased its $E_{g}$, rather than being eliminated in a volatile phase. In a further experiment, $\mathrm{MACl}$ was added alone into PVK, the band gap did not raise, in agreement with previous reports that MACl volatilize during the annealing process at the temperature from $100{ }^{\circ} \mathrm{C}$ to $140{ }^{\circ} \mathrm{C} \cdot{ }^{[67,79-81]}$ By replacing some of the iodine by bromine to shrink the lattice parameter, the solubility of $\mathrm{Cl}$ was improved, and it resulted in a factor of 2 increase in photocarrier lifetime and charge-carrier mobility.

\subsection{Other applications of chloride additives}

\subsubsection{Fabricate lead-less PSC}

Chloride additives have been employed with cations to partly replace $\mathrm{Pb}$ and thus fabricate more environmentally friendly PVK solar cells. ${ }^{[23]} \mathrm{Jin}$ et al. ${ }^{[82]}$ replaced $\mathrm{PbI}_{2}$ by $3 \%$ of $\mathrm{ZnCl}_{2}$. The modified device showed a great improvement in PCE from $16.4 \%$ to $18.2 \%$, and the corresponding $J_{s c}, V_{o c}, F F$ under reverse scan were 22.04 mA.cm ${ }^{-2}, 1.09 \mathrm{~V}$ and $75.76 \%$. As illustrated in Fig. 6A, the grain size increased up to $\sim 350 \mathrm{~nm}$ with $3 \% \mathrm{ZnCl}_{2}$ doping, without cracks nor pinholes. However, $\mathrm{ZnI}_{2}$ doped film showed a similar increased 
Cite this paper as: F. Cheng, J. Zhu, Th. Pauporté, Chlorides, other Halides and Pseudohalides as Additives for the Fabrication of Efficient and Stable Perovskite Solar Cells.

ChemSusChem 14 (2021) 3665-3692. DOI: 10.1002/cssc.202101089

crystal in grain size, confirming the crucial impact of $\mathrm{Zn}$ on the nucleation and crystal growth process. The FWHM of the (110) peak in XRD measurements decreased with increasing $\mathrm{ZnCl}_{2}$, indicating a better crystallinity, which is consistent with the SEM results. The film with $3 \%$ of $\mathrm{ZnCl}_{2}$ showed the strongest intensity of PL and the maximum of $84.3 \mathrm{~ns}$ PL lifetime, which implies that $\mathrm{ZnCl}_{2}$ doping reduces the traps and defects in the PVK layer. The MAI $\left(\mathrm{PbI}_{2}\right)_{0.97}\left(\mathrm{ZnCl}_{2}\right)_{0.03}$-based device had a 3\% hysteresis index, much lower than the control device $(10 \%)$. The recombination resistance $\left(\mathrm{R}_{\mathrm{rec}}\right)$ of electrical impedance spectroscopy (EIS) increased from $202.4 \Omega$ to $910.9 \Omega$, indicating a decrease in recombination. The modified device degraded $7 \%$ of its initial PCE value after aging for 30 days in an ambient environment at $25-28{ }^{\circ} \mathrm{C}$ with $30-55 \%$ humidity without encapsulation.

Tsai et al. ${ }^{[83]}$ replaced $\mathrm{PbI}_{2}$ by $75 \%$ of $\mathrm{SnCl}_{2}$. The device of $\mathrm{FTO} / \mathrm{TiO}_{2} / \mathrm{Al}_{2} \mathrm{O}_{3} / \mathrm{MASn}_{\mathrm{y}} \mathrm{Pb}_{1-\mathrm{y}} \mathrm{I}_{3}(\mathrm{Cl}) / \mathrm{NiO} / \mathrm{C}$ structure had a best $5.13 \%$ PCE with further addition of $30 \mathrm{~mol} \% \mathrm{SnF}_{2} . \mathrm{SnCl}_{2}$ modified the conduction band energy $\left(E_{C B}\right)$, the valence band energy $\left(E_{V B}\right)$ and lattice structure $(0 \%$, tetragonal structure; $25 \%$, orthorhombic structure; $50 \%$ of which with a substantially smaller unit cell; 75\%, pseudocubic structure.) of PVK (Fig. 6B and 6C). The device modified by $\mathrm{SnCl}_{2}$ showed anomalous optical and optoelectronic properties compared to the $\mathrm{SnI}_{2}$ control.
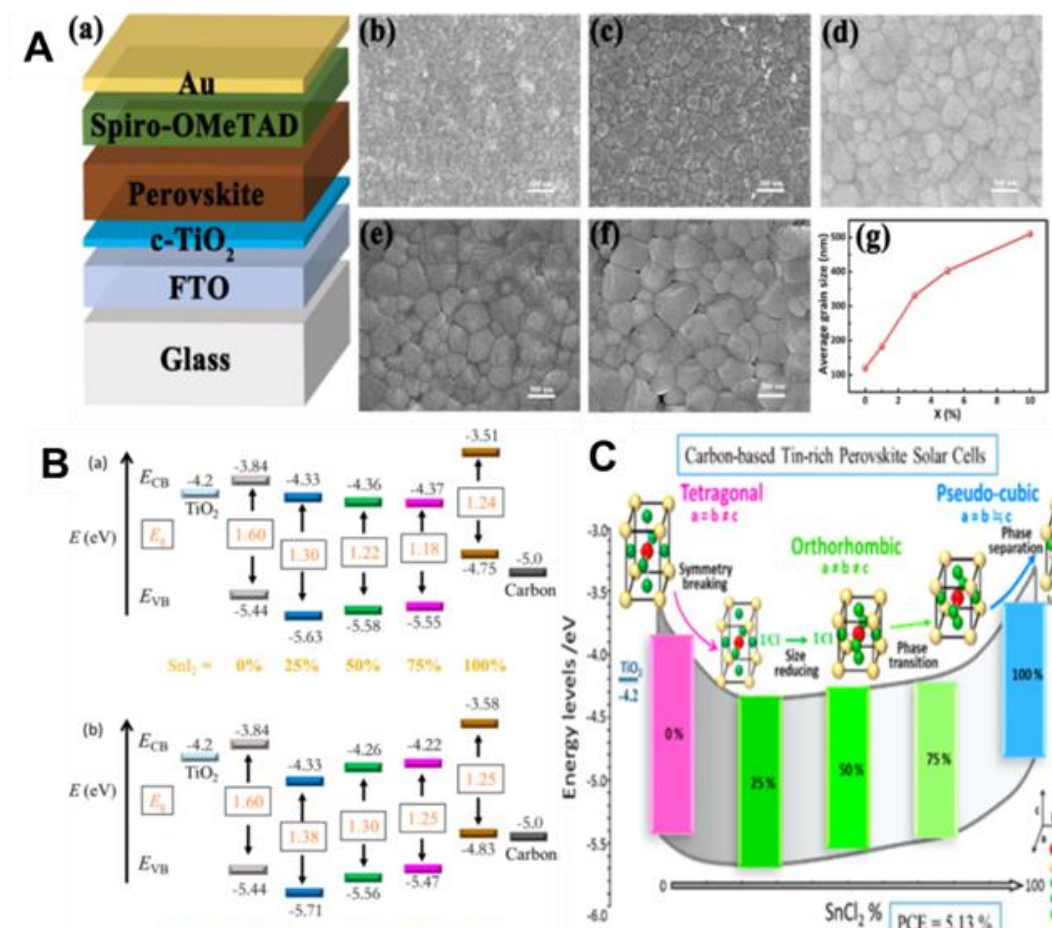

C Carbon-tased Tin-ich Peronsilic Solar Cels

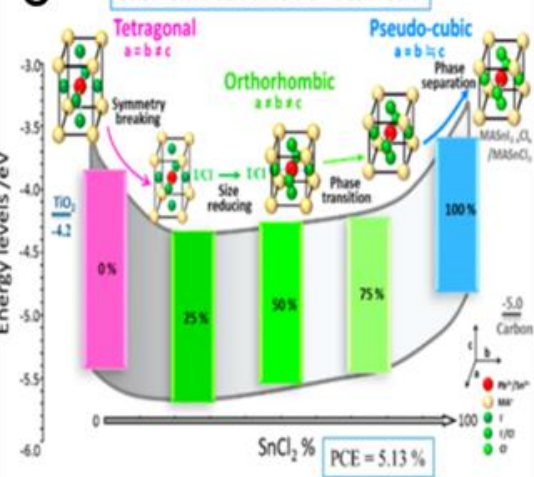

Fig. $6(A)$ a) Schematic device architecture of MAI $\left(\mathrm{PbI}_{2}\right)_{1-x}\left(\mathrm{ZnCl}_{2}\right)_{x}$ PVK solar cells. $\left.b-f\right)$ SEM surface images of the $\operatorname{MAI}\left(\mathrm{PbI}_{2}\right)_{1-x}\left(\mathrm{ZnCl}_{2}\right)_{x} \mathrm{PVK}$ film with different $\mathrm{ZnCl}_{2}(x=0,1,3,5$, and 10\%) content. $\mathrm{g})$ Average grain

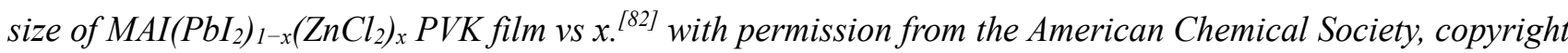


Cite this paper as: F. Cheng, J. Zhu, Th. Pauporté, Chlorides, other Halides and Pseudohalides as Additives for the Fabrication of Efficient and Stable Perovskite Solar Cells.

ChemSusChem 14 (2021) 3665-3692. DOI: 10.1002/cssc.202101089

2017 (B) Potential energy diagrams (energies in eV with respect to vacuum) of a) $\mathrm{CH}_{3} \mathrm{NH}_{3} \mathrm{Sn}_{4} \mathrm{~Pb}_{1-y} \mathrm{I}_{3}$ and b)

$\mathrm{CH}_{3} \mathrm{NH}_{3} \mathrm{Sn}_{4} \mathrm{~Pb}_{1-y} \mathrm{I}_{3}(\mathrm{Cl})$ films with $\mathrm{Sn} / \mathrm{Pb}$ ratios controlled with $\mathrm{SnI}_{2} / \mathrm{PbI}_{2}$ and $\mathrm{SnCl}_{2} / \mathrm{PbI}_{2}$ precursors, respectively, at varied concentrations as indicated. (C) The lattice structure of $\mathrm{PVK}$ modified by $\mathrm{SnCl}_{2}$ concentration. ${ }^{[83]}$ with permission from the American Chemical Society, copyright 2016

\subsubsection{Fabrication of 2D/3D dimensional PVKs.}

Hybrid 2D/3D PVKs are gaining an increasing interest in the field of halide PSC, the 3D component acts as an active material, while its $2 \mathrm{D}$ part provides protection against environmental degrading agents.

Wu et al. ${ }^{[84]}$ added dodecylammonium-chloride (DACl) into the precursor solution of $\mathrm{FA}_{1-\mathrm{x}} \mathrm{MA}_{\mathrm{x}} \mathrm{PbI}_{3}$. On the XRD pattern, the 3D-PVK peaks shifted towards higher angles and three peaks below $10^{\circ}$ were present, indicating the formation of 2D-PVK. SEM images of PVKs films with increasing concentration of DACl showed denser and larger jigsaw-like crystals oriented perpendicular to the substrates. The PL-lifetime was improved from $3.15 \mathrm{~ns}$ to $26 \mathrm{~ns}$ by lowering the dimensionality. Incorporation of $8 \% \mathrm{DACl}$ into the film reduced the defect levels by 2D-PVK formation. The moisture stability test showed that PVK retained the absorption structural characteristics even after being exposed to a humid environment ( $\mathrm{RH}>50 \%)$ for more than 50 days. The best performance device exhibited a PCE of 5\%,82\% of which was maintained after 6 days and $64 \%$ after 9 days in $\mathrm{RH} 50 \%$ and at a temperature of $85^{\circ} \mathrm{C}$.

$\mathrm{Cl}$ additive is also used in LED. It enables PVK blue-LEDs with narrowband and spectrally stable, without wavelength shift ${ }^{[85,86]}$ and it enhances the photoluminescence quantum efficiency. ${ }^{[86]}$

The list of the main chloride additives employed in PSC, cell structure, PCEs and $J-V$ curve parameters are summarized in the Table 3.

In summary, the role of chloride on the PVK synthesis mechanism has been explained by the formation of intermediate species. They favor the growth and crystallization of the final compound. They endow PVKs with high crystallinity as well as enhanced the grain orientation and increased charge carrier lifetime, increased diffusion length and electron-hole collection efficiency. Chloride additives have been employed to passivate the charged defects of the surface and grain boundaries as well as to control of crystallization and formation of PVK films for attaining efficient and stable photovoltaics. $\mathrm{K}^{+}$counter cation passivates trap states due to defects and blocks the iodide obility. Many groups have investigated the possible mechanism of chloride additives engineered PVK crystallization process. $\mathrm{Cl}^{-}$additives slows down the PVK formation rate to give uniform PVK film via forming the intermediate phase with $\mathrm{PbI}_{2}$ and reducing the reaction rate between $\mathrm{PbI}_{2}$ and MAI. 
Cite this paper as: F. Cheng, J. Zhu, Th. Pauporté, Chlorides, other Halides and Pseudohalides as Additives for the Fabrication of Efficient and Stable Perovskite Solar Cells.

ChemSusChem 14 (2021) 3665-3692. DOI: 10.1002/cssc.202101089

However, just little or no chloride is incorporated into the bulk PVK: most $\mathrm{Cl}^{-}$evaporates during PVK annealing. Interestingly, $\mathrm{Cl}^{-}$additives can be used to stabilize the black $\alpha$-phase $\mathrm{FAPbI}_{3}$, because $\mathrm{Cl}^{-}$additive can enhance the intensity of the p orbital of I at the HOMO state and the interaction of FA and I. Finally, with synergy effect of other passivator, efficiency of $24.02 \%$ for (MA)FAPbI ${ }_{3} \mathrm{PVK}_{\text {has }}$ been achieved. 
Cite this paper as: F. Cheng, J. Zhu, Th. Pauporté, Chlorides, other Halides and Pseudohalides as Additives for the Fabrication of Efficient and Stable Perovskite Solar Cells.

ChemSusChem 14 (2021) 3665-3692. DOI: 10.1002/cssc.202101089

Table 3. Main chloride additives used in PVK, concentration, cell structure, PCE and J-V curve parameters.

\begin{tabular}{|c|c|c|c|c|c|c|c|}
\hline $\begin{array}{l}\text { Chloride additives in } \\
\text { the precursor }\end{array}$ & Concentration/ $\mathrm{PbI} 2^{\mathrm{a}}$ & Device structure & PCE $(\%)$ & $\mathrm{J}_{\mathrm{sc}}\left(\mathrm{mA} \cdot \mathrm{cm}^{-2}\right)$ & $\mathrm{V}_{\mathrm{oc}}(\mathrm{V})$ & $\mathrm{FF}(\%)$ & Year Ref. \\
\hline $\mathrm{KCl}$ & $9 \mathrm{~mol} \%$ & $\mathrm{FTO} / \mathrm{c}-\mathrm{TiO}_{2} / \mathrm{mp}-\mathrm{TiO}_{2} / \mathrm{Cs}_{0.1} \mathrm{FA}_{0.9} \mathrm{PbI}_{3} / \mathrm{PEAI} /$ spiro-OMeTAD/Au & 19.16 & 25.24 & 0.992 & 76.54 & $2021^{[50]}$ \\
\hline $\mathrm{KCl}$ & $0.75 \mathrm{~mol} \% / \mathrm{DMSO}$ & ITO/PEDOT:PSS/MAPbI3/PC61BM/C60/BCP/Al & 15.08 & 18.33 & 1.04 & 74.67 & $2016^{[54]}$ \\
\hline $\mathrm{KCl}+\mathrm{NH}_{4} \mathrm{Cl}$ & $5 \mathrm{~mol} \%, 30 \mathrm{~mol} \%$ & $\mathrm{FTO} / \mathrm{c}-\mathrm{TiO}_{2} / \mathrm{mp}-\mathrm{TiO}_{2} / \mathrm{Cs}_{0.1} \mathrm{FA}_{0.9} \mathrm{PbI}_{3} / \mathrm{PEAI} /$ spiro-OMeTAD/Au & 20.05 & 25.21 & 1.012 & 78.61 & $2021^{[50]}$ \\
\hline $\mathrm{FACl}$ & $10 \mathrm{~mol} \%$ & $\mathrm{FTO} / \mathrm{TiO}_{2} / \mathrm{MAPbI}_{3-\mathrm{x}} \mathrm{Cl}_{\mathrm{x}} /$ spiro-OMeTAD/Au & 13.75 & 22.5 & 0.888 & 69.00 & $2019^{[70]}$ \\
\hline $\mathrm{FACl}, \mathrm{ADAHCl}$ & $10 \mathrm{mg} \cdot \mathrm{mL}^{-1} ; 3 \mathrm{mg} \cdot \mathrm{mL}^{-1}(\mathrm{CB})$ & $\mathrm{FTO} / \mathrm{SnO}_{2} /\left(\mathrm{FAPbI}_{3}\right)_{0.87}\left(\mathrm{MAPbBr}_{3}\right)_{0.13} /$ spiro-OMeTAD/Au & 21.20 & 23.4 & 1.152 & 78.30 & $2019^{[71]}$ \\
\hline $\mathrm{Cl}-\mathrm{FACl}$ & $5 \mathrm{~mol} \%$ & $\mathrm{ITO} / \mathrm{P}_{3} \mathrm{CT}-\mathrm{N} / \mathrm{MAPbI}_{3-\mathrm{x}} \mathrm{Cl}_{\mathrm{x}} / \mathrm{PC}_{61} \mathrm{BM} / \mathrm{BCP} / \mathrm{Ag}$ & 20.36 & 22.1 & 1.12 & 81.97 & $2019^{[87]}$ \\
\hline $\mathrm{PbCl}_{2}$ & $2.50 \mathrm{~mol} \%$ & $\mathrm{FTO} / \mathrm{TiO}_{2} / \mathrm{MAPbI}_{3} /$ spiro-OMeTAD/Au & 18.10 & 23.5 & 1.04 & 75.00 & $2013^{[52]}$ \\
\hline $\mathrm{PbCl}_{2}$ & $5 \mathrm{~mol} \%$ & $\mathrm{FTO} / \mathrm{TiO}_{2} / \mathrm{MAPbI}_{3} /$ spiro-OMeTAD/Au & 17.05 & 21.53 & 1.04 & 75.90 & $2019^{[53]}$ \\
\hline $\mathrm{DACl}$ & 8 vo $\% /$ PPS $^{\mathrm{b}}$ & ITO/PEDOT:PSS/FAMAPbI/3/PCBM/BCP/Ag & 5 & 13.57 & 0.845 & 44.00 & $2019^{[84]}$ \\
\hline $\mathrm{NH}_{4} \mathrm{Cl}$ & $0.8 \mathrm{~mol} \%$ & 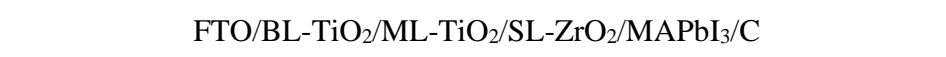 & 9.89 & 22.38 & 0.878 & 50.30 & $2019^{[56]}$ \\
\hline $\mathrm{NH}_{4} \mathrm{Cl}$ & $0.2 \mathrm{M}$ & ITO/PEDOT:PSS/MAPbI $3 / \mathrm{PCBM} / \mathrm{Ag}$ & 12.50 & 20.6 & 0.83 & 73.00 & $2020^{[55]}$ \\
\hline $\mathrm{NH}_{4} \mathrm{Cl}$ & $0.3 \mathrm{M}$ & $\mathrm{MgF}_{2} /$ Willow Glass/ITO/PTAA/MAPbI $3 / \mathrm{C} 60 / \mathrm{BCP} / \mathrm{Cu}$ & 19.72 & 22.83 & 1.092 & 79.10 & $2020^{[88]}$ \\
\hline $\mathrm{NH}_{4} \mathrm{Cl}$ & $30 \mathrm{~mol} \%$ & $\mathrm{FTO} / \mathrm{c}-\mathrm{TiO}_{2} / \mathrm{mp}-\mathrm{TiO}_{2} / \mathrm{Css}_{0.1} \mathrm{FA} 0.9 \mathrm{PbI}_{3} / \mathrm{PEAI} /$ spiro-OMeTAD/Au & 19.34 & 25.32 & 1.004 & 76.08 & $2021^{[50]}$ \\
\hline $\mathrm{MACl}$ & $48 \mathrm{~mol} \%$ & $\mathrm{FTO} / \mathrm{c}-\mathrm{TiO}_{2} / \mathrm{mp}-\mathrm{TiO}_{2} / \mathrm{FA}_{0.94} \mathrm{MA}_{0.06} \mathrm{PbI}_{3} / \mathrm{PEAI} /$ spiro-OMeTAD/Au & 22.18 & 25.94 & 1.06 & 80.62 & $2020^{[67]}$ \\
\hline $\mathrm{MACl}$ & $20 \mathrm{~mol} \%$ & $\mathrm{FTO} / \mathrm{c}-\mathrm{TiO}_{2} / \mathrm{MAPbI}_{3} /$ spiro-OMeTAD/Au & 17.70 & 21.3 & 1.02 & 81.00 & $2019^{[89]}$ \\
\hline $\mathrm{MACl}$ & $15 \mathrm{mg} \cdot \mathrm{mL}^{-1}$ & $\mathrm{FTO} / \mathrm{TiO}_{2} / \mathrm{SnO}_{2} /\left(\mathrm{FAPbI}_{3}\right)_{0.87}\left(\mathrm{MAPbBr}_{3}\right)_{0.13} /$ spiro-OMeTAD/Au & 21.65 & 23.2 & 1.193 & 78.20 & $2019^{[66]}$ \\
\hline $\mathrm{MACl}$ & $40 \mathrm{~mol} \%$ & $\mathrm{FTO} / \mathrm{c}-\mathrm{TiO}_{2} / \mathrm{mp}-\mathrm{TiO}_{2} / \mathrm{FAPbI} / \mathrm{PEAI} /$ spiro-OMeTAD$/ \mathrm{Au}$ & 24.02 & 25.92 & 1.13 & 82.00 & $2019^{[38]}$ \\
\hline $\mathrm{MACl}$ & $20 \mathrm{mg} \cdot \mathrm{mL}^{-1}$ & $\mathrm{FTO} / \mathrm{SnO}_{2} / \mathrm{FA}_{x} \mathrm{MA}_{1-\mathrm{x}} \mathrm{PbI}_{3} /$ spiro-OMeTAD/Au & 20.40 & 23.88 & 1.08 & 78.38 & $2020^{[75]}$ \\
\hline $\mathrm{MACl}, \mathrm{CNT}-\mathrm{NH}_{2}$ & $0.21 \mathrm{M} ; 0.05 \mathrm{mg} \cdot \mathrm{mL}^{-1}$ & $\mathrm{FTO} / \mathrm{c}-\mathrm{TiO}_{2} / \mathrm{SnO}_{2} / \mathrm{MA}_{0.85} \mathrm{FA}_{0.15} \mathrm{PbI}_{3} / \mathrm{Spiro}-\mathrm{OMeTAD} / \mathrm{Ag}$ & 21.05 & 23.52 & 1.091 & 82.00 & $2019^{[65]}$ \\
\hline $\mathrm{MACl}$ & $10 \mathrm{mg} \cdot \mathrm{mL}^{-1}$ & $\mathrm{FTO} / \mathrm{c}-\mathrm{TiO}_{2} /(\mathrm{GA})(\mathrm{MA})_{\mathrm{n}} \mathrm{Pb}_{\mathrm{n}} \mathrm{I}_{3 \mathrm{n}+1}(\mathrm{n}=3) /$ spiro-OMeTAD/Au & 18.48 & 22.26 & 1.14 & 72.67 & $2019^{[64]}$ \\
\hline $\mathrm{MACl}$ & $0.5 \mathrm{M}$ & $\mathrm{FTO} / \mathrm{TiO}_{2} / \mathrm{SnO}_{2} / \mathrm{FA}_{0.87} \mathrm{MA}_{0.13}\left(\mathrm{Ge}_{0.03} \mathrm{~Pb}_{0.97}\right)\left(\mathrm{I}_{0.9} \mathrm{Br}_{0.1}\right)_{3} /$ spiro-OMeTAD/Au & 22.70 & 24.67 & 1.18 & 78.00 & $2020^{[68]}$ \\
\hline $\mathrm{ZnCl}_{2}$ & $3 \mathrm{~mol} \% / \mathrm{MAI}$ & $\mathrm{FTO} / \mathrm{c}-\mathrm{TiO}_{2} / \mathrm{MAI}\left(\mathrm{PbI}_{2}\right)_{1-\mathrm{x}}\left(\mathrm{ZnCl}_{2}\right)_{\mathrm{x}} /$ spiro-OMeTAD/Au & 18.20 & 22.04 & 1.09 & 75.76 & $2017^{[82]}$ \\
\hline
\end{tabular}


Cite this paper as: F. Cheng, J. Zhu, Th. Pauporté, Chlorides, other Halides and Pseudohalides as Additives for the Fabrication of Efficient and Stable Perovskite Solar Cells.

ChemSusChem 14 (2021) 3665-3692. DOI: 10.1002/cssc.202101089

$\mathrm{SnCl}_{2}$

$75 \mathrm{~mol} \% / \mathrm{MAI}$

$\mathrm{FTO} / \mathrm{TiO}_{2} / \mathrm{Al}_{2} \mathrm{O}_{3} / \mathrm{MASn}_{\mathrm{y}} \mathrm{Pb}_{1-\mathrm{y}} \mathrm{I}_{3-\mathrm{x}} \mathrm{Cl}_{\mathrm{x}} / \mathrm{NiO} / \mathrm{C}$

5.13

19.63

0.457

$57.20 \quad 2016^{[83]}$

${ }^{a}$ Compared to $\mathrm{PbI}_{2}$ precursor if not otherwise precised. ${ }^{\mathrm{b}} \mathrm{PPS}$ : perovskite precursor solution. 
Cite this paper as: F. Cheng, J. Zhu, Th. Pauporté, Chlorides, other Halides and Pseudohalides as Additives for the Fabrication of Efficient and Stable Perovskite Solar Cells.

ChemSusChem 14 (2021) 3665-3692. DOI: 10.1002/cssc.202101089

\section{Other halides and pseudo-halides additives for PVK films}

\subsection{Halogen acids additives for PVK films}

The PVK precursor solution is made of colloids of a lead polyhalide framework between organic and inorganic components. ${ }^{[17,90]}$ These colloids act as a nucleation center and determine the coverage and morphology of deposited thin films, especially large colloids induce a poor film morphology. Hydrohalic acids can dissolve large colloid particles and manipulate the colloidal concentration in the precursor solution, resulting in the modulation of the PVK morphology during the deposition process. Compared to neutral additives, the addition of acids can disrupt the interaction between solvent molecules and lower the solution viscosity, which, in turn, affects the solvent evaporation rate and determine the PVK crystallization rate.

Acids can improve the solubility of PVK precursors and help to obtain uniform and well-covering PVK films. In 2014, Eperon et al. ${ }^{[91]}$ reported that the addition of HI helps to form uniform and continuous thin film. McMeekin et al. ${ }^{[92]}$ investigated the nucleation and growth stages of PVK films by adding $\mathrm{HI}$ and $\mathrm{HBr}$ acids into $\mathrm{FA}_{0.83} \mathrm{Cs}_{0.17} \mathrm{~Pb}\left(\mathrm{Br}_{0.2} \mathrm{I}_{0.8}\right)_{3}$ precursor solution. As shown in Fig. $7 \mathrm{~A}$, the colloids in suspension gradually dissolved, and the content of small colloidal particles increased with longer aging time after addition of acid. It critically impacted the crystallization kinetics and morphology of the thin films since colloids act as nucleation center (Fig. 7B, C). Finally, large grains and well-covering films were obtained by reducing the density of nucleation sites. However, a distinct trade-off between the grain sizes and pinhole density was observed. Since crystal growth also occurred in the vertical direction, the large crystal grains tended to be accompanied with undesirable pinholes. Heo et al. ${ }^{[93]}$ deposited dense $\mathrm{MAPbBr}_{3} \mathrm{PVK}$ films with well-surface coverage by adding $\mathrm{HBr}$ into $\mathrm{MAPbBr}$ precursor solution. The nucleation time of $\mathrm{MAPbBr}_{3}$ was retarded during spin-coating process due to the improved solubility of $\mathrm{MAPbBr}_{3}$ in $\mathrm{DMF}+\mathrm{HBr}$ solution. A more-concentrated $\mathrm{MAPbBr}_{3}$ in $\mathrm{DMF}+\mathrm{HBr}$ solution helped to yield thinner and better-covering PVK layers. It was noticed that the addition of the same amount of $\mathrm{H}_{2} \mathrm{O}$ also enabled the formation of fully-covering $\mathrm{MAPbBr}_{3}$ layers, but the $\mathrm{H}_{2} \mathrm{O}$ produced the decomposition of $\mathrm{MAPbBr}_{3}$ into $\mathrm{MABr}$ and $\mathrm{PbBr}_{2}$. 
Cite this paper as: F. Cheng, J. Zhu, Th. Pauporté, Chlorides, other Halides and Pseudohalides as Additives for the Fabrication of Efficient and Stable Perovskite Solar Cells. ChemSusChem 14 (2021) 3665-3692. DOI: 10.1002/cssc.202101089
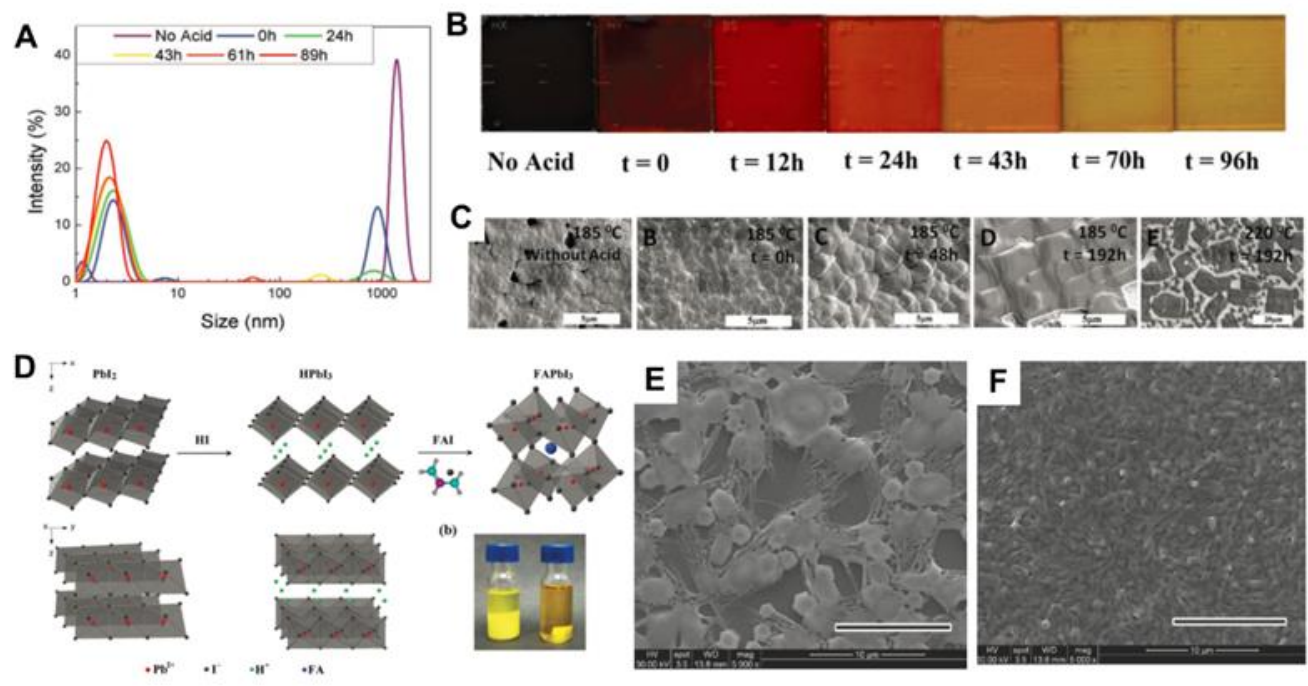

Fig. 7 Effect of acid additive on the colloid in the precursor solution. (A) Colloidal hydrodynamic size distribution of various PVK solutions. (B, C) Photographs and SEM views of thin films prepared with aged solution after the addition of Halogen acid. ${ }^{[92]}$ with permission from Wiley-VCH, copyright 2017. (D) Schematic illustration of $\mathrm{FAPbI}_{3}$ formation from $\mathrm{PbI}_{2}$ with $\mathrm{HI}$ additive. (E, F) SEM images fabricated from $\mathrm{FAI} / \mathrm{PbI}_{2}$ and $\mathrm{FAI}_{/} \mathrm{HPbI}_{3}$, respectively. ${ }^{[94]}$ with permission from Wiley-VCH, copyright 2015.

$\mathrm{HI}$ can react with $\mathrm{PbI}_{2}$ to form $\mathrm{HPbI}_{3}$ or $\mathrm{HPbI}_{\mathrm{x}}$, which show better solubility than $\mathrm{PbI}_{2}$ in $\mathrm{DMF}$ solution. Wang et al. ${ }^{[94]}$ developed $\mathrm{HPbI}_{3}$ to replace lead iodide and obtained highly uniform $\mathrm{FAPbI}_{3}$ films (Fig. 7D). They proposed that the best performances of the $\mathrm{HPbI}_{3}$ based $\mathrm{PVK}$ films may benefit from the slow crystallization process with exchange of $\mathrm{H}^{+}$and $\mathrm{FA}^{+}$ions in the $\mathrm{PbI}_{6}$ framework (Fig. 7E and 7F). Pang et al. ${ }^{[95]}$ demonstrated that the $\mathrm{HPbI}_{3}$ can serve as precursor compounds to deposit uniform $\mathrm{MAPbI}_{3} \mathrm{PVK}$ film upon $\mathrm{CH}_{3} \mathrm{NH}_{2}$ gas treatment. Upon exposed $\mathrm{HPbI}_{3}$ into $\mathrm{CH}_{3} \mathrm{NH}_{2}$ atmosphere, the $\mathrm{CH}_{3} \mathrm{NH}_{2}$ molecules can react with $\mathrm{H}^{+}$to form $\mathrm{CH}_{3} \mathrm{NH}_{3}{ }^{+}$. After annealing, $1 \mathrm{D} \mathrm{HPbI}_{3}$ structure transformed into 3D $\mathrm{MAPbI}_{3} \mathrm{PVK}$ structure. $\mathrm{H}^{+}$plays a critical role in the formation of a stoichiometric, ultrasmooth and fully covering $\mathrm{MAPbI}_{3} \mathrm{PVK}$ thin films. Eperon et al. ${ }^{[96]}$ first introduced $\mathrm{HI}$ additive into $\mathrm{CsPbI}_{3}$ precursor solution, which made the conversion temperature from yellow to the black phase decreased to $100^{\circ} \mathrm{C}$. It resulted in the formation of smooth and uniform black $\mathrm{CsPbI}_{3}$ films. $\mathrm{HPbI}_{3}$ was also employed to fabricate $\mathrm{CsPbI}_{3} \mathrm{PSCs}$ with improved stability and performance. ${ }^{[97]}$

In summary, halogen acid additives can modulate the morphology of PVK film via affecting the colloid particles and concentration in the precursor solution and reducing the crystallization rate. It results in better PVK morphology and trap states reduction. 
Cite this paper as: F. Cheng, J. Zhu, Th. Pauporté, Chlorides, other Halides and Pseudohalides as Additives for the Fabrication of Efficient and Stable Perovskite Solar Cells. ChemSusChem 14 (2021) 3665-3692. DOI: 10.1002/cssc.202101089

\subsection{Fluoride additives for PVK films}

Due to the small size and large electronegativity of fluorine, fluoride species can form strong ionic and intermolecular bonding with PVK. Such strong chemical reactivity between fluoride and PVK is beneficial for passivating surface and crystal boundaries defects. Generally, when fluoride is incorporated into PVK film, it is typically present on the surface of PVK, exhibiting surface hydrophobicity and therefore protect the PVK from moisture erosion. Metal fluoride, such as $\mathrm{SnF}_{2}$ and alkali fluoride, have been used in PSCs, especially, $\mathrm{SnF}_{2}$ is employed in the tin halide PVK for suppressing the oxidation from $\mathrm{Sn}^{2+}$ to $\mathrm{Sn}^{4+}$. Due to the toxicity of $\mathrm{Pb}$ which may limit the diffusion of the PSC technology, lead-free PVKs ASnX 3 have been intensively investigated. It is reported that $\mathrm{MASnI}_{3}$ has a bandgap around 1.2 to $1.3 \mathrm{eV}$ and an expected large short-circuit photocurrent. However, the PCEs of Sn-doped or entirely Sn-based PSCs are well-below that of Pb-based PSCs, and a large fraction of them is short-circuited. This mainly results from the oxidation of $\mathrm{Sn}^{2+}$ to $\mathrm{Sn}^{4+}$ in air and the intrinsic Sn-cation vacancies, as well as the poor morphology.

$\mathrm{SnF}_{2}$ additive can suppress the oxidation of $\mathrm{Sn}^{2+}$ to $\mathrm{Sn}^{4+}$. The tin-based $\mathrm{PVK} \mathrm{ASnX}$ are unintentionally holedoped to a high degree, due to the $\mathrm{Sn}$ vacancies and the oxidation of $\mathrm{Sn}^{2+}$. Recently, $\mathrm{SnF}_{2}$ additive in the leadfree PVK was shown to increase the Sn chemical potential and the formation energy of Sn vacancies, and then reduce the background carrier density and Sn defects. ${ }^{[98,99]}$ Handa et al. ${ }^{[100]}$ reported a blue-shifted absorption edge for pure $\mathrm{MASnI}_{3}$ thin film compared to the $\mathrm{MASnI}_{3}$ with $\mathrm{SnF}_{2}$ additive (Fig. 8A). It was assigned to the unintentional hole doping which induces a Burstein-Moss shift in the $\mathrm{SnF}_{2}$-free $\mathrm{MASnI}_{3}$ samples. They demonstrated that $\mathrm{SnF}_{2}$ additive reduces the hole density by about 1-2 orders of magnitude and suppresses the $\mathrm{Sn}^{4+}$ formation. The PL lifetime of $\mathrm{MASnI}_{3}$ with $\mathrm{SnF}_{2}$ additive increased by one order of magnitude, resulting in improved performance of devices. For the effect of $\mathrm{SnF}_{2}$ additive, Ma et al. proposed that $\mathrm{SnF}_{2}$ just act as an inhibitor of $\mathrm{Sn}^{2+}$ oxidation in the $\mathrm{CH}_{3} \mathrm{NH}_{3} \mathrm{SnI}_{3}$ precursor solution for preparing undoped $\left(\mathrm{Sn}^{4+}\right.$-free) film with lower defect concentration. Based on SEM images, XRD and UV-Vis spectra of $\mathrm{CH}_{3} \mathrm{NH}_{3} \mathrm{SnI}_{3}$ film with 20 mol\% $\mathrm{SnF}_{2}$, no $\mathrm{SnF}_{2}$ or $\mathrm{SnI}_{2}$ was found in the $\mathrm{CH}_{3} \mathrm{NH}_{3} \mathrm{SnI}_{3}$ film. ${ }^{[101]}$

$\mathrm{SnF}_{2}$ additive was used to modulate the crystallization process and improve the morphology of PVK films. F has a much smaller ionic radius $(1.33 \AA$ ) than I $(2.20 \AA)$, therefore F doping of iodide PVK would not induce a significant variation in the lattice parameter and unwanted phases of film. Liao et al. ${ }^{[102]}$ investigated the effect of $\mathrm{SnF}_{2}$ additive on the morphology of $\mathrm{FASnI}_{3}$ thin films. As shown in Fig. 8B, a flower-like structure with 
Cite this paper as: F. Cheng, J. Zhu, Th. Pauporté, Chlorides, other Halides and Pseudohalides as Additives for the Fabrication of Efficient and Stable Perovskite Solar Cells.

ChemSusChem 14 (2021) 3665-3692. DOI: 10.1002/cssc.202101089

many pinholes was observed for the pure $\mathrm{FASnI}_{3}$ thin film. With increasing $\mathrm{SnF}_{2}$ concentration, the flower-like structures disappeared and the $\mathrm{FASnI}_{3}$ films became more uniform. It was noticed that a higher amount of $\mathrm{SnF}_{2}$ $(>10 \%)$ induced sever phase segregation, resulting in obvious aggregates formation in the PVK film. As a result, the PCEs of Sn-based PSCs with optimized $10 \mathrm{~mol} \% \mathrm{SnF}_{2}$ additives increased to $6.22 \%$ in 2016 . Lee et al. ${ }^{[103]}$ selected $\mathrm{SnF}_{2}$-pyrazine complex as additive in $\mathrm{FASnI}_{3}$ precursor solution to restrict the phase separation and reduce Sn vacancies formation. They also demonstrated the role of DMSO in forming a uniform PVK layer. During the spin-coating process, the crystallization of FAI and $\mathrm{SnI}_{2}$ was retarded by using DMSO as solvent, thereby producing a film with much better quality. Finally, $\mathrm{FASnI}_{3}$ PSCs with addition of $\mathrm{SnF}_{2}-$ pyrazine complex achieved a high PCE of 4.8\%, and showed high reproducibility and stability for the encapsulated devices.

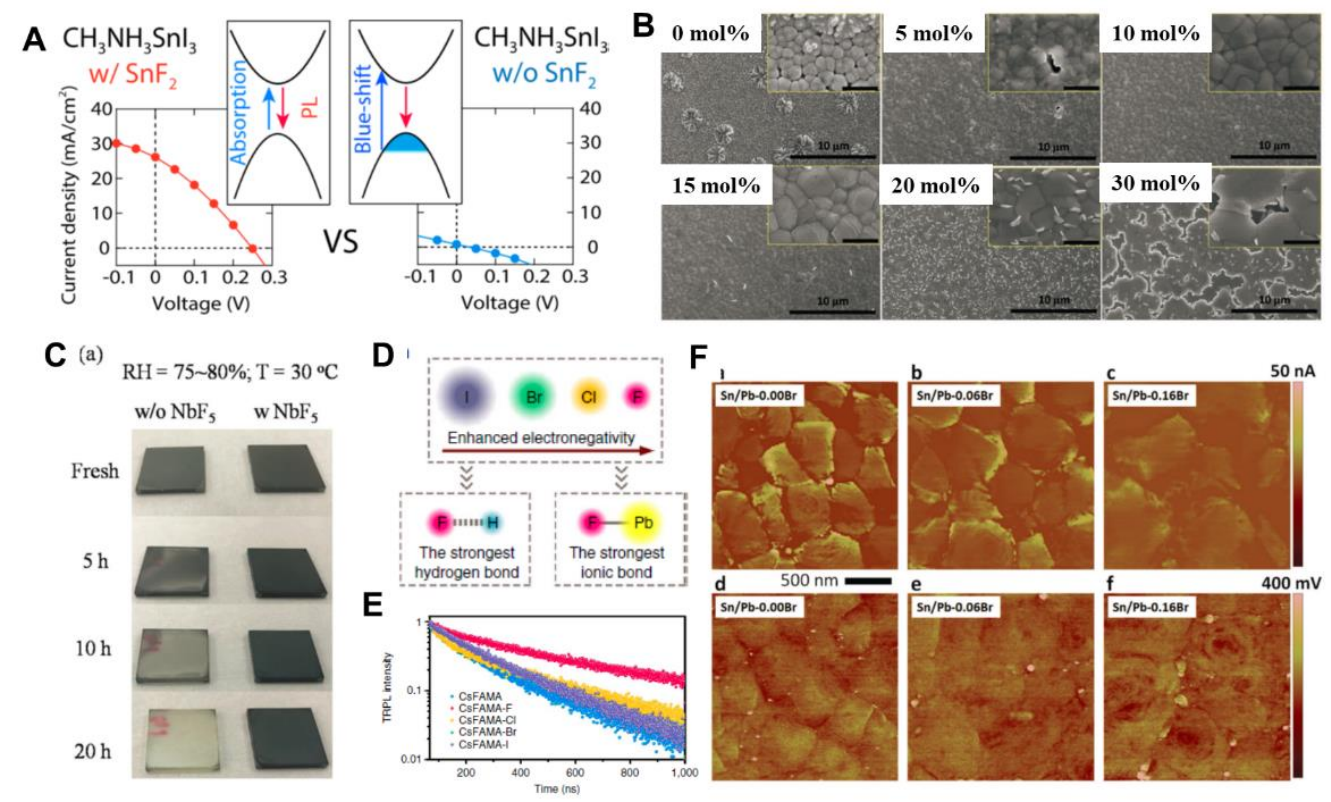

Fig. 8 (A) Current-voltage curves of a MASnI solar cells (prepared with and without $\mathrm{SnF}_{2}$ ) recorded under AM $1.5 G$ 1-sun irradiation. ${ }^{[100]}$ with permission from the American Chemical Society, copyright 2020. (B) SEM images of $\mathrm{FASnI}_{3}$ PVK films with varying concentration of $\mathrm{SnF}_{2}$, scale bar in all images are $10 \mu \mathrm{m}$ and $1 \mu \mathrm{m}$ (inset images). ${ }^{[102]}$ with permission from Wiley- $\mathrm{VCH}$, copyright 2017. (C) Humidity stability of $\mathrm{FA}_{0.85} \mathrm{MA}_{0.15} \mathrm{PbI}_{3}$ PVK films without and with $\mathrm{NbF}_{5} .{ }^{[104]}$ with permission from Wiley-VCH, copyright 2019. (D) Schematic illustration of hydrogen bond between halogen and MA/FA ions. (E) TRPL spectra for the $\left(\mathrm{Cs}_{0.05} \mathrm{FA}_{0.54} \mathrm{MA}_{0.41}\right) \mathrm{Pb}\left(\mathrm{I}_{0.98} \mathrm{Br}_{0.02}\right)_{3} \mathrm{PVK}$ film with different sodium halide additives. ${ }^{[105]}$ with permission from Springer Nature, copyright 2019. (F) AFM and (d) KPFM images of $\left(\mathrm{FASnI}_{3}\right)_{0.6}\left(\mathrm{MAPbI}_{3}\right)_{0.4-x}\left(\mathrm{MAPbBr}_{3}\right)_{x}(x=$ 0, 0.06, 0.16) PVK films. ${ }^{[106]}$ with permission from Wiley-VCH, copyright 2018.

$\mathrm{SnF}_{2}$ additive was used to improve the phase stability. The use of $\mathrm{Sn}^{2+}$ cation results in a lower bandgap of 
Cite this paper as: F. Cheng, J. Zhu, Th. Pauporté, Chlorides, other Halides and Pseudohalides as Additives for the Fabrication of Efficient and Stable Perovskite Solar Cells.

ChemSusChem 14 (2021) 3665-3692. DOI: 10.1002/cssc.202101089

PVK compared to $\mathrm{Pb}^{2+},{ }^{[107]}$ while the phase transformation and facile oxidation of $\mathrm{Sn}^{2+}$ to $\mathrm{Sn}^{4+}$ lead to the instability and poor performance for the PSCs. It is known that the tolerance factors of the stable PVK materials $\mathrm{ABX}_{3}$ should lie between 0.78-1.05, where the tolerance factor is defined as: $t=\left(R_{A}+R_{X}\right) / 2\left(R_{B}+R_{X}\right)$ with $R_{A}$, $R_{B}$ and $R_{X}$ the ionic radii of $\mathrm{A}, \mathrm{B}$ and $\mathrm{X}$ ions, respectively. When $\mathrm{F}$ ion $\left(\mathrm{as} \mathrm{SnF}_{2}\right)$ is introduced stoichiometrically, into the $\mathrm{ASnI}_{3} \mathrm{PVK}$, forming a ASnI $3 \mathrm{~F}_{\mathrm{x}} \mathrm{PVK}$ layer, the tolerance factor $t$ becomes larger as $x$ increases due to the smaller F ionic radius, and enhances the phase stability of Sn-based PVK. Therefore, fluoride complex was introduced as additive to improve the stability of Sn-based PVK. Wu et al. ${ }^{[108]}$ demonstrated that F ion dopant inhibits the oxidation process, and slows down the phase transformation of $\mathrm{CsSnI}_{3}$ into $\mathrm{Cs}_{2} \mathrm{SnI}_{6}$.

Alkali fluoride is beneficial for reducing the positive and negative charged defects by forming chemical bonds with lead-based PVK. Yuan et al. ${ }^{[104]}$ presented an efficient method to prevent the phase transformation from black $\alpha$-phase to yellow non-PVK $\delta$-phase by adding $\mathrm{NbF}_{5}$ material (Fig. $8 \mathrm{C}$ ). The $\mathrm{FA}_{0.85} \mathrm{MA}_{0.15} \mathrm{PbI}_{3} \mathrm{PVK}_{\text {film }}$ with $\mathrm{NbF}_{5}$ could maintain the black color without bleaching to transparent after $20 \mathrm{~h}$, and the stability of PSC was much improved. The fluorine and niobium elements were distributed over the PVK surface, the strong $\mathrm{Pb}$ $\mathrm{F}$ and $\mathrm{Nb}-\mathrm{I}$ interactions between $\mathrm{NbF}_{5}$ and $\mathrm{FA}_{0.85} \mathrm{MA}_{0.15} \mathrm{PbI}_{3}$ were probably the main reasons for the improved phase stability after $\mathrm{NbF}_{5}$ addition. Li et al. ${ }^{[105]}$ explored an effective passivation of cation and anion vacancy defects via adding $\mathrm{NaF}$ into the triple-cation $\mathrm{PVK}\left(\mathrm{Cs}_{0.05} \mathrm{FA}_{0.54} \mathrm{MA}_{0.41}\right) \mathrm{Pb}\left(\mathrm{I}_{0.98} \mathrm{Br}_{0.02}\right)_{3}$ layer. They compared the passivation effect of $\mathrm{NaX}(\mathrm{X}=\mathrm{Cl}, \mathrm{Br}, \mathrm{F})$ with tunable bond strength of halide with PVK layer (Fig. 8D). Although all sodium halides could improve the PVK quality, the fluoride-containing material gave the best results (Fig. $8 \mathrm{E})$. Since the $\mathrm{F}$ ions can form hydrogen bonds (N-H...F) with organic cations and ionic bonds with $\mathrm{Pb}$ at the PVKs surface, $\mathrm{F}$ ions are effective in passivating both the organic cations and halide vacancies. Meanwhile, the increased ionic bonding of PVK with fluoride ions also immobilized both organic cations and halide anions. Finally, the addition of NaF resulted in a best PCE of $21.46 \%$ in planar PSCs, and superb thermal and environmental stability for the PVK layer and devices.

\subsection{Bromide additives for PVK films}

The bandgap of organic halide PVK can be tuned by the $p$-orbital of halide, since the electronic structure of PVK is related to both halide and metal $p$-orbitals. Substitute iodide by bromide anion to create mixed-halide PVK can broaden the band gap of PVK film, generate longer lifetimes and improve stability. ${ }^{[109]}$ The mixedhalide PVK films also exhibit enhanced stability toward ambient conditions. ${ }^{[110]}$ Noh et al. ${ }^{[11]}$ first tuned the 
Cite this paper as: F. Cheng, J. Zhu, Th. Pauporté, Chlorides, other Halides and Pseudohalides as Additives for the Fabrication of Efficient and Stable Perovskite Solar Cells.

ChemSusChem 14 (2021) 3665-3692. DOI: 10.1002/cssc.202101089

bandgap of $\mathrm{MAPbX}_{3}$ from $1.6 \mathrm{eV}$ to $2.2 \mathrm{eV}$ covering almost the entire visible spectrum via adjusting the $\mathrm{Br} / \mathrm{I}$ ratios. With this approach, Huang et al. ${ }^{[12]}$ designed a novel prismatic PSC by connecting four $\mathrm{MAPbI}_{\mathrm{x}} \mathrm{Br}_{3-\mathrm{x}}$ $(x=3,2,1,0)$ subcells with different bandgaps in the same horizontal plane. Thermodynamic losses are mitigated by this approach and the incident high-to-low energy photons are harvested by horizontally aligned $\mathrm{MAPbI}_{\mathrm{x}} \mathrm{Br}_{3}$ $x$ subcells. As a result, the corresponding newly designed PSC generated a record $\mathrm{V}_{\text {oc }}$ of $5.3 \mathrm{~V}$ and PCE of $21.3 \%$. The PVK with bandgap of 1.3-1.4 eV is pivotal for single junction PSCs because of the balance between absorption loss of sub-bandgap photons and thermalization loss of above-bandgap photons. Yang et al.[113] incorporated $20 \% \mathrm{Br}$ into $\mathrm{MASn}_{0.5} \mathrm{~Pb}_{0.5} \mathrm{I}_{3}$ to obtain an ideal bandgap $(1.35 \mathrm{eV})$ absorber layer for single junction PSCs. This mixed-halide $\mathrm{MAPb}_{0.5} \mathrm{Sn}_{0.5}\left(\mathrm{I}_{0.8} \mathrm{Br}_{0.2}\right)_{3} \mathrm{PVK}$ reduced the $\mathrm{V}_{\text {oc, }}$ loss at $0.45 \mathrm{~V}$ and improved PCE to $17.63 \%$.

Bromine incorporation can passivate grain boundaries. It is known that low- $\mathrm{E}_{\mathrm{g}}$ mixed $\mathrm{Pb}-\mathrm{Sn} \mathrm{PSCs}$ exhibits large $V_{o c}$ deficits and low FF, because of the high dark saturation current density caused by high leakage current from grain boundaries. ${ }^{[114,115]} \mathrm{Li}$ et al. ${ }^{[106]}$ demonstrated that $\mathrm{Br}$ incorporation can passivate defects at grain boundaries and lower the dark saturation current density of low $\mathrm{E}_{\mathrm{g}}$ mixed Sn-Pb PSCs. PVK films were prepared by spin-coating $\left(\mathrm{FASnI}_{3}\right)_{0.6}\left(\mathrm{MAPbI}_{3}\right)_{0.4-\mathrm{x}}\left(\mathrm{MAPbBr}_{3}\right)_{\mathrm{x}}(\mathrm{x}=0,0.04,0.06,0.08$, and 0.16$)$ precursor solutions. In the fabrication process of annealing at $100{ }^{\circ} \mathrm{C}$, the high temperature would drive $\mathrm{Br}$ out of PVK crystal lattice, resulting in higher $\mathrm{Br}$ concentration at grain boundaries than in grain bulk. Consequently, the grain boundaries contain a higher density of negatively charged defects than grain interiors confirmed by KPFM map (Fig. 8F). With Br additive, the mixed low- $\mathrm{E}_{\mathrm{g}}(1.272 \mathrm{~V}) \mathrm{Sn}-\mathrm{Pb} \mathrm{PSCs}$ have achieved low $V_{o c}$ deficits of $0.384 \mathrm{~V}$, high FF of $75 \%$ and a PCE of $>19 \%$. Although mixed $\mathrm{Sn}-\mathrm{Pb} \mathrm{PVK}$ layer possesses ideal-bandgap for photovoltaic application, the best PCEs of Sn-Pb binary PSCs with $<18 \%$ are lower than $1.5-1.6 \mathrm{eV}$ bandgap pure-Pb-based PSCs with PCE of $24 \% .{ }^{[16]}$ The poor efficiency of Sn-Pb binary PSCs is attributed to the high defect density associated with $\mathrm{Sn}^{2+}$ oxidation, which leads to lower open circuit voltage $(<0.9 \mathrm{~V}) .{ }^{[117]}$ Therefore, some organic substances, such as $\mathrm{SnF}_{2}$-Prazine, ${ }^{[103]}$ guanidinium thiocyanate, ${ }^{[118]}$ have been used as additive to reduce the high defect density caused by $\mathrm{Sn}^{2+}$ oxidation. Zhou et al. ${ }^{[119]}$ discovered that guanidinium bromide (GABr) in the PVK film can passivate the defect related with $\mathrm{Sn}^{2+}$ oxidation, which improved the structural and photoelectric characteristics of $\mathrm{Sn}-\mathrm{Pb}$ binary PVK $\left(\mathrm{FA}_{0.7} \mathrm{MA}_{0.3} \mathrm{~Pb}_{0.7} \mathrm{Sn}_{0.3} \mathrm{I}_{3}\right)$ thin films. With optimized GABr concentration of $12 \%$, Sn-Pb binary PVK films display increased grain size, decreased charge-carrier recombination, and reduced trap state densities, resulting in best PCE of $20.63 \%$ with a small $\mathrm{V}_{\text {oc }}$ deficit of $0.33 \mathrm{~V}$. 
Cite this paper as: F. Cheng, J. Zhu, Th. Pauporté, Chlorides, other Halides and Pseudohalides as Additives for the Fabrication of Efficient and Stable Perovskite Solar Cells. ChemSusChem 14 (2021) 3665-3692. DOI: 10.1002/cssc.202101089

Lewis base usually act as electron donor, which can interact with positively charged under-coordinated $\mathrm{Pb}^{2+}$ ions. Organic Lewis base, such as thiophene, pyridine, thiourea etc, could efficiently passivate the undercoordinated $\mathrm{Pb}^{2+}$ and thus enhance the PCE and stability of PSCs. Zhang et al. ${ }^{[120]}$ applied N-(4-bromophenyl)thiourea (BrPh-ThR) as the Lewis base in the PVK solution precursor to investigate the cooperation passivation effect of organic cation and bromide. $\mathrm{BrPh}-\mathrm{ThR}$ as an S-donor has a strong ability to coordinate with $\mathrm{PbI}_{2}$, which is beneficial for the large grain PVK formation and defect passivation of the $\mathrm{Pb}^{2+}$ defects at crystal grain boundaries and surface. As a result, they obtained a $20.4 \%$ device efficiency with BrPh-ThR additive in precursor solution, compared with $19.3 \%$ for the control PSCs.

\subsection{Iodide additives for PVK films}

Recent studies show that the performance of PVK film could be improved through addition of solid iodine $\left(\mathrm{I}_{2}\right)$, organic iodide, $\mathrm{PbI}_{2}$ and alkali metal iodides, LiI, NaI, KI, RbI and CsI. A complete understanding of these issues is important for obtaining high efficiency PSCs.

\subsubsection{Iodide ions additive}

A large number of iodide additives have been employed in the literature to prepare 2D/3D PVK layers. The complete reporting of this research field is out of the scope of the present review and one can report on the recent review by Zhang et al. ${ }^{[121]}$ to have an overview on the topic. The most successful approach developed up to now for getting highly stable PSCs has been to adopt a triple mesoscopic architecture where the HTL/metal back contact is replaced by a mesoporous carbon counter-electrode. ${ }^{[58,122,123]}$ Such cells have recently successfully passed items of the IEC61215:2016 PV qualification test. ${ }^{[124]}$ The employment of 5-Ammonium valeric acid iodide (5-AVAI) additive was shown important to facilitate the porous scaffold filling, to improve the contact with the oxide scaffold and to strengthen the $\mathrm{MAPbI}_{3}$ grain boundaries due to bifunctionality. ${ }^{[124]} 4$ (aminomethyl) benzoic acid hydroiodide additive has also been employed efficiently for the same purpose. ${ }^{[125]}$ Yang et al. ${ }^{[126]}$ reported a defect-engineering strategy with iodide management for fabricating formamidiniumlead-halide-based PVK. Solid iodine $\left(\mathrm{I}_{2}\right)$ was dissolved in isopropanol (IPA) and formed to $\mathrm{I}_{3}{ }^{-}$ions, which was added into the dripping solution of FAI ( $+\mathrm{MABr}$ ) for increasing the proportion of the crystalline $\alpha-\mathrm{FAPbI}_{3}$ phase and reducing the concentration of defects in the entire PVK layer. The fabricated PSCs exhibited a 
Cite this paper as: F. Cheng, J. Zhu, Th. Pauporté, Chlorides, other Halides and Pseudohalides as Additives for the Fabrication of Efficient and Stable Perovskite Solar Cells.

ChemSusChem 14 (2021) 3665-3692. DOI: 10.1002/cssc.202101089

certified power conversion efficiency of $22.1 \%$ in small cells and $19.7 \%$ in 1 -square-centimeter cells.

\subsubsection{Excess amount of $\mathrm{PbI}_{2}$ and other inorganic iodide additives}

Although the precise stoichiometry of halide PVK precursor solution is important for making PVK film, a slight excess of $\mathrm{PbI}_{2}$ on the PVK grains is beneficial for the performances of PSCs. ${ }^{[127]}$ The mechanism for the effect of $\mathrm{PbI}_{2}$ on the PSCs performances have been investigated. Lead iodide, a p-type semiconductor with a large bandgap of $2.3 \mathrm{eV},{ }^{[128]}$ could passivate and eliminate defect states due to a band edge matching between $\mathrm{PVK}, \mathrm{PbI}_{2}$, and the HTL. ${ }^{[129 .}{ }^{130]}$ Zhang et al. ${ }^{[13]}$ investigated the $\mathrm{MAPbI}_{3}$ could decomposed into $\mathrm{PbI}_{2}$ and organic species with annealing time excess. By releasing the organic species, $\mathrm{PbI}_{2}$ formed in $\mathrm{PVK}$ films could passivate and eliminate defect states and enhance the device performance. Chen et al. ${ }^{[130]}$ demonstrated a selfinduced passivation strategy of $\mathrm{PbI}_{2}$ for the $\mathrm{MAPbI}_{3} \mathrm{PVK}$ to control the carrier injection and transfer behavior across the corresponding heterojunction. They discovered that the $\mathrm{MAPbI}_{3}$ would slightly decompose to $\mathrm{PbI}_{2}$ upon heating at $150{ }^{\circ} \mathrm{C}$ for more than $30 \mathrm{~min}$. As shown in Fig. 9A, $\mathrm{PbI}_{2}$ excess can fill $\mathrm{PVK}$ grain boundaries, thereby reducing the number of trapping sites and form a favorable type I band alignment. This $\mathrm{PbI}_{2}$ passivator can reduce the carrier recombination at the interface of $\mathrm{TiO}_{2} / \mathrm{PVK}$ and alleviate the barrier of charge extraction from PVK to HTL. The excess of $\mathrm{PbI}_{2}$ formed a passivating layer at the PVK gain boundaries and surface which induced to a longer recombination time, but too much $\mathrm{PbI}_{2}$ could act as an insulating layer and impair the device performance. ${ }^{[131]}$ However, it is difficult to control the amount of $\mathrm{PbI}_{2}$ by such self-induced approach with annealing technique. Kim et al. ${ }^{[127]}$ incorporated different amount of $\mathrm{PbI}_{2}$ into the PVK layers. They demonstrated that $\mathrm{PbI}_{2}$ excess in the PVK phases is highly beneficial for reducing the hysteresis of $J-V$ characteristics and ion migration. Finally, the best PSC fabricated using $\left(\mathrm{FAPbI}_{3}\right)_{0.85}\left(\mathrm{MAPbBr}_{3}\right)_{0.15}$ achieved a PCE of $20.1 \%$ with $5.7 \mathrm{~mol} \% \mathrm{PbI}_{2}$ excess incorporated. Zhang et al. ${ }^{[132]}$ developed a novel approach to fabricate PVK passivated by a controllable $\mathrm{PbI}_{2}$ amount by using hydrohalide deficient $\mathrm{PbI}_{2} \cdot \mathrm{xHI} / \mathrm{Br}(\mathrm{x}<1)$ precursors reacted with $\mathrm{CH}_{3} \mathrm{NH}_{2}$. Both $\mathrm{MAPbI}_{3}$ and $\mathrm{MAPbI}_{2} \mathrm{Br} \mathrm{PVK}$ solar cells prepared via $\mathrm{MA}+\left(\mathrm{PbI}_{2}+0.95 \mathrm{HI} / \mathrm{Br}\right)$ exhibited improved PV performance with a $V_{o c}$ enhancement due to less charge recombination by $\mathrm{PbI}_{2}$ passivation. Moreover, authors have hypothesized that a small excess of $\mathrm{PbI}_{2}$ is beneficial for preparing larger PVK grains or improving their crystallinity, resulting in enhanced devices' performances. ${ }^{[131,133,134]}$ Jiang et al. ${ }^{[134]}$ investigated the synergistic effect of $\mathrm{PbI}_{2}$ passivation and $\mathrm{Cl}$ inclusion for improving the $\mathrm{CH}_{3} \mathrm{NH}_{3} \mathrm{PbI}_{3}(\mathrm{Cl})$ PVK film growth and suppressing nonradiative recombination. It resulted in a record-high $V_{o c}$ over 1.15V for 
Cite this paper as: F. Cheng, J. Zhu, Th. Pauporté, Chlorides, other Halides and Pseudohalides as Additives for the Fabrication of Efficient and Stable Perovskite Solar Cells.

ChemSusChem 14 (2021) 3665-3692. DOI: 10.1002/cssc.202101089

the $\mathrm{CH}_{3} \mathrm{NH}_{3} \mathrm{PbI}_{3}(\mathrm{Cl})$ PSCs.

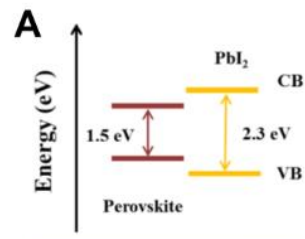

I: Perovskite/TiO ${ }_{2}$ interface

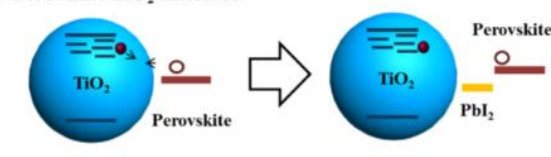

B

II: Perovskite/HTM interface
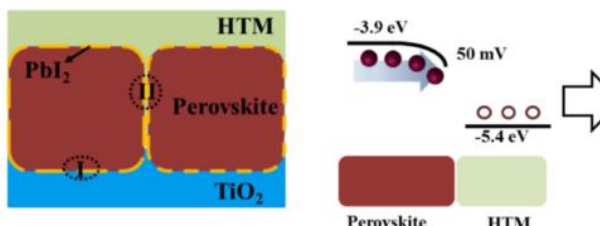

$-3.9 \mathrm{eV}$

$\frac{006}{30 \mathrm{mV}}$
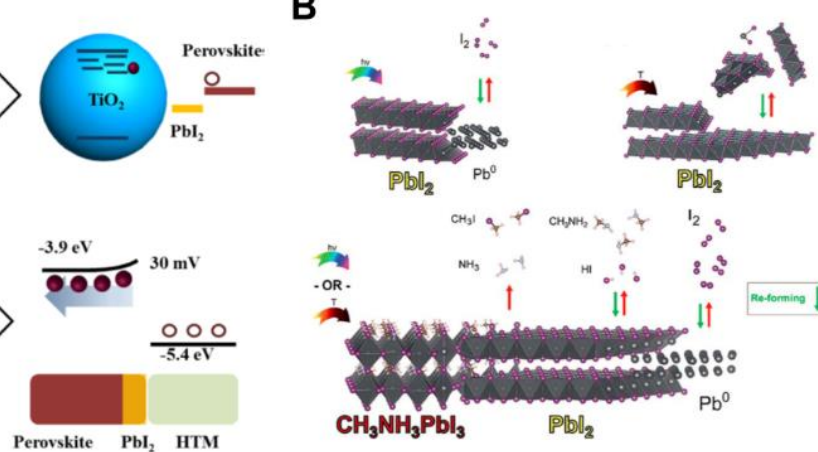

$\mathrm{Pbl}_{2}$

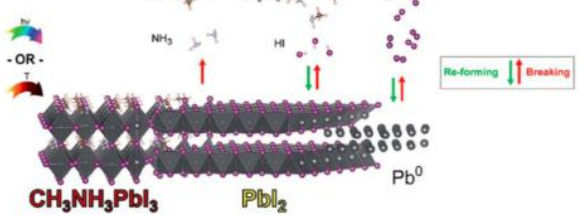

D

C

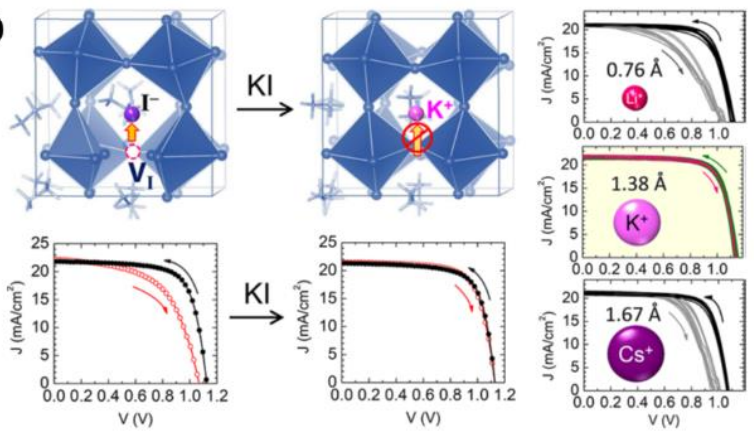

Fig. 9 (A) Proposed mechanism for $\mathrm{PbI}_{2}$ passivation in $\mathrm{CH}_{3} \mathrm{NH}_{3} \mathrm{PbI}_{3}$ Film. ${ }^{[130]}$ with permission from the American Chemical Society, copyright 2014. (B) The photodecomposition and thermal degradation processes of $\mathrm{PbI}_{2}$ and $\mathrm{MAPbI}_{3 .}{ }^{[135]}$ with permission from The Royal Society of Chemistry, copyright 2018.(C) Schematic illustration of PVK film showing halide-vacancy management and the potassium passivation effect. ${ }^{[136]}$ with permission from Springer Nature, copyright 2018. (D) Schematic view of MAPbI 3 hybrid PVK structure with I_Frenkel defect, and the passivation effect of KI on the device performance. ${ }^{[137]}$ with permission from the American Chemical Society, copyright 2018.

$\mathrm{PbI}_{2}$ excess at the surfaces and grain boundaries of PVK films, due to a larger bandgap than PVK, results in electronic insulation and negative effect for the cell performance. ${ }^{[138,139]}$ Especially, a small excess amount of $\mathrm{PbI}_{2}$ has a detrimental effect on the stability of $\mathrm{PVK} \cdot{ }^{[140]}$ As shown in Fig. 9B, $\mathrm{PbI}_{2}$ suffers photodecomposition to iodine gas $\left(\mathrm{I}_{2}\right)$ and lead $\left(\mathrm{Pb}^{0}\right)$ upon interaction with visible light. ${ }^{[135]} \mathrm{I}_{2}$ gas is released from $\mathrm{MAPbI}_{3}$ even in dark conditions during heating at temperatures as low as $40{ }^{\circ} \mathrm{C}$ to $80^{\circ} \mathrm{C}$, which correspond to solar cell working temperatures. Such intrinsic photolysis of $\mathrm{PbI}_{2}$ is related to the devices' instability under continuous light illumination. ${ }^{[135]}$ Tumen-Ulzii et al. ${ }^{[141]}$ further confirmed the detrimental effect of unreacted $\mathrm{PbI}_{2}$ on the longterm stability of PSCs. The PVK films were deposited from $1.12 \mathrm{M} \mathrm{Cs}_{0.05}\left(\mathrm{FA}_{1-\mathrm{x}} \mathrm{MA} \mathrm{A}_{\mathrm{x}}\right)_{0.95} \mathrm{~Pb}\left(\mathrm{I}_{1-\mathrm{y}} \mathrm{Br}_{\mathrm{y}}\right)_{3}$ precursor solution. Unreacted $\mathrm{PbI}_{2}$ were deposited at the surfaces and grain boundaries of $\mathrm{PVK}$ when the $\mathrm{PbI}_{2}$ concentrations in precursor solutions increased. The PCE of PSCs prepared with unreacted $\mathrm{PbI}_{2}$ reduced to $47 \%$ 
Cite this paper as: F. Cheng, J. Zhu, Th. Pauporté, Chlorides, other Halides and Pseudohalides as Additives for the Fabrication of Efficient and Stable Perovskite Solar Cells.

ChemSusChem 14 (2021) 3665-3692. DOI: 10.1002/cssc.202101089

of its initial value after $520 \mathrm{~h}$ of continuous illumination. However, the PCEs of PSCs without unreacted $\mathrm{PbI}_{2}$ retained $99 \%$ of their initial values. SEM images revealed that unreacted $\mathrm{PbI}_{2}$ in the original $\mathrm{PVK}$ film almost disappeared, but defects and pinholes increased after $520 \mathrm{~h}$ of continuous illumination. They proposed that the degradation of $\mathrm{Cs}_{0.05}\left(\mathrm{FA}_{1-\mathrm{x}} \mathrm{MA}_{\mathrm{x}}\right)_{0.95} \mathrm{~Pb}\left(\mathrm{I}_{1-\mathrm{y}} \mathrm{Br}_{\mathrm{y}}\right)_{3}$ PSCs was due to the photolysis of unreacted $\mathrm{PbI}_{2}$ into $\mathrm{Pb}^{0}$ and $\mathrm{I}_{2}$ gas under light illumination.

In addition to $\mathrm{PbI}_{2}$, alkali metal iodides are considered as important additives to enhance the performance of PVK, especially for eliminating hysteresis in PSCs. In 2017, Tang et al. ${ }^{[142]}$ were the first to report hysteresisfree PVK solar cells after adding a small amount of $\mathrm{KI}(5 \%)$ into the $\left(\mathrm{FA}_{0.85} \mathrm{MA}_{0.15} \mathrm{~Pb}\left(\mathrm{I}_{0.85} \mathrm{Br}_{0.15}\right)_{3}\right) \mathrm{PVK}$. With incorporation of $\mathrm{KI}$, the electron transfer barrier between $\mathrm{TiO}_{2} / \mathrm{PVK}$ is minimized, resulting in the elimination of $J-V$ hysteresis and a PCE of more than $20 \%$. Then after, Abdi-Jalebi et al. ${ }^{[136]}$ demonstrated that the KI fills the halide vacancies and acts as a passivation layer decorating the PVK surface and grain boundaries. As shown in Fig. 9C, the potassium-rich, halide-sequestering species at the grain boundaries and surfaces would inhibit halide migration and suppress any additional non-radiative decay arising from interstitial halides. They obtained a champion PCE of $21.5 \%$ with $\mathrm{KI}$ at $\sim 9.09 \%$, based on the (Cs,FA,MA) $\mathrm{Pb}\left(\mathrm{I}_{0.85} \mathrm{Br}_{0.15}\right)_{3} \mathrm{PVK}$, with the elimination of PSC hysteresis. A series of alkali metal iodides of LiI, NaI, KI, RbI and CsI were introduced into PVK films by Cao et al. ${ }^{[143]}$. They demonstrated that alkali cations can occupy the interstitial sites of the PVK lattice and suppress ion migration, which results in elimination of $J-V$ hysteresis and enhancement of photostability of PSCs. On the other hand, Son et al. ${ }^{[137]}$ found from DFT calculation that the hysteresis of PVK solar cells arises from the formation of iodide Frenkel defect not the migration of iodide vacancy. They compared the effect of adding alkali metal iodides (LiI, NaI, KI, RbI and CsI) in PVK material on reducing current-voltage hysteresis. KI was found the best candidate for preventing the formation of iodide Frenkel defect, because $\mathrm{K}$ interstitials are energetically the most stables. As a result, they prepared mixed PVK (FA 0.875 $\mathrm{MA}_{0.125} \mathrm{PbI}_{2.55} \mathrm{Br}_{0.45}$ ) based PSCs with complete removal of hysteresis (Fig. 9D). Meanwhile, the alkali halide additive is able to homogenize the halide distribution, which help for the formation of uniform and continuous PVK film, leading to hysteresis-free PSCs with improved performance. ${ }^{[144,145]}$

\subsection{Pseudo-halides additives for PVK films}

Pseudo-halides, such as thiocyanate $\left(\mathrm{SCN}^{-}\right)$or cyanide $\left(\mathrm{CN}^{-}\right)$have similar chemical behaviors and properties to halogen. The ionic radii of thiocyanate $\left(\mathrm{SCN}^{-}\right)$is $\sim 217 \mathrm{pm}$, which is close to the iodine ionic radius of 220 
Cite this paper as: F. Cheng, J. Zhu, Th. Pauporté, Chlorides, other Halides and Pseudohalides as Additives for the Fabrication of Efficient and Stable Perovskite Solar Cells. ChemSusChem 14 (2021) 3665-3692. DOI: 10.1002/cssc.202101089

pm and is expected to act as a substitute of halogen atoms in halide PVK..$^{[146-148]}$ To date, various pseudo-halide, such as $\mathrm{Pb}(\mathrm{SCN})_{2}, \mathrm{NH}_{4} \mathrm{SCN}$ and MASCN, have been incorporated into PVK film to adjust the PVK crystal nucleation and growth process and passivate the crystal defects, effectively enhancing the performance of PSCs.

The incorporation of pseudo-halide in the PVK layer can improve the grain size, material crystallinity and optical properties of PVK layers. ${ }^{[149]}$ In 2015 , Halder et al. ${ }^{[146]}$ reported that the incorporation of pseudo-halide in $\mathrm{MAPbI}_{3}$ can increase the optical bandgap up to $\sim 80 \mathrm{meV}$, and gives rise to a remarkable improvement in the photoluminescence (PL) emission quantum yield. Chen et al. ${ }^{[150]}$ reported the two-step preparation of $\mathrm{CH}_{3} \mathrm{NH}_{3} \mathrm{PbI}_{3-\mathrm{x}}(\mathrm{SCN})_{\mathrm{x}} \mathrm{PVK}$ via adding a small amount of $\mathrm{Pb}(\mathrm{SCN})_{2}$ into $\mathrm{PbI}_{2}$ solution. They revealed that the $\mathrm{CH}_{3} \mathrm{NH}_{3} \mathrm{PbI}_{3-\mathrm{x}}(\mathrm{SCN})_{\mathrm{x}}$ with optimized $5 \mathrm{wt} \% \mathrm{~Pb}(\mathrm{SCN})_{2}$ leads notably to stronger absorption at 400-625 $\mathrm{nm}$. In addition, Zhou et al. ${ }^{[151]}$ compared several preparation routes for investigating the effect of $\mathrm{Pb}(\mathrm{SCN})_{2}$ on the performance of PVK film (Fig. 10A). The $\mathrm{Cs}_{0.17} \mathrm{FA}_{0.83} \mathrm{PbI}_{3-\mathrm{x}} \mathrm{Br}_{\mathrm{x}}(\mathrm{x}=0.8)$ films deposited by the direct spincoating of $\mathrm{Cs}_{0.17} \mathrm{FA}_{0.83} \mathrm{PbI}_{3-\mathrm{x}} \mathrm{Br}_{\mathrm{x}}$ from $(\mathrm{CsI})_{0.17}(\mathrm{FAI})_{0.83}\left(\mathrm{PbI}_{2}\right)_{1-0.5 \mathrm{x}}\left(\mathrm{PbBr}_{2}\right)_{0.5 \mathrm{x}}$ (precursor solution $\mathrm{A}$ ) exhibited small grains and low crystallinity (Route 1). Then, they added 5 vol.\% of $\mathrm{Pb}(\mathrm{SCN})_{2}$ solution into solution $\mathrm{A}$ (Route 2). It led to increased grain size and crystallinity but $\mathrm{PbX}_{2}(\mathrm{X}=\mathrm{I}$ and $\mathrm{Br}$ ) impurity byproduct segregated randomly at the grain boundaries. Accordingly, they deposited PVK from $(\mathrm{CsI})_{0.17}(\mathrm{FAI})_{0.83}\left(\mathrm{~Pb}(\mathrm{SCN})_{2}+\right.$ $2 \mathrm{FAI})_{0.6}\left(\mathrm{~Pb}(\mathrm{SCN})_{2}+2 \mathrm{FABr}\right)_{0.4}$ (precursor solution $\left.\mathrm{C}\right)$, in which the molar ratio $\mathrm{FAX}: \mathrm{Pb}(\mathrm{SCN})_{2}=2: 1$. It resulted in a film with large grain size and high crystallinity without $\mathrm{PbX}_{2}$. Since the excess of MAX can passivate the defects, solution $\mathrm{B}$ but with higher $\mathrm{FAX}$ : $\mathrm{Pb}(\mathrm{SCN})_{2}$ ratio to 3:1 (route 4) was used to deposit PVK film. Highly crystallized and large grain $\sim 1300 \mathrm{~nm}$ PVK (Fig. 10A) was obtained by this Route 4 . With the synergistic effects of $\mathrm{Pb}(\mathrm{SCN})_{2}$ assisted crystallization and FAX grain boundary healing, the well-passivated PSC showed greatly reduced hysteresis and excellent photovoltaic performance.

$\mathrm{Pb}(\mathrm{SCN})_{2}$ affects the reaction between $\mathrm{PbI}_{2}$ and MAI, leading to the $\mathrm{PbI}_{2}$ residual in the $\mathrm{PVK}$ films. $\mathrm{PbI}_{2}$ is an undesirable byproduct that can be detected in the PVK film and which is detrimental for the stability of PSC. Yu et al. ${ }^{[152]}$ developed an efficient strategy combining $\mathrm{Pb}(\mathrm{SCN})_{2}$ additive $\left(1.0 \mathrm{~mol} \% \mathrm{~Pb}(\mathrm{SCN})_{2}\right)$ and a solvent annealing process to get large $\mathrm{PVK}$ grain size and avoiding $\mathrm{PbI}_{2}$ excess formation (Fig. 10B). As a result, the average grain size of wide-bandgap $\mathrm{FA}_{0.8} \mathrm{Cs}_{0.2} \mathrm{~Pb}\left(\mathrm{I}_{0.7} \mathrm{Br}_{0.3}\right)_{3} \mathrm{PVK}$ thin films $\left(E_{g}=1.75 \mathrm{eV}\right)$ increased from $66 \pm 24$ to $1036 \pm 317 \mathrm{~nm}$, and the mean carrier lifetime increased by more than 3-fold, from 330 to over 1000 ns. Kim et al. ${ }^{[153]}$ developed $\left(\mathrm{FA}_{0.65} \mathrm{MA}_{0.20} \mathrm{Cs}_{0.15}\right) \mathrm{Pb}\left(\mathrm{I}_{0.8} \mathrm{Br}_{0.2}\right)_{3}$ PSCs with an PCE of $\sim 20 \%$ by using PEAI and $\mathrm{Pb}(\mathrm{SCN})_{2}$ as additives. The cooperation of $\mathrm{PEA}^{+}$and $\mathrm{SCN}^{-}$provided a synergistic effect that enhanced 
Cite this paper as: F. Cheng, J. Zhu, Th. Pauporté, Chlorides, other Halides and Pseudohalides as Additives for the Fabrication of Efficient and Stable Perovskite Solar Cells.

ChemSusChem 14 (2021) 3665-3692. DOI: 10.1002/cssc.202101089

$\mathrm{PVK}$ morphology and reduced $\mathrm{PbI}_{2}$ formation. As a result, using both additives increased the charge-carrier mobility and lifetime of PVK to near $50 \mathrm{~cm}^{2} \mathrm{~V}^{-1} \mathrm{~s}^{-1}$ and $3 \mu \mathrm{s}$, higher values than that of control samples. The average PCE of PSCs increased from $16.3 \%$ to $18.7 \%$.
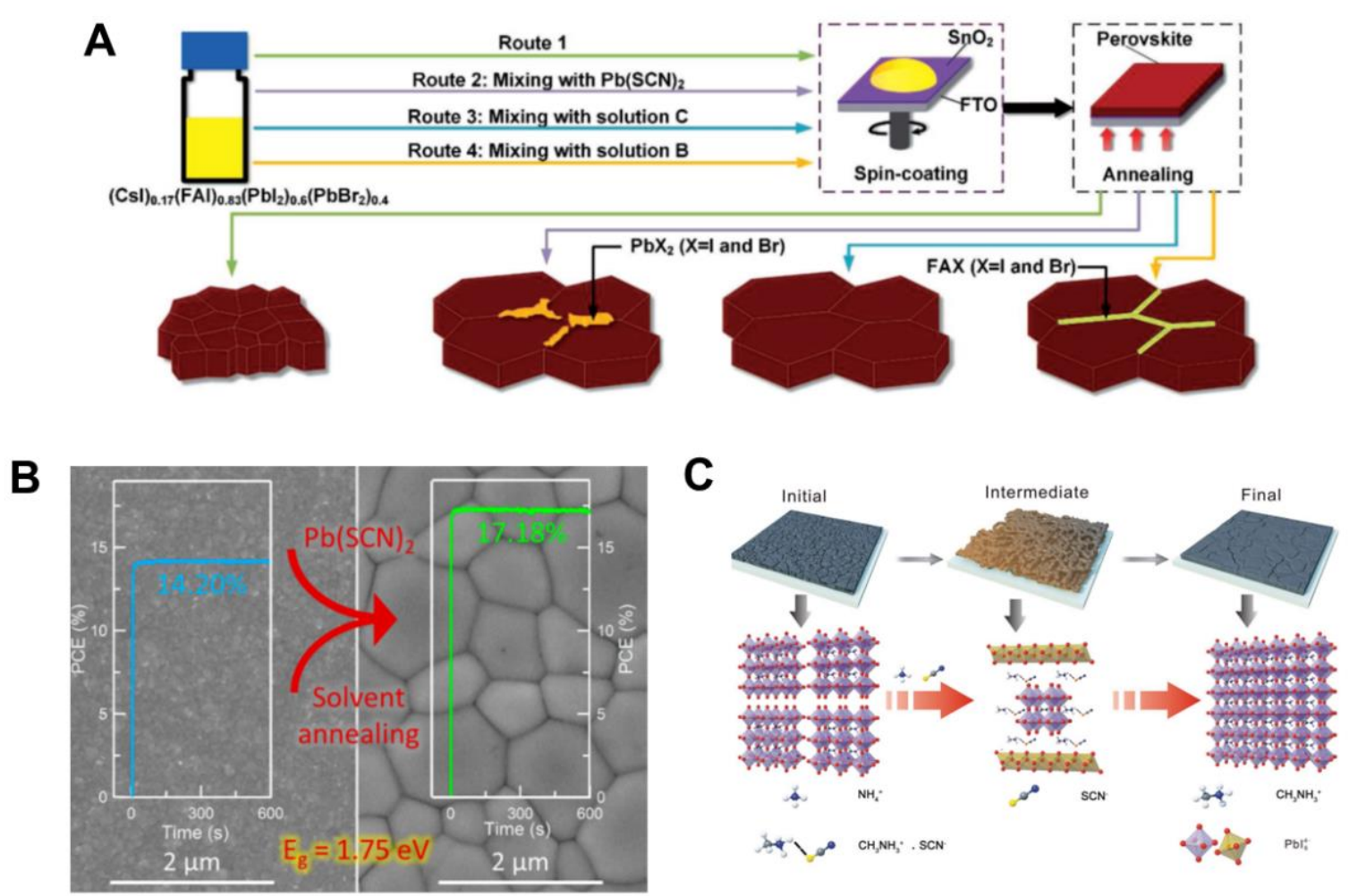

Fig. 10 (A) Schematics of different routes to prepare the $\mathrm{FA}_{0.17} \mathrm{Cs}_{0.83} \mathrm{PbI}_{3-x} B r_{x}(x=0.8) \mathrm{PVK}$ thin films. ${ }^{[151]}$ with permission from Wiley-VCH, copyright 2018. (B) SEM images of $\mathrm{FA}_{0.8} \mathrm{Cs}_{0.2} \mathrm{~Pb}\left(\mathrm{I}_{0.7} \mathrm{Br} \mathrm{r}_{0.3}\right)_{3} \mathrm{PVK}$ thin films before and after the synergistic effects of $\mathrm{Pb}(\mathrm{SCN})_{2}$ and solvent annealing process. ${ }^{[152]}$ with permission from the American Chemical Society, copyright 2017. (C) Schematic diagram of the recrystallization process: morphological evaluation and structure dynamic process of the $\mathrm{CH}_{3} \mathrm{NH}_{3} \mathrm{PbI}_{3}$ film with $\mathrm{NH}_{4} \mathrm{SCN}$ treatment. ${ }^{[154]}$ with permission from Wiley-VCH, copyright 2017.

In addition to $\mathrm{Pb}(\mathrm{SCN})_{2}$, volatile additives such as $\mathrm{NH}_{4} \mathrm{SCN}$ and MASCN have also been adopted to improve the crystallinity of PVK films and enhance cells performance. ${ }^{[154,155]}$ Dong et al. ${ }^{[154]}$ demonstrated a NH${ }_{4} \mathrm{SCN}$ induced recrystallization process (Fig. 10C) through an antisolvent method for improving the morphology and crystalline quality of the PVK film. First, when the prepared $\mathrm{MAPbI}_{3}$ (Initial film) was dipped into $\mathrm{NH}_{4} \mathrm{SCN}$ in IPA solution, it was partially dissolved and formed the mesoporous framework (Intermediate film) with $\mathrm{PbI}_{2}$ compound. Since $\mathrm{SCN}^{-}$has a stronger ionic bonding with $\mathrm{CH}_{3} \mathrm{NH}_{3}{ }^{+}$than $\mathrm{I}^{-}, \mathrm{CH}_{3} \mathrm{NH}_{3}{ }^{+}$is preferred to form ionic bonding with $\mathrm{SCN}^{-}$than $\mathrm{I}^{-}$in this intermediate state (Equation 2). Upon the annealing process, the formed $\mathrm{NH}_{3}$ and HSCN volatilized quickly (Equation 3). Subsequently, the undissolved polycrystal could play the role of 
Cite this paper as: F. Cheng, J. Zhu, Th. Pauporté, Chlorides, other Halides and Pseudohalides as Additives for the Fabrication of Efficient and Stable Perovskite Solar Cells.

ChemSusChem 14 (2021) 3665-3692. DOI: 10.1002/cssc.202101089

nucleus for the recrystallization process, new well-crystallized $\mathrm{MAPbI}_{3}$ (Final film) was formed and $\mathrm{PbI}_{2}$ impurity disappeared (Equation 4).

$$
\begin{array}{ll}
\mathrm{CH}_{3} \mathrm{NH}_{3} \mathrm{PbI}_{3}+\mathrm{SCN}^{-} \rightarrow \mathrm{PbI}_{6}{ }^{4-}+\mathrm{CH}_{3} \mathrm{NH}_{3} \cdot \cdot \mathrm{SCN}^{-} & \text {(dipping) (2) } \\
\mathrm{CH}_{3} \mathrm{NH}_{3}{ }^{+} \cdot \mathrm{SCN}^{-}+\mathrm{NH}_{4}{ }^{+} \rightarrow \mathrm{HSCN} \uparrow+\mathrm{NH}_{3} \uparrow & \text { (annealing)(3) } \\
\mathrm{PbI}_{6}{ }^{4-}+\mathrm{CH}_{3} \mathrm{NH}_{3}+\rightarrow \mathrm{CH}_{3} \mathrm{NH}_{3} \mathrm{PbI}_{3} & \text { (annealing) (4) }
\end{array}
$$

As a result, $\mathrm{MAPbI}_{3}$ prepared through such intermediate catalytic effect of $\mathrm{NH}_{4} \mathrm{SCN}$ exhibited large crystal grain sizes, as well as lower trap density, leading to a higher PCE of $19.44 \% . \mathrm{NH}_{4} \mathrm{SCN}$ additive strategy was also used in Cs-based and Sn-based PVK films for improving the crystallinity, stability and oxidation resistance in air atmosphere, promoting charge transfer and performances of devices. ${ }^{[156,157]}$

Zhang et al. ${ }^{[158]}$ employed ammonium thiocyanate $\left(\mathrm{NH}_{4} \mathrm{SCN}\right)$ as additive for the preparation of $\mathrm{MAPbX}_{3}$ layers. This compound was the most efficient at $15 \mathrm{~mol} \%$ in the PPS and provided better benefits compared to $\mathrm{NH}_{4} \mathrm{I}$ or $\mathrm{Pb}(\mathrm{SCN})_{2}$ additives. They showed a synergistic effect of both cation and anion for the control of the nucleation and growth of the perovskite layer which gave rise to bigger grains and more stable layers. The final composition of the layer was $\mathrm{MAPbI}_{3-\mathrm{x}} \mathrm{SCN}_{\mathrm{x}}$ and these authors showed the formation of the $\mathrm{NH}_{4} \mathrm{PbI}_{3-\mathrm{x}} \mathrm{SCN}_{\mathrm{x}}$ intermediate, more stable than the $\mathrm{MAPbI}_{3}$ one. It induces less defects and slow down the rate of crystallization. They have also linked the good stability of $\mathrm{MAPbI}_{3-\mathrm{x}} \mathrm{SCN}_{\mathrm{x}}$ with the linear shape of $\mathrm{SCN}^{-}$ions, strongly coordinated with $\mathrm{Pb}^{2+}$ ions.

The list of the main other halides and pseudo-halides employed as additives for PSC, the cell structure, PCEs and $J-V$ curve parameters are gathered in the Table 4.

We have reported that fluoride species can form strong ionic and intermolecular bonding with PVK, which is beneficial for passivating surface and crystal boundaries defects. They can endow the surfaces with hydrophobic properties and then protect the PVK from moisture erosion. In lead-free PVK, $\mathrm{SnF}_{2}$ can suppress the oxidation from $\mathrm{Sn}^{2+}$ to $\mathrm{Sn} 4+$, reducing the background carrier density and $\mathrm{Sn}$ defects for improving the performance of Sn-based PSCs. Bromide additives can broaden the band gap of PVK, control the PVK growth to get large grains. They passivate grain boundaries, passivate defects related to $\mathrm{Sn}^{2+}$ oxidation. It results in longer lifetimes, improve stability. Iodide additives act as candidates for preventing the formation of iodide Frenkel defect, forming uniform and continuous PVK film and leading to hysteresis-free PSCs with improved performances. Regarding pseudo-halides, they can act as a substitute of halogen atoms in the halide PVK, and the incorporation of pseudo-halide can improve the grain size, material crystallinity and optical properties of PVK layers. 
Cite this paper as: F. Cheng, J. Zhu, Th. Pauporté, Chlorides, other Halides and Pseudohalides as Additives for the Fabrication of Efficient and Stable Perovskite Solar Cells.

ChemSusChem 14 (2021) 3665-3692. DOI: 10.1002/cssc.202101089 
Cite this paper as: F. Cheng, J. Zhu, Th. Pauporté, Chlorides, other Halides and Pseudohalides as Additives for the Fabrication of Efficient and Stable Perovskite Solar Cells.

ChemSusChem 14 (2021) 3665-3692. DOI: 10.1002/cssc.202101089

Table 4. Other halides and pseudo-halides additives used in PVK, concentration, cell structure, PCE and J-V curve parameters.

\begin{tabular}{|c|c|c|c|c|c|c|c|}
\hline $\begin{array}{l}\text { Other halides and pseudo-halides } \\
\text { additives in the bulk }\end{array}$ & Concentration & Device structure & PCE $(\%)$ & $\mathrm{J}_{\mathrm{sc}}\left(\mathrm{mA} \cdot \mathrm{cm}^{-2}\right)$ & $\mathrm{V}_{\mathrm{oc}}(\mathrm{V})$ & $\mathrm{FF}(\%)$ & Year Ref. \\
\hline $\mathrm{SnF}_{2}$ & $20 \mathrm{~mol} \%$ & $\mathrm{FTO} / \mathrm{TiO}_{2} / \mathrm{MASnI}_{3} / \mathrm{PTAA} / \mathrm{Au}$ & 1.94 & 26.1 & 0.25 & 30.00 & $2017^{[100]}$ \\
\hline $\mathrm{SnF}_{2}-$-Pyrazine & $20 \mathrm{~mol} \%$ & 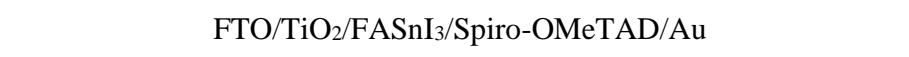 & 4.00 & 24.5 & 0.29 & 55.00 & $2016^{[103]}$ \\
\hline $\mathrm{NaF}$ & $0.1 \mathrm{~mol} \%$ & $\mathrm{ITO} / \mathrm{SnO}_{2} /\left(\mathrm{Cs}_{0.05} \mathrm{FA}_{0.54} \mathrm{MA}_{0.41}\right) \mathrm{Pb}\left(\mathrm{I}_{0.98} \mathrm{Br}_{0.02}\right)_{3} /$ spiro-OMeTAD/ & 21.92 & 24.23 & 1.126 & 80.35 & $2019^{[105]}$ \\
\hline $\mathrm{NbF}_{5}$ & $3 \mathrm{mg} \cdot \mathrm{mL}^{-1}$ & $\mathrm{FTO} / \mathrm{TiO}_{2} / \mathrm{PVK}\left(\mathrm{NbF}_{5}\right) / \mathrm{PCBM} / \mathrm{Ag}$ & 20.56 & 25.4 & 1.05 & 77.08 & $2019^{[106]}$ \\
\hline guanidinium bromide (GABr) & $12 \mathrm{~mol} \%$ & $\begin{array}{c}\text { ITO/EMIC-PEDOT:PSS/FA } \mathrm{F}_{0.7} \mathrm{MA}_{0.3} \mathrm{~Pb}_{0.7} \mathrm{Sn}_{0.3} \mathrm{I}_{3} / \mathrm{S} \text {-acetylthiocholine } \\
\text { chloride passivation layer } / \mathrm{C} 60 / \mathrm{BCP} / \mathrm{Ag}\end{array}$ & 20.63 & 26.61 & 1.02 & 76.00 & $2020^{[119]}$ \\
\hline \multicolumn{8}{|l|}{$\mathrm{N}$-(4-bromophenyl)-thiourea } \\
\hline$(\mathrm{BrPh}-\mathrm{ThR})$ & $0.6 \mathrm{mg} \cdot \mathrm{mL}^{-1}$ & $\mathrm{FTO} / \mathrm{TiO}_{2} /(\mathrm{FAI})_{0.81}\left(\mathrm{PbI}_{2}\right)_{0.85}(\mathrm{MABr})_{0.15}\left(\mathrm{PbBr}_{2}\right)_{0.15} /$ Spiro-OMeTAD/Au & 21.7 & 23.93 & 1.12 & 78.00 & $2018^{[120]}$ \\
\hline $\mathrm{RbI}$; CsI & $5 \mathrm{~mol} \% ; 5 \mathrm{~mol} \%$ & $\mathrm{FTO} / \mathrm{TiO}_{2} /\left(\mathrm{MAPbBr}_{3}\right)_{0.17}\left(\mathrm{FAPbI}_{3}\right)_{0.83} /$ Spiro-OMeTAD/Au & 19 & 22.7 & 1.1 & 76.00 & $2019^{[145]}$ \\
\hline ethylenediammonium diiodide & $1 \mathrm{~mol} \%$ & ITO/PEDOT:PSS/FASnI $3 / \mathrm{C} 60$ /BCP/Ag & 8.9 & 21.3 & 0.583 & 71.80 & $2018^{[159]}$ \\
\hline MASCN & $40 \mathrm{~mol} \%$ & $\mathrm{FTO} / \mathrm{TiO}_{2} / \mathrm{MAPbI}_{3} / \mathrm{Spiro-OMeTAD} / \mathrm{Au}$ & 18.22 & 23.2 & 1.064 & 76.94 & $2017^{[155]}$ \\
\hline $\mathrm{PEAI} ; \mathrm{Pb}(\mathrm{SCN})_{2}$ & $1 \mathrm{~mol} \% ; 2 \mathrm{~mol} \%$ & ITO/PTAA/(FA0.65MA0.20 Cs0.15) $\mathrm{Pb}\left(\mathrm{I}_{0.8} \mathrm{Br}_{0.2}\right)_{3} / \mathrm{C} 60 / \mathrm{BCP} / \mathrm{Ag}$ & 19.8 & 21.2 & 1.17 & 79.80 & $2019^{[153]}$ \\
\hline FASCN; PEAI & $5 \mathrm{~mol} \% ; 10 \mathrm{~mol} \%$ & ITO/PEDOT:PSS/FASnI $3 / \mathrm{PCBM} / \mathrm{Al}$ & 8.17 & 22.5 & 0.53 & 68.30 & $2018^{[160]}$ \\
\hline $\mathrm{Pb}(\mathrm{SCN})_{2}$ & $2 \mathrm{~mol} \%$ & $\begin{array}{l}\text { FTO/PEALD } \mathrm{SnO}_{2} / \mathrm{C} 60-\mathrm{SAM} /\left(\mathrm{MA}_{0.7} \mathrm{FA}_{0.3} \mathrm{PbI}_{3}\right)_{1-\mathrm{x}}\left(\mathrm{CsPbI}_{3}\right)_{\mathrm{x}} / \text { spiro- } \\
\text { OMeTAD/Au }\end{array}$ & 20.49 & 23.05 & 1.11 & 80.09 & $2018^{[161]}$ \\
\hline GuaSCN & $7 \mathrm{~mol} \%$ & ITO/PEDOT:PSS/(FASnI $)_{0.6}\left(\mathrm{MAPbI}_{3}\right)_{0.4} / \mathrm{C} 60 /$ bathocuproine/Ag & 18.7 & 28.7 & 0.82 & 79.00 & $2019^{[118]}$ \\
\hline $\mathrm{NH}_{4} \mathrm{SCN}$ & $1.5 \mathrm{~mol} \%$ & $\mathrm{ITO} / \mathrm{TiO}_{2} / \mathrm{CsPbBr}_{3} / \mathrm{Spiro}-\mathrm{OMeTAD} / \mathrm{Au}$ & 8.47 & 7.76 & 1.375 & 79.31 & $2020^{[156]}$ \\
\hline $\mathrm{NH}_{4} \mathrm{SCN}$ & $0.03 \mathrm{M} \cdot \mathrm{mL}^{-1}$ & ITO/PTAA/CH $3 \mathrm{NH}_{3} \mathrm{PbI}_{3} / \mathrm{PCBM} / \mathrm{BCP} / \mathrm{Ag}$ & 19.44 & 22.55 & 1.103 & 78.20 & $2017^{[154]}$ \\
\hline $\mathrm{NH}_{4} \mathrm{SCN}$ & $15 \mathrm{~mol} \%$ & ITO/PEDOT:PSS/ MAPbI ${ }_{3-\mathrm{x}} \mathrm{SCN}_{\mathrm{x}} / \mathrm{PC} 61 \mathrm{BM} / \mathrm{LiF} / \mathrm{Al}$ & 16.47 & 23.31 & 0.96 & 73.84 & $2018^{[158]}$ \\
\hline $\mathrm{Pb}(\mathrm{SCN})_{2}$ & $2 \mathrm{~mol} \%$ & $\mathrm{FTO} / \mathrm{TiO}_{2} / \mathrm{CsPb}_{3} / \mathrm{PTAA} / \mathrm{Au}$ & 17.03 & 20.34 & 1.09 & 77.00 & $2019^{[162]}$ \\
\hline
\end{tabular}


Cite this paper as: F. Cheng, J. Zhu, Th. Pauporté, Chlorides, other Halides and Pseudohalides as Additives for the Fabrication of Efficient and Stable Perovskite Solar Cells.

ChemSusChem 14 (2021) 3665-3692. DOI: 10.1002/cssc.202101089

\section{Halides at the interfaces of PSCs}

The ETL/PVK and HTL/PVK interfaces play a critical role on the performances of PSCs. They must be engineered to improve the PSC characteristics. Especially, interfacial modification is key to passivate the defects of metallic oxide ETL and PVK, improving the charge transfer and reducing the charge recombination. Moreover, they can induce PVK crystal modification, adjustment of the energylevel alignment and the stabilization of the PVK towards UV-light, humidity and oxygen degrading agents. Normally, the modification is obtained by adding the halide additive into the charge carrier precursor solution, spin-coating halide additive solution onto the charge carrier layers or by soaking the well-formed layer in an additive solution.

\subsection{Introduction of halogen atoms at the ETL/PVK interface}

Chlorine serves as contact passivator to mitigate the interfacial recombination. Defects at the ETL/PVK interface and induces charge recombination which has a negative effect on the performance and stability of PSCs and that must be addressed by passivating the surface of active layers. Tan et al. ${ }^{[163]}$ employed chlorine-capped $\mathrm{TiO}_{2}$ colloidal nanocrystal to suppress $\mathrm{TiO}_{2}$ deep trap states and reduce the interface recombination at the $\mathrm{TiO}_{2} / \mathrm{PVK}$ contact. DFT calculation showed that $\mathrm{Cl}$ at the interface results in a lower density of interfacial trap states, as well as in a stronger binding of $\mathrm{PVK}$ to $\mathrm{TiO}_{2}$ interface. As a result, the hysteresis-free planar PSCs with champion PCE of $20.1 \%$ for small-area devices $(0.049$ $\mathrm{cm}^{2}$ ) was obtained. F doping of $\mathrm{SnO}_{2}$ was used to adjust the Fermi level of ETL. ${ }^{[164]}$ The device $V_{o c}$ could be tailored by modulating the band offset at the interface of ETL and PVK. The grain boundary barriers and defects within the bilayer ETL could be largely restrained due to a matched lattice constant.

\subsection{Halides at the ETL/PVK interface}

Organic monolayer on ETL surface have been introduced to enhance the interfacial optoelectronic properties of PSCs. The metallic oxide and PVK can undergo chemical interaction with organic molecules, which can improve the PVK film quality and promote the electron extraction while 
Cite this paper as: F. Cheng, J. Zhu, Th. Pauporté, Chlorides, other Halides and Pseudohalides as Additives for the Fabrication of Efficient and Stable Perovskite Solar Cells.

ChemSusChem 14 (2021) 3665-3692. DOI: 10.1002/cssc.202101089

restricting the charge recombination between ETL and PVK. With this motivation, organic small molecular materials have been used for interfacial modification such as benzoic acid derivatives onto the $\mathrm{TiO}_{2}$ in PSCs. ${ }^{[165]}$ Pauporté et al. ${ }^{[166]}$ investigated the effect of self-assembled monolayers (SAMs) prepared by spin-coating benzoic acid derivatives onto the $\mathrm{TiO}_{2}$ of PSCs. As shown in Fig. 11A, a series of organic compounds with benzene and various terminal groups were tested $\left(\mathrm{Cl}, \mathrm{NO}, \mathrm{Br}, \mathrm{O}-\mathrm{CH}_{3}, \mathrm{NH}_{2}\right)$ and compared to $\beta$-alanine, an amino acid. The $-\mathrm{COO}$ anchoring group passivates the ETL surface via chemical bonding. The best functional group was found to be $\mathrm{Cl}$ (CBA) with a stabilized PCE reaching $20.9 \%$ (20.0\% for the pristine cell). The para-Cl group can establish a stable bonding with the PVK. The presence of this monolayer decreased interfacial trap states, improved the global PVK quality and created a structural continuity between $\mathrm{TiO}_{2}$ and PVK. This system was further studied by DFT ${ }^{[167]}$ that showed the bonding between $\mathrm{Cl}$ and $\mathrm{Pb}$ of the PVK (Fig. 11B). The computed density of states revealed that the $\mathrm{PVK}\left(\mathrm{MAPbI}_{3}\right.$ employed as a model PVK) contributes to the top of the valence band while $\mathrm{TiO}_{2}$ ETM contributes to the bottom of the conduction band. It indicated that an electron transfer from $\mathrm{MAPbI}_{3}$ to $\mathrm{TiO}_{2}$ is possible. Furthermore, these authors quantified the spin density of the reduced $\mathrm{MAPbI}_{3} / \mathrm{CBA} / \mathrm{TiO}_{2}$ system and calculated a quantitative (99.94\%) electron transfer from $\mathrm{MAPbI}_{3}$ to $\mathrm{TiO}_{2}$ to the interfacial engineering. They have also calculated an ultrafast electron injection time at 24 fs, and the dipole moment of $0.61 \mathrm{D}$ induced by CBA at the interface which is favorable for the charge transfer from $\mathrm{MAPbI}_{3}$ to $\mathrm{TiO}_{2}$.

Introducing inorganic metal halide materials at the ETL/PVK interface can adjust the band alignment, passivate the surface trap states and suppress the recombination process. As shown in Fig. 11C, p-type $\mathrm{CuI}$ on $\mathrm{TiO}_{2}$ surface was used to modify the $\mathrm{TiO}_{2}$ band alignment by shifting the conduction band bottom from $-4.13 \mathrm{eV}$ to $-3.93 \mathrm{eV}$. It resulted in a barrier-free contact and an increased open-circuit voltage. Meanwhile, the polarity of the $\mathrm{CuI}-$ modified $\mathrm{TiO}_{2}$ surface was favorable to pull electrons from $\mathrm{PVK}$ to the interface of ETL/PVK, improving electron extraction and reducing nonradiative recombination. ${ }^{[168]}$ In a similar manner, inorganic alkaline halide was used to passivate ionic defects with their cations and anions. $\mathrm{Li}$ et al. ${ }^{[169]}$ introduced $\mathrm{CsBr}$ onto the compact c- $\mathrm{TiO}_{2}$ surface in planar heterojunction solar cells, which reduced the pinholes density and resulted in the shifts of work function of $\mathrm{TiO}_{2}$ from 4.07 to 3.09 eV. Such $\mathrm{CsBr}$ surface modification enhanced the electron transfer and the stability of planar heterojunction devices under ultraviolet (UV) light soaking. It is reported that alkaline halides can 
Cite this paper as: F. Cheng, J. Zhu, Th. Pauporté, Chlorides, other Halides and Pseudohalides as Additives for the Fabrication of Efficient and Stable Perovskite Solar Cells.

ChemSusChem 14 (2021) 3665-3692. DOI: 10.1002/cssc.202101089

passivate both types of charged defects (positive and negative) with alkaline cation and halide anion. Yuan et al. ${ }^{[170]}$ demonstrated the interfacial passivation effect of $\mathrm{LiF}$ at the $\mathrm{SnO}_{2} / \mathrm{PVK}$ interface (Fig. 11D). The intermediate layer of LiF effectively blocks holes and promotes the electron transport. In order to identify the interfacial passivation by $\mathrm{Li}^{+}$and $\mathrm{F}^{-}$, devices with $\mathrm{PbF}_{2}\left(\mathrm{~F}^{-}\right.$only) or LiTFSI $\left(\mathrm{Li}^{+}\right.$ only) modified layer were fabricated. It was found that $\mathrm{F}^{-}$ion play a main role in the device performance improvement. Hysteresis-less planar PSCs with a PCE of $18.3 \%$ were fabricated by Ma et al. ${ }^{[171]}$ via passivating the compact $\mathrm{TiO}_{2} / \mathrm{PVK}$ interface with $\mathrm{NaCl}$. They immersed the $\mathrm{TiO}_{2}$ substrate in 0.5 mg. $\mathrm{mL}^{-1} \mathrm{NaCl}$ solution and then heated at $500{ }^{\circ} \mathrm{C}$ for $15 \mathrm{~min}$. By varying light intensities from 0.1 to $100 \mathrm{~mW} \mathrm{~cm}{ }^{-2}$, the $V_{o c}$ versus light intensity slope of the devices based on pristine $\mathrm{TiO}_{2}$ and $\mathrm{NaCl}$ modified $\mathrm{TiO}_{2}$ were $1.23 \mathrm{kT} / \mathrm{q}$ and $1.14 \mathrm{kT} / \mathrm{q}$, respectively (where $\mathrm{k}$ is the Boltzmann constant, $\mathrm{T}$ is absolute temperature, and $\mathrm{q}$ is the elementary charge). It indicated that the doping treatment reduced the trap density at the $\mathrm{TiO}_{2} / \mathrm{PVK}$ interface and improved the electrical property of $\mathrm{TiO}_{2}$. To further understand the mechanism of charge transfer and recombination, transient photocurrent (TPC) under short-circuit condition and transient photovoltage (TPV) under open-circuit conditions measurements were performed. TPC decay lifetime was faster at $0.51 \mu$ s for $\mathrm{TiO}_{2}-\mathrm{NaCl}$ while TPV exhibited a longer decay lifetime of $24.67 \mu$ s for $\mathrm{TiO}_{2}-\mathrm{NaCl}$. It indicated more efficient charge transfer, extraction process and efficient suppression of charge recombination, respectively. The hysteresis index was reduced from $12.6 \%$ to $2.7 \%$ after the doping treatment. The trap density of $\mathrm{TiO}_{2}$ and $\mathrm{TiO}_{2}-\mathrm{NaCl}$ measured by space charge limited current (SCLC) were $7.08 \times 10^{16} \mathrm{~cm}^{-3}$ and $5.19 \times 10^{16} \mathrm{~cm}^{-3}$, respectively. The electron mobility of $\mathrm{TiO}_{2}-\mathrm{NaCl}$ increased to $7.20 \times 10^{-4} \mathrm{~cm}^{2} \mathrm{~V}^{-1} \mathrm{~s}^{-1}$ compared to that of pristine $\mathrm{TiO}_{2}\left(3.48 \times 10^{-4}\right.$ $\left.\mathrm{cm}^{2} \mathrm{~V}^{-1} \mathrm{~s}^{-1}\right)$. Finally, the film was more homogeneous after $\mathrm{NaCl}$ doping.

Jang et al. ${ }^{[172]}$ developed a deposition and diffusion method of alkaline chlorides onto ZnO ETL to effectively passivate both shallow and deep trap states, which were present in PVK crystallized layer and at the PVK/ETL interface. Dual trap passivation dramatically improved the PCE, reduced the photocurrent hysteresis, and enhanced the long-term stability of PSCs. The ZnO layers were modified by immersing them in aqueous alkaline chloride $(\mathrm{LiCl}, \mathrm{NaCl}, \mathrm{KCl}, \mathrm{CsCl})$, the reduction in defect-related PL emissions was the most prominent in the $10 \mathrm{mM} \mathrm{KCl}$ modified $\mathrm{ZnO}$ sample. Interfacial defect passivation was due to both $\mathrm{K}$ and $\mathrm{Cl}$. As a result of time-correlated single-photon counting (TCSPC) analysis, the $\mathrm{ZnO}-\mathrm{KCl}$ sample exhibited a substantially shorter decay time (2.73 ns). The charge 
Cite this paper as: F. Cheng, J. Zhu, Th. Pauporté, Chlorides, other Halides and Pseudohalides as Additives for the Fabrication of Efficient and Stable Perovskite Solar Cells.

ChemSusChem 14 (2021) 3665-3692. DOI: 10.1002/cssc.202101089

recombination lifetime and charge transport time of the modified PSCs were $204 \mu$ s and $1.7 \mu$ s, respectively. The average grain size of the $\mathrm{KCl}$ modified PVK sample was about $450 \mathrm{~nm}$, whereas that of the unmodified sample was about $300 \mathrm{~nm}$. TEM coupled with EDS mapping showed the penetration of $\mathrm{K}$ and $\mathrm{Cl}$ atoms throughout the PVK layers. The $\mathrm{KCl}$ modified low-temperature processed PSCs (LPSC) achieved the highest PCE of $22.6 \%$. With an active area of $1.12 \mathrm{~cm}^{2}$, L-PSC-KCl reached $21.3 \%$, which was one of the highest values among the reported L-PSCs with an active area of $>1 \mathrm{~cm}^{2}$ thus far. The long-term shelf-life of unencapsulated L-PSCs was tested following the ISOSD-1 protocol (in the dark, $25^{\circ} \mathrm{C}, 40 \%$ humidity, in air). ${ }^{[173]}$ The L-PSC-KCl maintained $90 \%$ of its initial PCE after $1400 \mathrm{~h}$. Moreover, Liu et al. ${ }^{[174]}$ also observed that the inorganic binary alkaline halide salts treatment of the $\mathrm{SnO}_{2} / \mathrm{PVK}$ interface can significantly increase the open-circuit voltage and eliminate hysteresis.

A

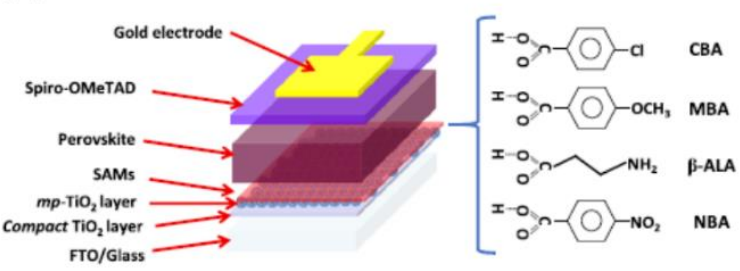

C

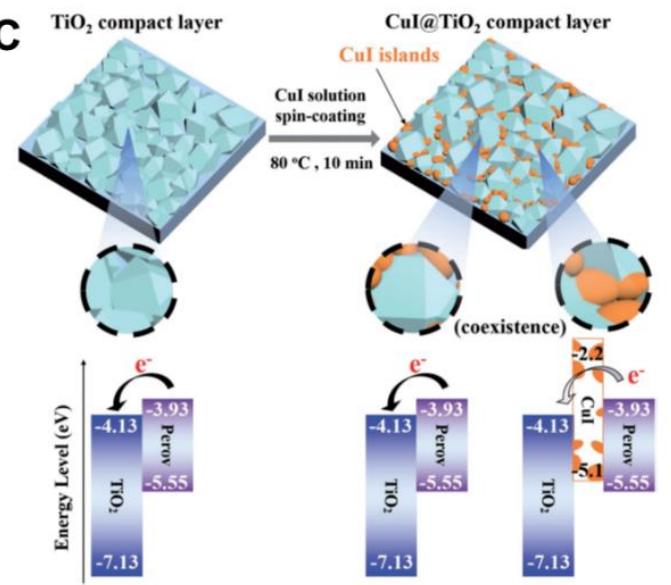

B
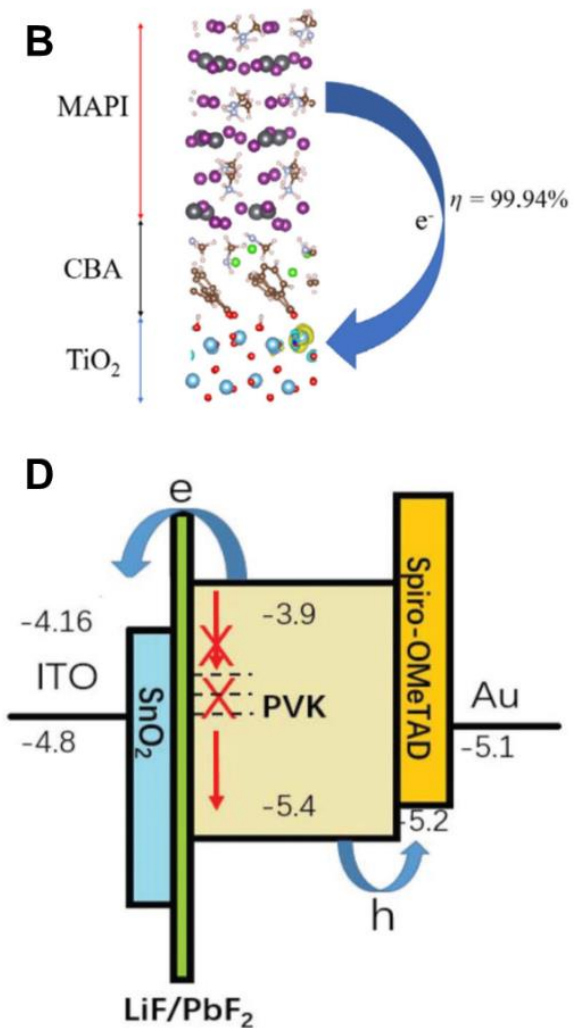

Fig. 11 (A) PSC cell structure and mesoporous mp-TiO2 layer covered by SAMs (in red) of parasubstituted benzoic acid derivatives and $\beta$-alanine. ${ }^{[166]}$ with permission from The American Chemical Society, copyright 2020. Spin density of the reduced MAPI-CBA-TiO ${ }_{2}$ interface system and calculated charge injection efficiency.[167] with permission from Wiley-VCH, copyright 2020. (C) Schematic illustration of the deposition of CuI on TiO ${ }_{2}$ compact layer.In CuI@TiO2-based devices, electrons transfer from $\mathrm{PVK}$ to exposed $\mathrm{TiO}_{2}$ not $\mathrm{CuI}$ due to the high conduction band energy level of CuI. ${ }^{[168]}$ with permission from Wiley-VCH, copyright 2018 (D) Structure of the PSC with a thin layer of LiF or $\mathrm{PbF}_{2}$ on $\mathrm{SnO}_{2}$ layer. ${ }^{[170]}$ with permission from The Royal Society of Chemistry, copyright 2018. 
Cite this paper as: F. Cheng, J. Zhu, Th. Pauporté, Chlorides, other Halides and Pseudohalides as Additives for the Fabrication of Efficient and Stable Perovskite Solar Cells.

ChemSusChem 14 (2021) 3665-3692. DOI: 10.1002/cssc.202101089

\subsection{PVK layer surface engineering}

Due to the ionic nature of PVK materials, undesirable electronic defects and pinholes can be observed at the surface and grain boundaries of PVK layers. Such defects decrease the charge collection efficiency and increase the charge recombination during the photoelectric conversion process, the best performance of PSCs still lags behind the theoretical limit of Shockley-Queisser efficiency. Moreover, the crystal defects and uncoordinated ions at the surface and grain boundaries are supposed to affect the stability of PSCs. Thus, in order to develop the high-efficiency and stable PSCs, it is essential to passivate the crystal defects at the crystal surface and grain boundaries.

\subsubsection{Hydrophobic organo-halogen at the surface of PVK}

Some organic insulating tunneling layers consisting of hydrophobic groups can cover the surface of PVK film, suppressing carrier recombination and protecting the PVK from decomposition caused by moisture. The fluorinated organic compounds are known to be hydrophobic, and have been used to improve the stability of PVK by grafting on the surface of PVK crystals. Wang et al. ${ }^{[175]}$ chose a hydrophobic insulating fluoro-silane, trichloro(3,3,3-trifluoropropyl)silane, as a tunneling layer deposited on the top of $\mathrm{MAPbI}_{3} \mathrm{PVK}$ film to fabricate water-resistant devices (Fig. 12A). As shown in Fig. 12B, the silanes were hydroxylated to the silanols with tiny amount of $\mathrm{H}_{2} \mathrm{O}$. Then, they underwent a cross-linking by forming Si-O-Si bonds, this fluoro-silane insulating organic layer protected the underneath PVK films from water attack. Meanwhile, this tunneling layer spatially separated photogenerated electrons and holes at the PVK/polymer HTM interface. It reduced the carrier surface recombination and significantly increased the device performance. Considering the conductivity of fluorinated compounds, the conductive fluorinated perylenediimide (F-PDI) was introduced to fill in at grain boundaries and surface of the PVK film (Fig. 12C). ${ }^{[176]}$ The conductive F-PDI chemical bonding to PVK film effectively passivated defects and promoted the charge transport. Meanwhile, hydrogen bond formed between F-PDI and $\mathrm{MA}^{+}$reduced the mobility of $\mathrm{MA}^{+}$in the $\mathrm{MAPbI}_{3} \mathrm{PVK}$ and therefore improved the thermal and moisture stability. F-PDI-incorporated device based on the 
Cite this paper as: F. Cheng, J. Zhu, Th. Pauporté, Chlorides, other Halides and Pseudohalides as Additives for the Fabrication of Efficient and Stable Perovskite Solar Cells.

ChemSusChem 14 (2021) 3665-3692. DOI: 10.1002/cssc.202101089

$\left(\mathrm{FA}_{0.83} \mathrm{MA}_{0.17}\right)_{0.95} \mathrm{~Pb}\left(\mathrm{Br}_{0.17} \mathrm{I}_{0.83}\right)_{3}$ absorber showed champion efficiencies of $19.26 \%$, and maintains $80 \%$ of its initial efficiency even after exposure to RH of $50 \%$ for 30 days. In another work, Wu et al. ${ }^{[177]}$ developed a $\mathrm{CF}_{4}$ plasma treatment for fluorinating the whole PSC device. A strongly bonded $\mathrm{C}-\mathrm{F}_{\mathrm{x}}$ layer covered the top and lateral surface of PSCs, which exhibited an excellent water-repellent property, without any change after immersion into water for $5 \mathrm{~min}$. Liu et al. ${ }^{[178]}$ introduced a two-dimensional (2D) $\mathrm{A}_{2} \mathrm{PbI}_{4} \mathrm{PVK}$ layer using pentafluorophenylethylammonium (FEA) as a fluoroarene cation inserted between the 3D light-harvesting PVK film and the hole-transporting material (HTM). The perfluorinated benzene moiety conferred an ultra-hydrophobic character to the spacer layer, protecting the PVK material from ambient moisture while mitigating ionic diffusion in the device.

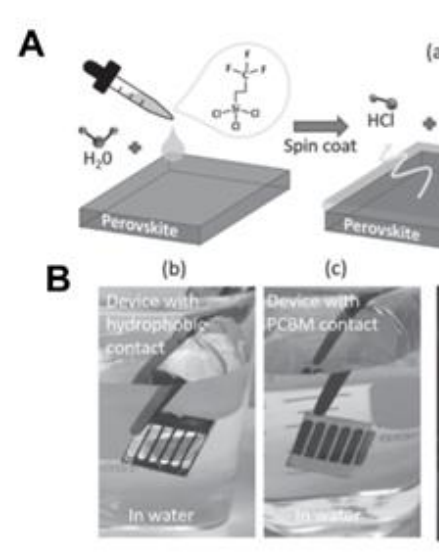

D

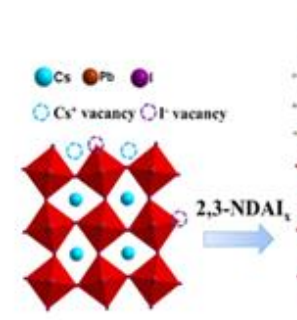

(a)
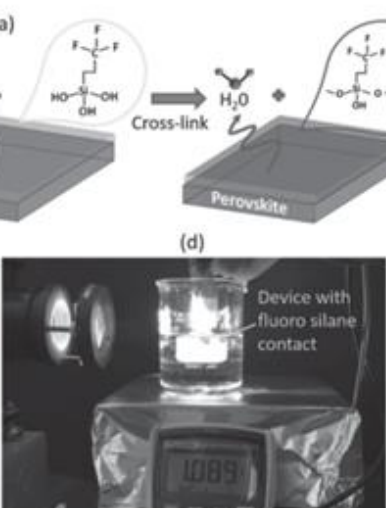

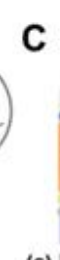

(c)
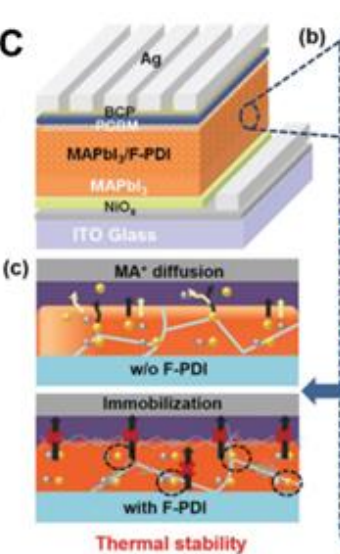

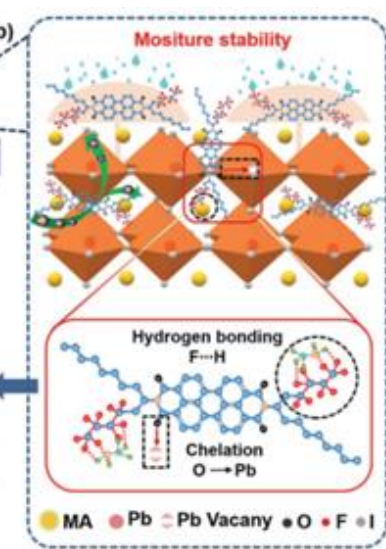

$\mathbf{F}$

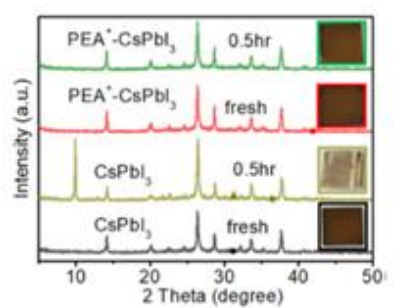

Fig. 12 (A) Schematic illustration for the cross-link process of fluoro-silane layer on the PVK film. (B) The humidity stability test for the PVK layers with and without fluoro-silane contact. ${ }^{[175]}$ with permission from Wiley-VCH, copyright 2016. (C) Schematic illustration of PSCs structure, the interactions between F-PDI and $\mathrm{MAPbI}_{3}$ PVK. ${ }^{[176]}$ with permission from Wiley-VCH, copyright 2019.(D) Schematic illustration of defect passivation and water resistance effect with naphthalenediammonium iodide. ${ }^{[191]}$ with permission from The Royal Society of Chemistry, copyright 1996. (E) Schematic illustration of $\mathrm{PEA}^{+}$cations at $\mathrm{CsPbI}$ surface termination (F) XRD patterns and photographs of the $\mathrm{CsPbI}_{3}$ and $\mathrm{PEA} \mathrm{A}^{+}-$ $\mathrm{Cs}_{\mathrm{PbI}}$ thin films after exposed to ambient environment with $85 \%-90 \%$ RH at RT for $0.5 \mathrm{hr}^{[179]}$ with permission from Elsevier, copyright 2018. 
Cite this paper as: F. Cheng, J. Zhu, Th. Pauporté, Chlorides, other Halides and Pseudohalides as Additives for the Fabrication of Efficient and Stable Perovskite Solar Cells.

ChemSusChem 14 (2021) 3665-3692. DOI: 10.1002/cssc.202101089

\subsubsection{Passivation of PVK defects and near surface film modification}

It is known that the imperfections in hybrid perovskite could induce a large density of traps. There are three types of defects in the $\mathrm{MAPbI}_{3}$ : vacancies $\left(\mathrm{V}_{\mathrm{MA}}, \mathrm{V}_{\mathrm{Pb}}, \mathrm{V}_{\mathrm{I}}\right)$, interstitials $\left(\mathrm{MA}_{\mathrm{i}}, \mathrm{Pb}_{\mathrm{i}}, \mathrm{I}_{\mathrm{i}}\right)$ and antisite substitutions ( $\mathrm{MA}_{\mathrm{Pb}}, \mathrm{Pb}_{\mathrm{MA}}, \mathrm{MA}_{\mathrm{I}}, \mathrm{Pb}_{\mathrm{I}}, \mathrm{I}_{\mathrm{MA}}, \mathrm{I}_{\mathrm{Pb}}$ ), where in the latter $\mathrm{A}_{\mathrm{B}}$ indicates that $\mathrm{A}$ is substituted by B. The first-principles calculations are performed to investigate the electronic structure, dielectric properties and defect properties of perovskite. Buin et al. ${ }^{[180]}$ showed the origin of major sources of deep traps for the perovskite materials via analysis of defect aggregation in terms of defect binding energies with DFT calculations. They concluded that the halide vacancies are the major source of deep traps in Cl-based perovskite, while lead interstitials are the dominant source of defects in Br-based perovskites. M. H. Du ${ }^{[181]}$ calculated defects in $\mathrm{MAPbI}_{3}$ and showed that iodine vacancy is a low energy deep trap and non-radiative recombination centre. Thus, alloying iodide with chloride can reduce the lattice constant of the iodide and increases the formation energy of interstitial defects. As mentioned above, excess of halide or using mixed halides approach can prevent the formation of deep energy level.

Contrary to organo-halogen molecules, halide compounds are often used to passivate $\mathrm{Pb}$ interstitial and halide vacancies. Ammonium derivative halide salts are popular passivators that can reduce the cation and anion defects at PVK/HTL interface through hydrogen bonding or ionic bonding with PVK bulk. Until now, PTN-Br, ${ }^{[182]} \mathrm{MAI},{ }^{[183]} \mathrm{FABr},{ }^{[184]}$ phenyltrimethylammonium bromide (PTABr), ${ }^{[185]}$ imidazolium iodide (IAI), ${ }^{[186]}$ ethylammonium iodide $(\mathrm{EAI}),{ }^{[187]}$ guanidinium hydroiodide (GAI), ${ }^{[188]}$ $\mathrm{NH}_{4} \mathrm{~F}^{[189]}$ Phenylhydrazinium iodide $(\mathrm{PHAI}),{ }^{[190]}$ Phenylethylammonium iodide (PEAI), ${ }^{[67]}$ Naphthalenediammonium $\left(2,3-\mathrm{NDA}^{\mathrm{x}+}\right),^{[191]}$ 5-Ammonium valeric acid iodide $(5-\mathrm{AVAI}),^{[192]} \mathrm{n}$ propylammonium iodide (PAI) and propane-1,3-diammonium iodide $\left(\mathrm{PDAI}_{2}\right)^{[67]}$ have been notably inserted between PVK/HTL interface to passivate defects and to accelerate the carrier transfer to the contact and to reduce the recombination in devices. Among those, $\mathrm{PTABr}$ on $\mathrm{CsPbI}_{3}$ only induces a less than $5 \mathrm{~nm}$ blue shift in UV-vis absorbance, while the gradient of $\mathrm{Br}$ doping on the surface enhances the phase stability and significantly improves the stability of PSCs. ${ }^{[185]}$ Wang et al. ${ }^{[193]}$ reported that choline iodide $(\mathrm{CHI})$ treatment of $\mathrm{CsPb}_{3}$ increases the charge carrier and improves the energy-level alignment of PVK/ETL interface by $120 \mathrm{mV}$. PCE of CHI-modified PSCs reached $18.4 \%$. Zhang et al. ${ }^{[191]}$ introduced the $\pi$-conjugated naphthalenediammonium onto the surface of $\mathrm{CsPbI}_{3} \mathrm{PVK}$ film via 
Cite this paper as: F. Cheng, J. Zhu, Th. Pauporté, Chlorides, other Halides and Pseudohalides as Additives for the Fabrication of Efficient and Stable Perovskite Solar Cells.

ChemSusChem 14 (2021) 3665-3692. DOI: 10.1002/cssc.202101089

anchoring ammonium groups occupying A-site vacancies (Fig. 12D). This strategy largely improved humidity stability of $\mathrm{CsPbI}_{3} \mathrm{PVK}$ film and gave highly reproducible inorganic PSCs with a champion stabilized efficiency of $16.69 \%$ and a $V_{o c}$ of $1.08 \mathrm{~V}$. Zheng et al. ${ }^{[194]}$ reported that choline zwitterions, such as L-a-phosphatidylcholine, choline chloride and choline iodide, can effectively passivate ionic defects in hybrid PVK with their negative- and positive-charged components. This defect passivation reduced the open-circuit-voltage deficit of PSCs to $0.39 \mathrm{~V}$, boosted the PCE up to $20.66 \%$ and enhanced the stability of films in ambient conditions. However, the mechanism of passivation effect with organic halide salts is not clear.

For the organic-inorganic hybrid PVK, a thin layer of 2D PVK can be formed on top of 3D PVK after post-treatment with an isopropyl alcohol (IPA) solution containing bulky organic cations ammonium. In this case, IPA partly dissolves the organic cation and favors the generation of a surface layer. ${ }^{[67]}$ This layer improves the interface between the PVK and the HTL. PEAI has attracted much attention for the passivation of the PVK grain boundaries and surfaces in several studies. ${ }^{[67,195]}$ You et al. ${ }^{[37]}$ found that PEAI itself can effectively passivate the PVK defects and therefore improves the efficiency of the devices. PEAI can also form a $(\mathrm{PEA})_{2} \mathrm{PbI}_{4} 2 \mathrm{D} \mathrm{PVK}$ layer after reaction with $\mathrm{I}$ and $\mathrm{Pb}$ sources. ${ }^{[156]}$ Pauporté et al. ${ }^{[67]}$ employed PEAI to treat $\mathrm{FA}_{0.94} \mathrm{MA}_{0.06} \mathrm{PbI}_{3}$ PVK layers. They showed that this treatment, without any thermal annealing, leads to the spontaneous formation of a crystallized ( $\mathrm{PEA})_{2} \mathrm{PbI}_{4} 2 \mathrm{D} \mathrm{PVK}$ nanolayer at the PVK film surface due to partial organic cation dissolution. It favored a fast transfer of photogenerated holes toward the HTL and reduced the recombination at and near the PVK/HTL interface in PSCs. The solar cell PCE was improved from $20.4 \%$ to $22.2 \%$ and the hysteresis became negligible. However, the reaction of PEAI seems to depend on the type of PVK. Actually, Wang et al ${ }^{[179]}$ demonstrated that $\mathrm{CsPbI}_{3}$ could not cation exchange with PEAI to form 2D PVK layer, the PEAI on the $\mathrm{CsPbI}_{3}$ layer just formed a surface termination layer (Fig. 12E), which enhanced phase stability and moisture resistance (Fig. 12F). Li et al. ${ }^{[197]}$ investigated the surface treatment of methylammonium-free PVK layers by PAI and propane-1,3-diammonium (PDA) iodide. They observed a boosting of the PCE and an improvement of the solar cell stability for both treatments compared to the untreated PVK layer. Exceptional thermal and humidity stabilities were attained with PDA.

Hybrid 3D/2D PVKs possess longer carrier lifetimes and lower defect densities. ${ }^{[198,199]}$ Chen et al. ${ }^{[192]}$ prepared a versatile ultrathin $2 \mathrm{D}$ PVK (5-AVA) $)_{2} \mathrm{PbI}_{4}$ layer by spin-coating 5-AVAI solution on the 
Cite this paper as: F. Cheng, J. Zhu, Th. Pauporté, Chlorides, other Halides and Pseudohalides as Additives for the Fabrication of Efficient and Stable Perovskite Solar Cells.

ChemSusChem 14 (2021) 3665-3692. DOI: 10.1002/cssc.202101089

$\left(\mathrm{FAPbI}_{3}\right)_{0.88}\left(\mathrm{CsPbr}_{3}\right)_{0.12}$, which suppressed ion migration and improved interfacial charge extraction efficiency. Meanwhile, 5-AVA-modified devices showed enhanced moisture stability and photostability due to the excellent moisture stability of hydrophobic nature of interfacial 2D layer. So far, many ammonium halide salts such as n-hexyl trimethyl ammoniumbromide, ${ }^{[200]} \mathrm{n}$-hexylammonium bromide, ${ }^{[201]}$ cyclopropylammonium iodide, ${ }^{[202]}$ alkyl ammonium bromides, ${ }^{[203]}$ diethylenetriamine ${ }^{[204]}$ have been employed to construct 2D PVK layer between PVK and HTL interface for improving performances of PSCs.

\subsection{HTL surface engineering}

HTLs play a key role in extracting and transporting the holes in the photoconversion process of PSCs. Among a variety of HTMs, organic poly(bis(4-phenyl)-(2,4,6-trimethylphenyl)amine) (PTAA), 2,2',7,7'-tetrakis(N,N-di(4-methoxyphenyl)amino)-9,9'-spirobifluorene (Spiro-MeOTAD) and inorganic $\mathrm{NiO}_{\mathrm{x}}, \mathrm{CuSCN}$ are the most common. In order to achieve high performance of PSCs, considerable efforts, i.e. additives, interface treatment, new materials have been successfully made to enhance energy alignment at HTL interface, thermal/photochemical stability, hole mobility and electrical conductivity of HTLs.

Modified HTLs materials with organo-halogen molecular doping is an efficient strategy to increase the performances of PSCs. Chen et al. ${ }^{[205]}$ reported a doping approach to tailor the optoelectronic properties of HTL by spin-coating an acetonitrile solution of 2,2'-(perfluoronaphthalene-2,6diylidene)dimalononitrile (F6TCNNQ) onto the $\mathrm{NiO}_{x}$. The F6TCNNQ doping increased Fermi level of $\mathrm{NiO}_{\mathrm{x}}$ HTLs from $-4.63 \mathrm{eV}$ to $-5.07 \mathrm{eV}$, and reduced the valence band maximum from $0.58 \mathrm{eV}$ to 0.29 $\mathrm{eV}$, leading to an increase in champion PCE of CsFAMA mixed cations and $\mathrm{MAPbI}_{3}$-based devices to $20.86 \%$ and $19.75 \%$, respectively. Alkali halide were introduced as interlayer between HTL/PVK to manipulate the properties of PVK and improve the performance of inverted PSCs. Chen et al. ${ }^{[206]}$ reported a facial strategy for suppressing interfacial recombination by alkali chloride interface modification of $\mathrm{NiO}_{\mathrm{x}}$ HTL surface. They revealed that alkali chloride interface modification results in improved properties of CSFAMA-based PVK and reduced interfacial recombination owing to the interface contact healing by halide elements. Finally, this KCl-doping strategy led to a significant improvement in the $V_{o c}$ from $1.07 \mathrm{eV}$ for pristine $\mathrm{NiO}_{\mathrm{x}}$ to $1.15 \mathrm{eV}$ for $\mathrm{KCl}$-treated $\mathrm{NiO}_{\mathrm{x}}$, resulting in a 
Cite this paper as: F. Cheng, J. Zhu, Th. Pauporté, Chlorides, other Halides and Pseudohalides as Additives for the Fabrication of Efficient and Stable Perovskite Solar Cells.

ChemSusChem 14 (2021) 3665-3692. DOI: 10.1002/cssc.202101089

power conversion efficiency approaching $21 \%$. Moreover, the PVK deposited on the alkali halide modified $\mathrm{NiO}_{\mathrm{x}}$ layer exhibited lower rates of ion migration, showing improved device stability.

In conclusion, we have shown that halides compounds are also employed at the interface of ETL/PVK and PVK/HTL, suppressing the defects of ETL and PVK, improving the charge transfer and reducing the charge recombination. Meanwhile, modification of interfaces of PSCs improves the PVK crystallinity, energy-level alignment and the stabilization of the PSCs against UV-light, humidity and oxygen degrading agents.

\section{Conclusion and Outlook}

PSCs have attracted special attentions due to their excellent power conversion efficiency, low cost and great promise for the future of solar energy. The best PSC has already achieved a certified PCE of $25.5 \%$ after an unprecedented rapid performance rise. However, high requirement with respect to large area high efficiency devices and stability are still the challenge and focuses major efforts on the PSC research. The primary requirement to achieve high efficiency and stable devices is to understand in great depth the optoelectronic loss mechanism for the devices and the degradation mechanism of individual layers in PSCs. Although various mechanisms still need to be explored, the bulk and surface trap states and large numbers of grain boundaries are the main reasons reported up to now affecting the performances of PSCs. To overcome the bulk and surface trap states, one of the ways is additive/ compositional engineering in the PVK bulk. On the other hand, interfacial modifications to form proper capping/buffer layer or charge transport layer are considered as effective strategies to improve stability and efficiency of PSCs.

Herein, we have given an in-depth review of the various strategies and halide/pseudo-halide compounds employed as additives for films and interfaces quality improvements. If many experimental works have been implemented and analyzed throughout the paper, the exact role of these additive should be rationalized. Developing modelling and theoretical works could help the understanding.

Halide additives-engineered PVKs have been proved as an effective approach to passivate the defects in the PVK bulk and interfaces, reducing energy loss and improving the performance of PSCs. However, complete understanding of passivation mechanism and PVK crystallization process has yet to be totally resolved, due to the limited characterization technique for the defect types and density in different PVK 
Cite this paper as: F. Cheng, J. Zhu, Th. Pauporté, Chlorides, other Halides and Pseudohalides as Additives for the Fabrication of Efficient and Stable Perovskite Solar Cells.

ChemSusChem 14 (2021) 3665-3692. DOI: 10.1002/cssc.202101089

materials. It renders difficult to guide the design of efficient additives and achieve universal efficient passivation strategy. Thus, a further understanding of passivation mechanism through characterizing the traps types and concentration at the PVK surface and grain boundaries, as well as revealing the role of additives on the PVK crystallization process will be crucial for highly efficient and stable PSCs. New techniques to understand the crystallization mechanism and growth direction of the crystals in the layer must be developed. Developing double (or more) mixed halide additive is of high interest and must be developed to achieve multiple and synergistic beneficial effects (phase purity, better crystallinity, grain boundaries reduction, defect passivation, monolithic morphology ...).

Concerning the PVK surface treatment by halide compounds, it will be necessary to better control the properties of the produced interfacial layers including their thickness and their chemical composition. An in-depth understanding of why the treatment with a halide compound is beneficial with a PVK and not with another is required and give an important research direction for future works. Halide additives in charge carrier layers have mainly been used in inorganic materials. A further understanding if their effects are bulk or near-interface related is still necessary and give another important research direction for the future. For the testing of the device stability, standardized aging tests should be implemented on the perovskites and devices implementing halide/pseudo-halide additives. The objective should be to meet stability standards of IEC61215:2016 qualification tests, for instance, a target that would necessitate to encapsulate tightly and efficiently the solar cells.

\section{Acknowledgements}

Dr. Jie Zhang acknowledges the program for the Guangdong Basic and Applied Basic Research Foundation (2020A1515010378), the Science and Technology Program of Guangzhou (201804010176), the Fundamental Research Funds for the Central Universities (2019MS049) and the NSFC (21703070) for financial support. Prof. Thierry Pauporté acknowledges the French research Agency (ANR) for financial support via the Moreless project ANR-18-CE05-0026.

\section{References:}

[1] J. H. Im, C. R. Lee, J. W. Lee, S. W. Park, N. G. Park, Nanoscale 2011, 3, 4088-4093. 
Cite this paper as: F. Cheng, J. Zhu, Th. Pauporté, Chlorides, other Halides and Pseudohalides as Additives for the Fabrication of Efficient and Stable Perovskite Solar Cells.

ChemSusChem 14 (2021) 3665-3692. DOI: 10.1002/cssc.202101089

[2] H. P. Zhou, Q. Chen, G. Li, S. Luo, T. B. Song, H. S. Duan, Z. R. Hong, J. B. You, Y. S. Liu, Y. Yang, Science 2014, 345, 542-546.

[3] A. Mei, X. Li, L. Liu, Z. Ku, T. Liu, Y. Rong, M. Xu, M. Hu, J. Chen, Y. Yang, M. Graetzel, H. Han, Science 2014, 345, 295-298.

[4] W.-J. Yin, J.-H. Yang, J. Kang, Y. Yan, S.-H. Wei, J. Mater. Chem. A 2015, 3, 8926-8942.

[5] N.-G. Park, Mater. Today 2015, 18, 65-72.

[6] M. A. Green, A. Ho-Baillie, H. J. Snaith, Nat. Photonics 2014, 8, 506-514.

[7] W. J. Yin, T. Shi, Y. Yan, Adv. Mater. 2014, 26, 4653-4658.

[8] C. C. Stoumpos, C. D. Malliakas, M. G. Kanatzidis, Inorg. Chem. 2013, 52, 9019-9038.

[9] S. D. Stranks, G. E. Eperon, G. Grancini, C. Menelaou, M. J. P. Alcocer, T. Leijtens, L. M. Herz, A. Petrozza, H. J. Snaith, Science 2013, 342, 341-344.

[10] R. J. Sutton, G. E. Eperon, L. Miranda, E. S. Parrott, B. A. Kamino, J. B. Patel, M. T. Hrantner, M. B. Johnston, A. A. Haghighirad, D. T. Moore, Adv. Energy Mater. 2016, 6, 1502458.

[11] J. Zhang, P. Barboux, T. Pauporté, Adv. Energy Mater. 2014, 4, 1400932.

[12] J. Zhang, E. J. Juárez-Pérez, I. Mora-Seró, B. Viana, T. Pauporté, J. Mater. Chem. A 2015, 3, 4909-4915.

[13] J. Zhang, T. Pauporté, J. Phys. Chem. C 2015, 119, 14919-14928.

[14] M. Ulfa, P. Wang, J. Zhang, J. Liu, W. D. de Marcillac, L. Coolen, S. Peralta, T. Pauporté, ACS Appl. Mater. Inter. 2018, 10, 35118-35128.

[15] J. Qian, M. Ernst, N. Wu, A. Blakers, Sustainable Energy Fuels 2019, 3, 1439-1447.

[16] P. Roy, N. K. Sinha, S. Tiwari, A. Khare, Solar Energy 2020, 198, 665-688.

[17] B. Li, D. Binks, G. Cao, J. Tian, Small 2019, 15, 1903613.

[18] D. Zheng, T. Zhu, T. Pauporté, ACS Appl. Energy Mater. 2020, 3, 10349-10361.

[19] M. Ulfa, P. Wang, Z. Shao, B. Viana, T. Pauporte, in Oxide-Based Materials And Devices Ix, Vol. 10533 (Eds: D. J. Rogers, D. C. Look, F. H. Teherani) 2018.

[20] P.J. Wang, Z.P. Shao, M. Ulfa, T. Pauporté, J. Phys. Chem. C, 2017, 121, 9131-9141.

[21] M. Ulfa, T. Zhu, F. Goubard, T. Pauporté, J. Mater. Chem. A 2018, 6, 13350-13358.

[22] M. Ulfa, T. Pauporté, B. Thanh-Tuan, F. Goubard, J. Phys. Chem. C 2018, 122, 11651-11658.

[23] L. Gollino, T. Pauporté, Solar RRL 2021, 5, 2000616. 
Cite this paper as: F. Cheng, J. Zhu, Th. Pauporté, Chlorides, other Halides and Pseudohalides as Additives for the Fabrication of Efficient and Stable Perovskite Solar Cells.

ChemSusChem 14 (2021) 3665-3692. DOI: 10.1002/cssc.202101089

[24] https://www.nrel.gov/pv/cell-efficiency.html., accessed May $23^{\text {rd }}, 2021$.

[25] S. Ruhle, Solar Energy 2016, 130, 139-147.

[26] N. G. Park, H. Segawa, ACS Photonics 2018, 5.

[27] C. Ma, N. G. Park, Chem 2020, 6, 1254-1264.

[28] M. Stolterfoht, C. M. Wolff, Y. Amir, A. Paulke, L. Perdigon-Toro, P. Caprioglio, D. Neher, Energy Environ. Sci. 2017, 10, 1530-1539.

[29] Z. Ni, C. Bao, Y. Liu, Q. Jiang, W.-Q. Wu, S. Chen, X. Dai, B. Chen, B. Hartweg, Z. Yu, Z. Holman, J. Huang, Science 2020, 367, 1352-1358.

[30] Q. Fu, X. Tang, B. Huang, T. Hu, L. Tan, L. Chen, Y. Chen, Adv. Sci. 2018, 5, 1700387;

[31] F. Bella, G. Griffini, J.-P. Correa-Baena, G. Saracco, M. Gratzel, A. Hagfeldt, S. Turri, C. Gerbaldi, Science 2016, 354, 203-206.

[32] A. Mahapatra, D. Prochowicz, M. M. Tavakoli, S. Trivedi, P. Kumar, P. Yadav, J. Mater. Chem. $A$ 2020, 8, 27-54.

[33] K. O. Kosmatos, L. Theofylaktos, E. Giannakaki, D. Deligiannis, T. Stergiopoulos, Energy Environ. Mater. 2019, 2, 79-92.

[34] S. Liu, Y. Guan, Y. Sheng, Y. Hu, H. Han, Adv. Energy Mater. 2019, 10, 1902492.

[35] S. Ghosh, T. Singh, Nano Energy 2019, 63, 103828.

[36] T. Zhu, D. Zheng, M.-N. Rager, T. Pauporté, Solar RRL 2020, 4, 2000348.

[37] Q. Jiang, Y. Zhao, X. Zhang, X. Yang, Y. Chen, Z. Chu, Q. Ye, X. Li, Z. Yin, J. You, Nat. Photonics 2019, 13, 460-466.

[38] M. Kim, G.-H. Kim, T. K. Lee, I. W. Choi, H. W. Choi, Y. Jo, Y. J. Yoon, J. W. Kim, J. Lee, D. Huh, H. Lee, S. K. Kwak, J. Y. Kim, D. S. Kim, Joule 2019, 3, 2179-2192.

[39] G. Kim, H. Min, K. S. Lee, D. Y. Lee, S. I. Seok, Science 2020, 370, 108-112.

[40] M. Lyu, N. G. Park, Solar RRL 2020, 4, 2000331.

[41] Q. Chen, C. R. Jack, D. Wang, Z. Mokhtar, Z. Liu, Appl. Surf. Sci. 2020, 536, 147949.

[42] S. You, X. Xi, X. Zhang, H. Wang, P. Gao, X. Ma, S. Bi, J. Zhang, H. Zhou, Z. Wei, J. Mater. Chem. A 2020, 8, 17756-17764;

[43] N. Pant, A. Kulkarni, M. Yanagida, Y. Shirai, T. Miyasaka, K. Miyano, Adv. Mater. Inter. 2020, 7, 1901748; 
Cite this paper as: F. Cheng, J. Zhu, Th. Pauporté, Chlorides, other Halides and Pseudohalides as Additives for the Fabrication of Efficient and Stable Perovskite Solar Cells.

ChemSusChem 14 (2021) 3665-3692. DOI: 10.1002/cssc.202101089

[44] P. Singh, P. J. S. Rana, P. Dhingra, P. Kar, J. Mater. Chem. C 2016, 4, 3101-3105;

[45] C. Mu, J. Pan, S. Feng, Q. Li, D. Xu, Adv. Energy Mater. 2016, 7, 1601297.

[46] H.-S. Kim, C.-R. Lee, J.-H. Im, K.-B. Lee, T. Moehl, A. Marchioro, S.-J. Moon, R. HumphryBaker, J.-H. Yum, J. E. Moser, M. Graetzel, N.-G. Park, Scientific reports 2012, 2, 591.

[47] J. M. Ball, M. M. Lee, A. Hey, H. J. Snaith, Energy Environ. Sci. 2013, 6, 1739-1743.

[48] W. Zhang, S. Pathak, N. Sakai, T. Stergiopoulos, P. K. Nayak, N. K. Noel, A. A. Haghighirad, V. M. Burlakov, D. W. deQuilettes, A. Sadhanala, W. Li, L. Wang, D. S. Ginger, R. H. Friend, H. J. Snaith, Nat. Commun. 2015, 6, 10030.

[49] J. Xu, C. C. Boyd, Z. J. Yu, A. F. Palmstrom, D. J. Witter, B. W. Larson, R. M. France, J. Werner, S. P. Harvey, E. J. Wolf, W. Weigand, S. Manzoor, M. F. A. M. van Hest, J. J. Berry, J. M. Luther, Z. C. Holman, M. D. McGehee, Science 2020, 367, 1097-1104.

[50] D. Zheng, T. Zhu, T. Pauporté, Solar RRL 2021, DOI : 10.1002/solr.202100010.

[51] M. M. Lee, J. Teuscher, T. Miyasaka, T. N. Murakami, H. J. Snaith, Science 2012, 338, 643-647.

[52] P. Ngoc Duy, V. T. Tiong, P. Chen, L. Wang, G. J. Wilson, J. Bell, H. Wang, J. Mater. Chem. A 2017, 5, 5195-5203.

[53] X. Cao, L. Zhi, Y. Jia, Y. Li, K. Zhao, X. Cui, L. Ci, K. Ding, J. Wei, Electrochim. Acta 2018, $275,1-7$.

[54] K. M. Boopathi, R. Mohan, T.-Y. Huang, W. Budiawan, M.-Y. Lin, C.-H. Lee, K.-C. Ho, C.-W. Chu, J. Mater. Chem. A 2016, 4, 1591-1597.

[55] M. Murata, T. Oizumi, M. Gi, R. Tsuji, M. Arita, A. Fujii, M. Ozaki, Sol. Energy Mater. Sol. Cells 2020, 208, 110409.

[56] B. Zong, W. Fu, Z.-a. Guo, S. Wang, L. Huang, B. Zhang, H. Bala, J. Cao, X. Wang, G. Sun, Z. Zhang, J. Colloid Interface Sci. 2019, 540, 315-321.

[57] D. Zheng, C. Tong, T. Zhu, Y. Rong, T. Pauporte, Nanomaterials 2020, 10, 2512.

[58] F. X. Xie, H. Su, J. Mao, K. S. Wong, W. C. H. Choy, J. Phys. Chem. C 2016, 120, 21248-21253.

[59] Z. Li, C. Kolodziej, C. McCleese, L. Wang, A. Kovalsky, A. C. Samia, Y. Zhao, C. Burda, Nanoscale Adv. 2019, 1, 827-833.

[60] L. Mao, C. C. Stoumpos, M. G. Kanatzidis, J. Am. Chem. Soc. 2019, 141, 1171-1190;

[61] Y. Fu, H. Zhu, J. Chen, M. P. Hautzinger, X. Y. Zhu, S. Jin, Nat. Rev. Mater. 2019, 4, 169-188; 
Cite this paper as: F. Cheng, J. Zhu, Th. Pauporté, Chlorides, other Halides and Pseudohalides as Additives for the Fabrication of Efficient and Stable Perovskite Solar Cells.

ChemSusChem 14 (2021) 3665-3692. DOI: 10.1002/cssc.202101089

[62] H. Tsai, W. Nie, J.-C. Blancon, C. C. S. Toumpos, R. Asadpour, B. Harutyunyan, A. J. Neukirch, R. Verduzco, J. J. Crochet, S. Tretiak, L. Pedesseau, J. Even, M. A. Alam, G. Gupta, J. Lou, P. M. Ajayan, M. J. Bedzyk, M. G. Kanatzidis, A. D. Mohite, Nature 2016, 536, 312-316;

[63] X. Zhang, R. Munir, Z. Xu, Y. Liu, H. Tsai, W. Nie, J. Li, T. Niu, D.-M. Smilgies, M. G. Kanatzidis, A. D. Mohite, K. Zhao, A. Amassian, S. Liu, Adv. Mater. 2018, 30, 1707166.

[64] T. Luo, Y. Zhang, Z. Xu, T. Niu, J. Wen, J. Lu, S. Jin, S. Liu, K. Zhao, Adv. Mater. 2019, 31, 1903848.

[65] Y. Wang, W. Li, T. Zhang, D. Li, M. Kan, X. Wang, X. Liu, T. Wang, Y. Zhao, Small Methods 2020, 4, 1900511.

[66] M. M. Tavakoli, M. Saliba, P. Yadav, P. Holzhey, A. Hagfeldt, S. M. Zakeeruddin, M. Graetzel, Adv. Energy Mater. 2019, 9, 1802646.

[67] T. Zhu, D. Zheng, J. Liu, L. Coolen, T. Pauporte, ACS Appl. Mater. Inter. 2020, 12, 37197-37207.

[68] G. M. Kim, A. Ishii, S. Oz, T. Miyasaka, Adv. Energy Mater. 2020, 10, 1903299.

[69] M. M. Tavakoli, P. Yadav, D. Prochowicz, M. Sponseller, A. Osherov, V. Bulović, J. Kong, Adv. Energy Mater. 2019, 9, 1803587.

[70] A. Suzuki, M. Kato, N. Ueoka, T. Oku, J. Electron. Mater. 2019, 48, 3900-3907.

[71] Y. Wu, X. Li, S. Fu, L. Wan, J. Fang, J. Mater. Chem. A. 2019, 7, 8078-8084

[72] H. Min, M. Kim, S.-U. Lee, H. Kim, G. Kim, K. Choi, J. H. Lee, S. I. Seok, Science 2019, 366, 749-753.

[73] M. I. Dar, N. Arora, P. Gao, S. Ahmad, M. Graetzel, M. K. Nazeeruddin, Nano Lett. 2014, 14, 6991-6996.

[74] B. Yang, J. Keum, O. S. Ovchinnikova, A. Belianinov, S. Chen, M.-H. Du, I. N. Ivanov, C. M. Rouleau, D. B. Geohegan, K. Xiao, J. Am. Chem. Soc. 2016, 138, 5028-5035.

[75] M. Mateen, Z. Arain, Y. Yang, X. Liu, S. Ma, C. Liu, Y. Ding, X. Ding, M. Cai, S. Dai, ACS Appl. Mater. Inter. 2020, 12, 10535-10543.

[76] H. Chen, Y. Xia, B. Wu, F. Liu, T. Niu, L. Chao, G. Xing, T. Sum, Y. Chen, W. Huang, Nano Energy 2019, 56, 373-381.

[77] L. Cojocaru, S. Uchida, A. K. Jena, T. Miyasaka, J. Nakazaki, T. Kubo, H. Segawa, Chem. Lett. 2015, 44, 1089-1091. 
Cite this paper as: F. Cheng, J. Zhu, Th. Pauporté, Chlorides, other Halides and Pseudohalides as Additives for the Fabrication of Efficient and Stable Perovskite Solar Cells.

ChemSusChem 14 (2021) 3665-3692. DOI: 10.1002/cssc.202101089

[78] S. Colella, E. Mosconi, P. Fedeli, A. Listorti, F. Gazza, F. Orlandi, P. Ferro, T. Besagni, A. Rizzo, G. Calestani, G. Gigli, F. De Angelis, R. Mosca, Chem. Mater. 2013, 25, 4613-4618.

[79] F. Xie, C. C. Chen, Y. Wu, X. Li, M. Cai, X. Liu, X. Yang, L. Han, Energy Environ. Sci. 2017, 10, 1942-1949;

[80] T. Leijtens, R. Prasanna, K. A. Bush, G. E. Eperon, J. A. Raiford, A. Gold-Parker, E. J. Wolf, S. A. Swifter, C. C. Boyd, H.-P. Wang, M. F. Toney, S. F. Bent, M. D. McGehee, Sustainable Energy Fuels 2018, 2, 2450-2459;

[81] B. Chen, Z. Yu, K. Liu, X. Zheng, Y. Liu, J. Shi, D. Spronk, P. N. Rudd, Z. Holman, J. Huang, Joule 2019, 3, 177-190.

[82] J. Jin, H. Li, C. Chen, B. Zhang, L. Xu, B. Dong, H. Song, Q. Dai, ACS Appl. Mater. Inter. 2017, 9, 42875-42882.

[83] C.-M. Tsai, H.-P. Wu, S.-T. Chang, C.-F. Huang, C.-H. Wang, S. Narra, Y.-W. Yang, C.-L. Wang, C.-H. Hung, E. W.-G. Diau, ACS Energy Lett. 2016, 1, 1086-1093.

[84] N. Ali, X. Wang, S. Rauf, S. Attique, A. Khesro, S. Ali, N. Mushtaq, H. Xiao, C. P. Yang, H. Wu, Solar Energy 2019, 189, 325-332.

[85] D. Ma, P. Todorovic, S. Meshkat, M. I. Saidaminov, Y.-K. Wang, B. Chen, P. Li, B. Scheffel, R. Quintero-Bermudez, J. Z. Fan, Y. Dong, B. Sun, C. Xu, C. Zhou, Y. Hou, X. Li, Y. Kang, O. Voznyy, Z.-H. Lu, D. Ban, E. H. Sargent, J. Am. Chem. Soc. 2020, 142, 5126-5134;

[86] Q. Wang, X. Wang, Z. Yang, N. Zhou, Y. Deng, J. Zhao, X. Xiao, P. Rudd, A. Moran, Y. Yan, J. Huang, Nat. Commun. 2019, 10, 5633.

[87] Y. Wu, X. Li, S. Fu, L. Wan, J. Fang, J. Mater. Chem. A 2019, 7, 8078-8084.

[88] X. Dai, Y. Deng, C. H. Van Brackle, S. Chen, P. N. Rudd, X. Xiao, Y. Lin, B. Chen, J. Huang, Adv. Energy Mater. 2020, 10, 1903108.

[89] B. Lee, T. Hwang, S. Lee, B. Shin, B. Park, Scientific reports 2019, 9, 4803.

[90] K. Yan, M. Long, T. Zhang, Z. Wei, H. Chen, S. Yang, J. Xu, J. Am. Chem. Soc. 2015, 137, $4460-4468$.

[91] G. E. Eperon, S. D. Stranks, C. Menelaou, M. B. Johnston, L. M. Herz, H. J. Snaith, Energy Environ. Sci. 2014, 7, 982-988.

[92] D. P. McMeekin, Z. Wang, W. Rehman, F. Pulvirenti, J. B. Patel, N. K. Noel, M. B. Johnston, 
Cite this paper as: F. Cheng, J. Zhu, Th. Pauporté, Chlorides, other Halides and Pseudohalides as Additives for the Fabrication of Efficient and Stable Perovskite Solar Cells.

ChemSusChem 14 (2021) 3665-3692. DOI: 10.1002/cssc.202101089

S. R. Marder, L. M. Herz, H. J. Snaith, Adv. Mater. 2017, 29, 1607039.

[93] J. H. Heo, D. H. Song, S. H. Im, Adv. Mater. 2014, 26, 8179-8183.

[94] F. Wang, H. Yu, H. Xu, N. Zhao, Adv. Funct. Mater. 2015, 25, 1120-1126.

[95] S. Pang, Y. Zhou, Z. Wang, M. Yang, A. R. Krause, Z. Zhou, K. Zhu, N. P. Padture, G. Cui, J. Am. Chem. Soc. 2016, 138, 750-753.

[96] G. E. Eperon, G. M. Paternò, R. J. Sutton, A. Zampetti, A. A. Haghighirad, F. Cacialli, H. J. Snaith, J. Mater. Chem. A 2015, 3, 19688-19695.

[97] S. Xiang, Z. Fu, W. Li, Y. Wei, J. Liu, H. Liu, L. Zhu, R. Zhang, H. Chen, ACS Energy Lett. 2018, 3, 1824-1831.

[98] L. Ma, F. Hao, C. C. Stoumpos, B. T. Phelan, M. R. Wasielewski, M. G. Kanatzidis, J. Am. Chem. Soc. 2016, 138, 14750-14755;

[99] M. H. Kumar, S. Dharani, W. L. Leong, P. P. Boix, R. R. Prabhakar, T. Baikie, C. Shi, H. Ding, R. Ramesh, M. Asta, Adv. Mater. 2014, 26, 7122-7127.

[100] T. Handa, T. Yamada, H. Kubota, S. Ise, Y. Miyamoto, Y. Kanemitsu, J. Phys. Chem. C 2017, $121,16158-16165$.

[101] L. Ma, F. Hao, C.C. Stoumpos, B.T. Phelan, M.R. Wasielewski, M.G. Kanatzidis, J. Am. Chem. Soc. 2016, 138, 14750-14755.

[102] W. Liao, D. Zhao, Y. Yu, C. R. Grice, C. Wang, A. J. Cimaroli, P. Schulz, W. Meng, K. Zhu, R. G. Xiong, Y. Yan, Adv. Mater. 2016, 28, 9333-9340.

[103] S. J. Lee, S. S. Shin, Y. C. Kim, D. Kim, T. K. Ahn, J. H. Noh, J. Seo, S. I. Seok, J. Am. Chem. Soc. 2016, 138, 3974-3977.

[104] S. Yuan, F. Qian, S. Yang, Y. Cai, Q. Wang, J. Sun, Z. Liu, S. Liu, Adv. Funct. Mater. 2019, 29, 1807850.

[105] N. Li, S. Tao, Y. Chen, X. Niu, C. K. Onwudinanti, C. Hu, Z. Qiu, Z. Xu, G. Zheng, L. Wang, Y. Zhang, L. Li, H. Liu, Y. Lun, J. Hong, X. Wang, Y. Liu, H. Xie, Y. Gao, Y. Bai, S. Yang, G. Brocks, Q. Chen, H. Zhou, Nat. Energy 2019, 4, 408-415.

[106] C. Li, Z. Song, D. Zhao, C. Xiao, B. Subedi, N. Shrestha, M. M. Junda, C. Wang, C.-S. Jiang, M. Al-Jassim, R. J. Ellingson, N. J. Podraza, K. Zhu, Y. Yan, Adv. Energy Mater. 2019, 9, 1803135. 
Cite this paper as: F. Cheng, J. Zhu, Th. Pauporté, Chlorides, other Halides and Pseudohalides as Additives for the Fabrication of Efficient and Stable Perovskite Solar Cells.

ChemSusChem 14 (2021) 3665-3692. DOI: 10.1002/cssc.202101089

[107] Y. Ogomi, A. Morita, S. Tsukamoto, T. Saitho, N. Fujikawa, Q. Shen, T. Toyoda, K. Yoshino, S. S. Pandey, T. Ma, S. Hayase, J. Phys. Chem. Lett. 2014, 5, 1004-1011.

[108] J. Wu, F. Fang, Z. Zhao, T. Li, R. Ullah, Z. Lv, Y. Zhou, D. Sawtell, RSC Adv. 2019, 9, 3711937126.

[109] L. Deying, Y. Wenqiang, W. Zhiping, S. Aditya, H. Qin, S. Rui, S. Ravichandran, G. F. Trindade, J. F. Watts, X. Zhaojian, Science 2018, 360, 1442-1446.

[110] A. Aziz, N. Aristidou, X. Bu, R. J. E. Westbrook, S. A. Haque, M. S. Islam, Chem. Mater. 2019, $32,400-409$.

[111] J. H. Noh, S. H. Im, J. H. Heo, T. N. Mandal, S. I. Seok, Nano Lett. 2013, 13, 1764-1769.

[112] J. Huang, S. Xiang, J. Yu, C.-Z. Li, Energy Environ. Sci. 2019, 12, 929-937.

[113] Z. B. Yang, A. Rajagopal, A. K. Y. Jen, Adv. Mater. 2017, 29, 1704418.

[114] G. E. Eperon, H. J. Snaith, M. T. Hrantner, Nat. Rev. Chem. 2017, 1, 0095;

[115] M. Anaya, G. Lozano, M. E. Calvo, H. Míguez, Joule 2017, 1, 769-793.

[116] W. S. Yang, B. W. Park, E. H. Jung, N. J. Jeon, Y. C. Kim, D. U. Lee, S. S. Shin, J. Seo, E. K. Kim, J. H. Noh, Science 2017, 356, 1376-1379.

[117] R. Prasanna, A. Gold-Parker, T. Leijtens, B. Conings, A. Babayigit, H. G. Boyen, M. F. Toney, M. D. Mcgehee, J. Am. Chem. Soc. 2017, 139, 11117-11124.

[118] J. Tong, Z. Song, D. H. Kim, X. Chen, C. Chen, A. F. Palmstrom, P. F. Ndione, M. O. Reese, S. P. Dunfield, O. G. Reid, J. Liu, F. Zhang, S. P. Harvey, Z. Li, S. T. Christensen, G. Teeter, D. Zhao, M. M. Al-Jassim, M. F. A. M. van Hest, M. C. Beard, S. E. Shaheen, J. J. Berry, Y. Yan, K. Zhu, Science 2019, 364, 475-479.

[119] X. Zhou, L. Zhang, X. Wang, C. Liu, S. Chen, M. Zhang, X. Li, W. Yi, B. Xu, Adv. Mater. 2020, 32, 1908107.

[120] F. Zhang, D. Bi, N. Pellet, C. Xiao, Z. Li, J. J. Berry, S. M. Zakeeruddin, K. Zhu, M. Grätzel, Energy Environ. Sci. 2018, 11, 3480-3490.

[121] F. Zhang, H. Lu, J. Tong, J. J. Berry, M. C. Beard, K. Zhu, Energy Environ. Sci. 2020, 13, 11541186.

[122] G. Grancini, C. Roldán-Carmona, I. Zimmermann, E. Mosconi, X. Lee, D. Martineau, S. Narbey, F. Oswald, F. De Angelis, M. Graetzel, M. K. Nazeeruddin, Nat. Commun. 2017, 8, 15684; 
Cite this paper as: F. Cheng, J. Zhu, Th. Pauporté, Chlorides, other Halides and Pseudohalides as Additives for the Fabrication of Efficient and Stable Perovskite Solar Cells.

ChemSusChem 14 (2021) 3665-3692. DOI: 10.1002/cssc.202101089

[123] M. Xu, W. Ji, Y. Sheng, Y. Wu, H. Han, Nano Energy 2020, 74, 104842.

[124] A. Mei, Y. Sheng, Y. Ming, Y. Hu, Y. Rong, W. Zhang, S. Luo, G. Na, C. Tian, X. Hou, Y. Xiong, Z. Zhang, S. Liu, S. Uchida, T.-W. Kim, Y. Yuan, L. Zhang, Y. Zhou, H. Han, Joule 2020, 4, 2646-2660.

[125] Y. Hu, Z. Zhang, A. Mei, Y. Jiang, X. Hou, Q. Wang, K. Du, Y. Rong, Y. Zhou, G. Xu, H. Han, Adv. Mater. 2018, 30, 1705786.

[126] W. S. Yang, B. W. Park, E. H. Jung, N. J. Jeon, Y. C. Kim, D. U. Lee, S. S. Shin, J. Seo, E. K. Kim, J. H. Noh, Science 2017, 356, 1376-1379.

[127] Y. C. Kim, N. J. Jeon, J. H. Noh, W. S. Yang, J. Seo, J. S. Yun, A. Ho-Baillie, S. Huang, M. A. Green, J. Seidel, T. K. Ahn, S. I. Seok, Adv. Energy Mater. 2016, 6, 1502104.

[128] T. Supasai, N. Rujisamphan, K. Ullrich, A. Chemseddine, T. Dittrich, Appl. Phys. Lett. 2013, 103, 183906.

[129] A. Calloni, A. Abate, G. Bussetti, G. Berti, R. Yivlialin, F. Ciccacci, L. Duò, J. Phys. Chem. C 2015;

[130] Q. Chen, H. Zhou, T. B. Song, S. Luo, Z. Hong, H. S. Duan, L. Dou, Y. Liu, Y. Yang, Nano Lett. 2014, $14,4158-4163$.

[131] L. Wang, C. McCleese, A. Kovalsky, Y. Zhao, C. Burda, J. Am. Chem. Soc. 2014, 136, 1220512208.

[132] T. Zhang, N. Guo, G. Li, X. Qian, Y. Zhao, Nano Energy 2016, 26, 50-56.

[133] C. Roldán-Carmona, P. Gratia, I. Zimmermann, G. Grancini, P. Gao, M. Graetzel, M. K. Nazeeruddin, Energy Environ. Sci. 2015, 8, 3550-3556;

[134] F. Jiang, Y. Rong, H. Liu, T. Liu, L. Mao, W. Meng, F. Qin, Y. Jiang, B. Luo, S. Xiong, J. Tong, Y. Liu, Z. Li, H. Han, Y. Zhou, Adv. Funct. Mater. 2016, 26, 8119-8127.

[135] E. J. Juarez-Perez, L. K. Ono, M. Maeda, Y. Jiang, Z. Hawash, Y. Qi, J. Mater. Chem. A 2018, 6, 9604-9612.

[136] M. Abdi-Jalebi, Z. Andaji-Garmaroudi, S. Cacovich, C. Stavrakas, B. Philippe, J. M. Richter, M. Alsari, E. P. Booker, E. M. Hutter, A. J. Pearson, S. Lilliu, T. J. Savenije, H. Rensmo, G. Divitini, C. Ducati, R. H. Friend, S. D. Stranks, Nature 2018, 555, 497-501.

[137] D. Y. Son, S. G. Kim, J. Y. Seo, S. H. Lee, H. Shin, D. Lee, N. G. Park, J. Am. Chem. Soc. 2018, 
Cite this paper as: F. Cheng, J. Zhu, Th. Pauporté, Chlorides, other Halides and Pseudohalides as Additives for the Fabrication of Efficient and Stable Perovskite Solar Cells.

ChemSusChem 14 (2021) 3665-3692. DOI: 10.1002/cssc.202101089

140, 1358-1364.

[138] Y. H. Lee, J. Luo, R. Humphry-Baker, P. Gao, M. Grätzel, M. K. Nazeeruddin, Adv. Funct. Mater. 2015, 25, 3925-3933;

[139] D. Bi, A. M. El-Zohry, A. Hagfeldt, G. Boschloo, Acs Photonics 2015, 2, 589-594.

[140] F. Liu, Q. Dong, M. K. Wong, A. B. Djurišić, A. Ng, Z. Ren, Q. Shen, C. Surya, W. K. Chan, J. Wang, A. M. C. Ng, C. Liao, H. Li, K. Shih, C. Wei, H. Su, J. Dai, Adv. Energy Mater. 2016, 6, 1502206.

[141] G. Tumen-Ulzii, C. Qin, D. Klotz, M. R. Leyden, P. Wang, M. Auffray, T. Fujihara, T. Matsushima, J. W. Lee, S. J. Lee, Y. Yang, C. Adachi, Adv. Mater. 2020, 32, 1905035.

[142] Z. Tang, T. Bessho, F. Awai, T. Kinoshita, M. M. Maitani, R. Jono, T. N. Murakami, H. Wang, T. Kubo, S. Uchida, H. Segawa, Scientific reports 2017, 7, 12183.

[143] J. Cao, S. X. Tao, P. A. Bobbert, C. P. Wong, N. Zhao, Adv. Mater. 2018, 30, 1707350.

[144] M. Abdi-Jalebi, M. I. Dar, A. Sadhanala, S. P. Senanayak, M. Franckevičius, N. Arora, Y. Hu, M. K. Nazeeruddin, S. M. Zakeeruddin, M. Grätzel, R. H. Friend, Adv. Energy Mater. 2016, 6, 1502472.

[145] J.-P. Correa-Baena, Science 2019.

[146] A. Halder, R. Chulliyil, A. S. Subbiah, T. Khan, S. Chattoraj, A. Chowdhury, S. K. Sarkar, J. Phys. Chem. Lett. 2015, 6, 3483-3489;

[147] Y. Yu, C. Wang, C. R. Grice, N. Shrestha, J. Chen, D. Zhao, W. Liao, A. J. Cimaroli, P. J. Roland, R. J. Ellingson, Y. Yan, Chemsuschem 2016, 9, 3288-3297;

[148] B. Walker, G. H. Kim, J. Y. Kim, Adv. Mater. 2019, 31, 1807029.

[149] C. Wang, D. Zhao, Y. Yu, N. Shrestha, C. R. Grice, W. Liao, A. J. Cimaroli, J. Chen, R. J. Ellingson, X. Zhao, Y. Yan, Nano Energy 2017, 35, 223-232.

[150] Y. Chen, B. Li, W. Huang, D. Gao, Z. Liang, Chem. Commun. 2015, 51, 11997-11999.

[151] Y. Zhou, Y.-H. Jia, H.-H. Fang, M. A. Loi, F.-Y. Xie, L. Gong, M.-C. Qin, X.-H. Lu, C.-P. Wong, N. Zhao, Adv. Funct. Mater. 2018, 28, 1803130.

[152] Y. Yu, C. Wang, C. R. Grice, N. Shrestha, D. Zhao, W. Liao, L. Guan, R. A. Awni, W. Meng, A. J. Cimaroli, K. Zhu, R. J. Ellingson, Y. Yan, ACS Energy Lett. 2017, 2, 1177-1182.

[153] D. H. Kim, C. P. Muzzillo, J. Tong, A. F. Palmstrom, B. W. Larson, C. Choi, S. P. Harvey, S. 
Cite this paper as: F. Cheng, J. Zhu, Th. Pauporté, Chlorides, other Halides and Pseudohalides as Additives for the Fabrication of Efficient and Stable Perovskite Solar Cells.

ChemSusChem 14 (2021) 3665-3692. DOI: 10.1002/cssc.202101089

Glynn, J. B. Whitaker, F. Zhang, Z. Li, H. Lu, M. F. A. M. van Hest, J. J. Berry, L. M. Mansfield, Y. Huang, Y. Yan, K. Zhu, Joule 2019, 3, 1734-1745.

[154] H. Dong, Z. Wu, J. Xi, X. Xu, L. Zuo, T. Lei, X. Zhao, L. Zhang, X. Hou, A. K. Y. Jen, Adv. Funct. Mater. 2018, 28, 1704836.

[155] Q. Han, Y. Bai, J. Liu, K.-z. Du, T. Li, D. Ji, Y. Zhou, C. Cao, D. Shin, J. Ding, A. D. Franklin, J. T. Glass, J. Hu, M. J. Therien, J. Liu, D. B. Mitzi, Energy Environ. Sci. 2017, 10, 2365-2371.

[156] D. Wang, W. Li, Z. Du, G. Li, W. Sun, J. Wu, Z. Lan, ACS Appl Mater Interfaces 2020, 12, 10579-10587;

[157] F. Wang, X. Jiang, H. Chen, Y. Shang, H. Liu, J. Wei, W. Zhou, H. He, W. Liu, Z. Ning, Joule 2018, 2, 2732-2743.

[158] H. Zhang, M. Hou, Y. Xia, Q. Wei, Z. Wang, Y. Cheng, Y. Chen, W. Huang, J. Mater. Chem. A. 2018, 6, 9264-9270.

[159] E. Jokar, C.-H. Chien, A. Fathi, M. Rameez, Y.-H. Chang, E. W.-G. Diau, Energy Environ. Sci. 2018, $11,2353-2362$.

[160] H. Kim, Y. H. Lee, T. Lyu, J. H. Yoo, T. Park, J. H. Oh, J. Mater. Chem. A 2018, 6, 18173-18182.

[161] C. Wang, Z. Song, Y. Yu, D. Zhao, R. A. Awni, C. R. Grice, N. Shrestha, R. J. Ellingson, X. Zhao, Y. Yan, Sustainable Energy Fuels 2018, 2, 2435-2441.

[162] Z. Yao, Z. Jin, X. Zhang, Q. Wang, H. Zhang, Z. Xu, L. Ding, S. Liu, J. Mater. Chem. C 2019, 7, 13736-13742.

[163] H. Tan, A. Jain, O. Voznyy, X. Lan, F. P. G. de Arquer, J. Z. Fan, R. Quintero-Bermudez, M. Yuan, B. Zhang, Y. Zhao, F. Fan, P. Li, L. N. Quan, Y. Zhao, Z.-H. Lu, Z. Yang, S. Hoogland, E. H. Sargent, Science 2017, 355, 722-726.

[164] X. Gong, Q. Sun, S. Liu, P. Liao, Y. Shen, C. Gratzel, S. M. Zakeeruddin, M. Gratzel, M. Wang, Nano Lett. 2018, 18, 3969-3977.

[165] L. F. Zhu, Y. Z. Xu, J. J. Shi, H. Y. Zhang, X. Xu, Y. H. Zhao, Y. H. Luo, Q. B. Meng, D. M. Li, RSC Adv. 2016, 6, 82282-82288.

[166] T. Zhu, J. Su, F. Labat, I. Ciofini, T. Pauporte, ACS Appl. Mater. Inter. 2020, 12, 744-752.

[167] J. Su, T. Zhu, T. Pauporte, I. Ciofini, F. Labat, J. Comput. Chem. 2020, 41, 1740-1747.

[168] M. M. Byranvand, T. Kim, S. Song, G. Kang, S. U. Ryu, T. Park, Adv. Energy Mater. 2018, 8, 
Cite this paper as: F. Cheng, J. Zhu, Th. Pauporté, Chlorides, other Halides and Pseudohalides as Additives for the Fabrication of Efficient and Stable Perovskite Solar Cells.

ChemSusChem 14 (2021) 3665-3692. DOI: 10.1002/cssc.202101089

1702235.

[169] W. Li, W. Zhang, S. Van Reenen, R. J. Sutton, J. Fan, A. A. Haghighirad, M. B. Johnston, L. Wang, H. J. Snaith, Energy Environ. Sci. 2016, 9, 490-498.

[170] S. Yuan, J. Wang, K. Yang, P. Wang, X. Zhang, Y. Zhan, L. Zheng, Nanoscale 2018, 10, 1890918914.

[171] J. Ma, X. Guo, L. Zhou, Z. Lin, C. Zhang, Z. Yang, G. Lu, J. Chang, Y. Hao, ACS Appl. Energy Mater. 2018, 1, 3826-3834.

[172] R. Azmi, N. Nurrosyid, S.-H. Lee, M. Al Mubarok, W. Lee, S. Hwang, W. Yin, A. Tae Kyu, T.W. Kim, D. Y. Ryu, Y. R. Do, S.-Y. Jang, ACS Energy Lett. 2020, 5, 1396-1403.

[173] M. V. Khenkin, E. A. Katz, A. Abate, G. Bardizza, J. J. Berry, C. Brabec, F. Brunetti, V. Bulovic, Q. Burlingame, A. Di Carlo, R. Cheacharoen, Y.-B. Cheng, A. Colsmann, S. Cros, K. Domanski, M. Dusza, C. J. Fell, S. R. Forrest, Y. Galagan, D. Di Girolamo, M. Graetzel, A. Hagfeldt, E. von Hauff, H. Hoppe, J. Kettle, H. Koebler, M. S. Leite, S. Liu, Y.-L. Loo, J. M. Luther, C.-Q. Ma, M. Madsen, M. Manceau, M. Matheron, M. McGehee, R. Meitzner, M. K. Nazeeruddin, A. F. Nogueira, C. Odabasi, A. Osherov, N.-G. Park, M. O. Reese, F. De Rossi, M. Saliba, U. S. Schubert, H. J. Snaith, S. D. Stranks, W. Tress, P. A. Troshin, V. Turkovic, S. Veenstra, I. VisolyFisher, A. Walsh, T. Watson, H. Xie, R. Yildirim, S. M. Zakeeruddin, K. Zhu, M. Lira-Cantu, Nat. Energy 2020, 5, 35-49.

[174] X. Liu, Y. Zhang, L. Shi, Z. Liu, J. Huang, J. S. Yun, Y. Zeng, A. Pu, K. Sun, Z. Hameiri, J. A. Stride, J. Seidel, M. A. Green, X. Hao, Adv. Energy Mater. 2018, 8, 1800138.

[175] Q. Wang, Q. Dong, T. Li, A. Gruverman, J. Huang, Adv. Mater. 2016, 28, 6734-6739.

[176] J. Yang, C. Liu, C. Cai, X. Hu, Z. Huang, X. Duan, X. Meng, Z. Yuan, L. Tan, Y. Chen, $A d v$. Energy Mater. 2019, 9, 1900198.

[177] C. Wu, K. Wang, X. Feng, Y. Jiang, D. Yang, Y. Hou, Y. Yan, M. Sanghadasa, S. Priya, Nano letters 2019, 19, 1251-1259.

[178] Y. Liu, S. Akin, L. Pan, R. Uchida, N. Arora, J. V. Milic, A. Hinderhofer, F. Schreiber, A. R. Uhl, S. M. Zakeeruddin, A. Hagfeldt, M. I. Dar, M. Gratzel, Sci. Adv. 2019, 5, eaaw2543.

[179] Y. Wang, T. Zhang, M. Kan, Y. Li, T. Wang, Y. Zhao, Joule 2018, 2, 2065-2075.

[180] A. Buin, R. Comin, J. Xu, A.H. Ip, E.H. Sargent, Chem. Mater. 2015, 27, 4405-4412. 
Cite this paper as: F. Cheng, J. Zhu, Th. Pauporté, Chlorides, other Halides and Pseudohalides as Additives for the Fabrication of Efficient and Stable Perovskite Solar Cells.

ChemSusChem 14 (2021) 3665-3692. DOI: 10.1002/cssc.202101089

[181] M.H. Du, J. Mater. Chem. A. 2014, 2, 9091-9098.

[182] C. Liu, J. Tu, X. Hu, Z. Huang, X. Meng, J. Yang, X. Duan, L. Tan, Z. Li, Y. Chen, Adv. Funct. Mater. 2019, 29, 1808059.

[183] Z. Hawash, S. R. Raga, D.-Y. Son, L. K. Ono, N.-G. Park, Y. Qi, J. Phys. Chem. Lett. 2017, 8, $3947-3953$

[184] K. T. Cho, S. Paek, G. Grancini, C. Roldán-Carmona, P. Gao, Y. Lee, M. K. Nazeeruddin, Energy Environ. Sci. 2017, 10, 621-627.

[185] Y. Wang, T. Zhang, M. Kan, Y. Zhao, J. Am. Chem. Soc. 2018, 140, 12345-12348.

[186] M. Salado, A. D. Jodlowski, C. Roldan-Carmona, G. de Miguel, S. Kazim, M. K. Nazeeruddin, S. Ahmad, Nano Energy 2018, 50, 220-228.

[187] E. A. Alharbi, A. Y. Alyamani, D. J. Kubicki, A. R. Uhl, B. J. Walder, A. Q. Alanazi, J. Luo, A. Burgos-Caminal, A. Albadri, H. Albrithen, M. H. Alotaibi, J.-E. Moser, S. M. Zakeeruddin, F. Giordano, L. Emsley, M. Grätzel, Nat. Commun. 2019, 10, 3008.

[188] D. J. Kubicki, D. Prochowicz, A. Hofstetter, M. Saski, P. Yadav, D. Bi, N. Pellet, J. Lewiński, S. M. Zakeeruddin, M. Grätzel, L. Emsley, J. Am. Chem. Soc. 2018, 140, 3345-3351.

[189] Z. Ren, N. Wang, M. Zhu, X. Li, J. Qi, Electrochim. Acta 2018, 282, 653-661.

[190] M. A. R. Laskar, W. Luo, N. Ghimire, A. H. Chowdhury, B. Bahrami, A. Gurung, K. M. Reza, R. Pathak, R. S. Bobba, B. S. Lamsal, K. Chen, M. T. Rahman, S. I. Rahman, K. Emshadi, T. Xu, M. Liang, W.-H. Zhang, Q. Qiao, Adv. Funct. Mater. 2020, 30, 2000778.

[191] J. Zhang, J. Liu, A. Tan, J. Piao, Z. Fu, Chem. Commun. 2020, 56, 13816-13819.

[192] J. Chen, J.-Y. Seo, N.-G. Park, Adv. Energy Mater. 2018, 8, 1702714.

[193] Y. Wang, M. I. Dar, L. K. Ono, T. Zhang, M. Kan, Y. Li, L. Zhang, X. Wang, Y. Yang, X. Gao, Y. Qi, M. Gratzel, Y. Zhao, Science 2019, 365, 591-595.

[194] X. Zheng, B. Chen, J. Dai, Y. Fang, Y. Bai, Y. Lin, H. Wei, Xiao C. Zeng, J. Huang, Nat. Energy 2017, 2, 17102.

[195] J.-W. Lee, Z. Dai, T.-H. Han, C. Choi, S.-Y. Chang, S.-J. Lee, N. De Marco, H. Zhao, P. Sun, Y. Huang, Y. Yang, Nat. Commun. 2018, 9, 3021.

[196] L. N. Quan, M. Yuan, R. Comin, O. Voznyy, E. M. Beauregard, S. Hoogland, A. Buin, A. R. Kirmani, K. Zhao, A. Amassian, D. H. Kim, E. H. Sargent, J. Am. Chem. Soc. 2016, 138, 2649- 
Cite this paper as: F. Cheng, J. Zhu, Th. Pauporté, Chlorides, other Halides and Pseudohalides as Additives for the Fabrication of Efficient and Stable Perovskite Solar Cells.

ChemSusChem 14 (2021) 3665-3692. DOI: 10.1002/cssc.202101089 2655 .

[197] S. Li, Z. Liu, Z. Qiao, X. Wang, L. Cheng, Y. Zhai, Q. Xu, Z. Li, K. Meng, G. Chen, Adv. Funct. Mater. 2020, 30, 2005846.

[198] T. M. Koh, V. Shanmugam, X. Guo, S. S. Lim, O. Filonik, E. M. Herzig, P. Müller-Buschbaum, V. Swamy, S. T. Chien, S. G. Mhaisalkar, N. Mathews, J. Mater. Chem. A 2018, 6, 2122-2128;

[199] K. T. Cho, G. Grancini, Y. Lee, E. Oveisi, J. Ryu, O. Almora, M. Tschumi, P. A. Schouwink, G. Seo, S. Heo, Energy Environ. Sci. 2018, 11, 952-959.

[200] E. H. Jung, N. J. Jeon, E. Y. Park, C. S. Moon, T. J. Shin, T.-Y. Yang, J. H. Noh, J. Seo, Nature 2019, 567, 511-515.

[201] J. J. Yoo, S. Wieghold, M. C. Sponseller, M. R. Chua, S. N. Bertram, N. T. P. Hartono, J. S. Tresback, E. C. Hansen, J.-P. Correa-Baena, V. Bulović, T. Buonassisi, S. S. Shin, M. G. Bawendi, Energy Environ. Sci. 2019, 12, 2192-2199.

[202] C. Ma, C. Leng, Y. Ji, X. Wei, K. Sun, L. Tang, J. Yang, W. Luo, C. Li, Y. Deng, S. Feng, J. Shen, S. Lu, C. Du, H. Shi, Nanoscale 2016, 8, 18309-18314.

[203] J. J. Yoo, S. Wieghold, M. C. Sponseller, M. R. Chua, S. N. Bertram, N. T. P. Hartono, J. S. Tresback, E. C. Hansen, J.-P. Correa-Baena, V. Bulovic, T. Buonassisi, S. S. Shin, M. G. Bawendi, Energy Environ. Sci. 2019, 12, 2192-2199.

[204] H. Zhang, X. Ren, X. Chen, J. Mao, J. Cheng, Y. Zhao, Y. Liu, J. Milic, W.-J. Yin, M. Grätzel, W. C. H. Choy, Energy Environ. Sci. 2018, 11, 2253-2262.

[205] W. Chen, Y. Zhou, L. Wang, Y. Wu, B. Tu, B. Yu, F. Liu, H. W. Tam, G. Wang, A. B. Djurisic, L. Huang, Z. He, Adv. Mater. 2018, 30, 1800515.

[206] W. Chen, Y. Zhou, G. Chen, Y. Wu, B. Tu, F. Z. Liu, L. Huang, A. M. C. Ng, A. B. Djurišić, Z. He, Adv. Energy Mater. 2019, 9, 1803872. 
Cite this paper as: F. Cheng, J. Zhu, Th. Pauporté, Chlorides, other Halides and Pseudohalides as Additives for the Fabrication of Efficient and Stable Perovskite Solar Cells.

ChemSusChem 14 (2021) 3665-3692. DOI: 10.1002/cssc.202101089

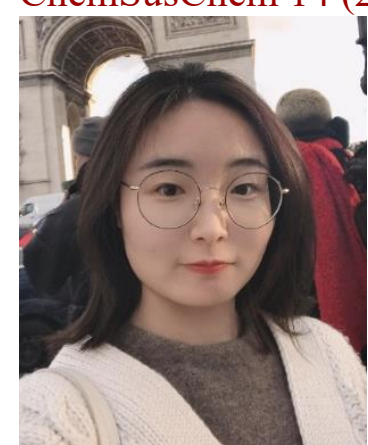

Fei Cheng received her master's degree from Guangzhou Institute of Chemistry, University of Chinese Academy of Sciences in 2019. She is a current Ph.D. student under the supervision of Prof. Thierry Pauporté in Chimie ParisTech-PSL University. Her research interests are focused on development of efficient and stable perovskite solar cells.

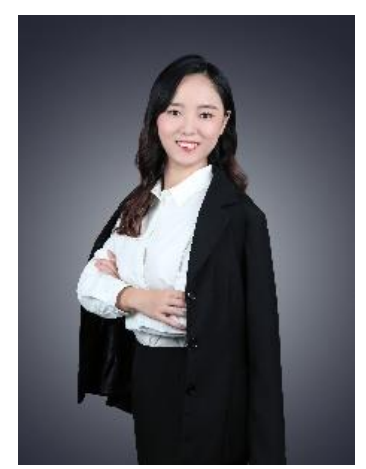

Dr. Jie Zhang is currently an assistant professor in the School of Chemistry and Chemical Engineering at the South China University of Technology. She received her M. Sc. and Ph. D. degree at the South China University of Technology and Chimie ParisTech in 2012 and 2015, respectively. Her interests concentrate on the synthesis of novel photo-functional materials and perovskite solar cells, including photochromic materials, low-dimensional perovskites and device engineering for perovskite solar cells.

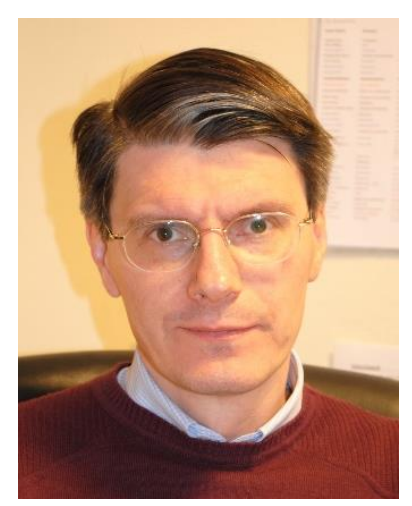

Prof. Thierry Pauporté is director of research at the Centre National de la Recherche Scientifique (CNRS) in France and works at Chimie-Paristech-PSL University. He is graduated in Chemistry from the École Normale Supérieure de Lyon. He received his Ph.D. in physical chemistry from Montpellier II University, France, in 1995. He works on the synthesis, characterization and understanding of fundamental chemical and physical properties of oxide and halide perovskite films and nanostructures. The applications of these materials and structures include light emitting diodes, perovskite solar cells, dye-sensitized solar cells, nanosensors, 
Cite this paper as: F. Cheng, J. Zhu, Th. Pauporté, Chlorides, other Halides and Pseudohalides as Additives for the Fabrication of Efficient and Stable Perovskite Solar Cells.

ChemSusChem 14 (2021) 3665-3692. DOI: 10.1002/cssc.202101089

photodetectors, photocatalysis, wettability and fouling. More information at : www.pauportegroup.com

\section{Table of Content}

Progresses made on the employment of halide and pseudo-halide additives in organo-metal perovskite solar cells are reviewed. Their function in morphology adjusting, phase stabilizing, energy-level adjusting, trap state passivation and hysteresis elimination are detailed. A deep understanding of the relationship between halide/pseudohalide additive and the improved properties of perovskite solar cell is presented.

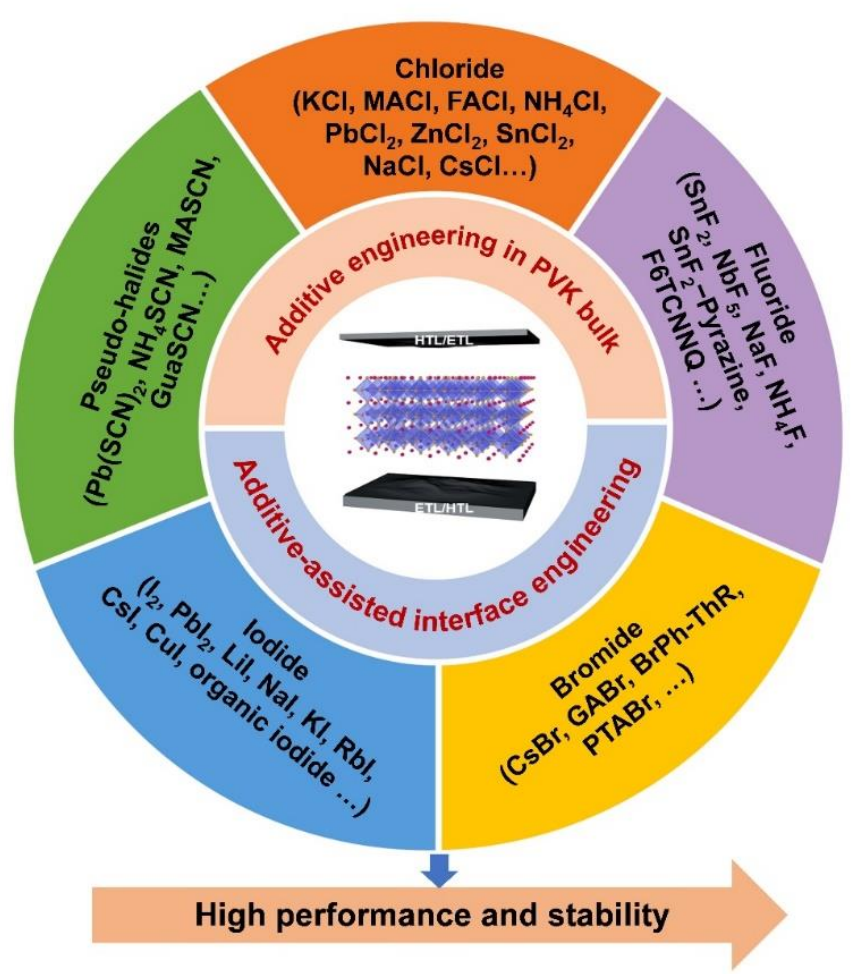

